Desafios do cuidado integral em saúde:

\title{
a dimensão espiritual do médico se relaciona com sua prática na abordagem espiritual do paciente?
}

\author{
Dissertação apresentada à Faculdade de Medicina da \\ Universidade de São Paulo para obtenção do título de Mestre em \\ Ciências
}

Programa de Medicina Preventiva

Orientador: Prof. Dr. José Eluf Neto

(Versão corrigida. Resolução CoPGr 5890/10, de 20 de dezembro de 2010. A versão original está disponível na Biblioteca da FMUSP. Houve sugestão da banca de modificação do título acima para: A dimensão espiritual do médico e suas implicações para a prática do cuidado integral em saúde: um levantamento nacional na visão de médicos de família e comunidade. A modificação, contudo, não é permitida pela resolução em vigor.) 


\section{Dados Internacionais de Catalogação na Publicação (CIP)}

Preparada pela Biblioteca da

Faculdade de Medicina da Universidade de São Paulo

Creprodução autorizada pelo autor

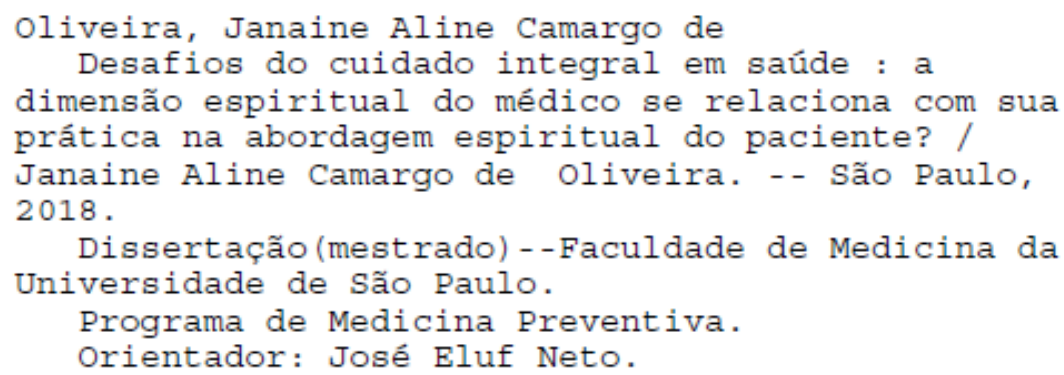

Descritores: 1.Espiritualidade 2.Comunicação em saúde 3.Atenção primária à saúde 4 . Integralidade em saúde 5.Medicina de família e comunidade 6. Estudos transversais

$\mathrm{USP} / \mathrm{FM} / \mathrm{DBD}-253 / 18$

Responsável: Kátia Maria Bruno Ferreira - CRB-8/6008 


\section{AGRADECIMENTO E TRAJETÓRIA}

"Se pude ver mais longe, foi por ter me apoiado em ombros de gigantes".

A presente dissertação de mestrado não é o ponto de partida nem tampouco a chegada dessa caminhada. Essas páginas são também entremeadas pela terceira margem, a das construções e transformações que vivenciamos na experiência de sermos humanos.

O universo da Ciência me abriu as portas e hoje reconheço nessa ferramenta uma forma de conhecer e retribuir à Vida. Os últimos anos foram repletos de aprendizado técnicocientífico e também das quebras paradigmáticas. Os professores José Eluf Neto e Ana Cláudia Camargo Gonçalves Germani constituíram dupla inusitada de orientadores, que me inspiraram e souberam me mostrar o melhor caminho. Tornei-me pesquisadora em meio aos desafios de ser também médica de família e comunidade em um sistema deveras potente, porém, contraditório. Tudo isso era inimaginável alguns anos atrás, quando deixei minha cidade em busca da minha formação.

Cresci na pequena Elias Fausto, tendo a oportunidade de me desenvolver em meio às amizades, à natureza e à sustentação oferecida por minha família. Sai de casa na adolescência para estudar. Ao longo dos oito anos em Minas Gerais, aprendi muito sobre a medicina do corpo e da alma. Encontrei no olhar para o ser humano integral a oportunidade de desvendar não uma máquina, mas sim, um ser único, singular e complexo. Compreendi que saúde é bem-estar, mas vai além. Saúde é instrumento para realizar sonhos e se tornar sujeito de sua Vida. Retornei a São Paulo profissionalmente realizada, pronta para formar novos médicos de família e comunidade ao longo do treinamento na residência médica. Foram quatro anos unindo o ensino à prática clínica. Quatro anos em que compreender o propósito dessa ação se fez maior que as adversidades do caminho. Tão maior que me levou a querer conhecer mais sobre o que potencializa e o que limita nossa sonhada prática no cuidado integral, a partir da dimensão que permeia o sentido e o significado da experiência humana: a espiritualidade.

Aos gigantes e pequeninos apoiadores dessa jornada de crescimento, registro em breves, mas profundas palavras, a minha gratidão por confiarem em meu potencial e me apoiarem incondicionalmente. Hoje me sinto realizada profissional e pessoalmente. 
Ainda que eu falasse as linguas dos homens e das anjos, e nãa tivesse amor, seria coma a metal que soa an cama a sina que tine. $E$ ainda que tivesse a dam de profecia, $e$ conhecesse todos as mistérios e tada a ciência, e ainda que tivesse tada a fé, de maneira tal que transpartasse os montes, $e$ nãa tivesse amor, nada seria.

Paula de Tarsa 


\section{SUMÁRIO}

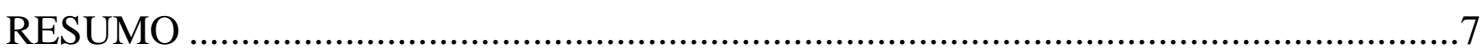

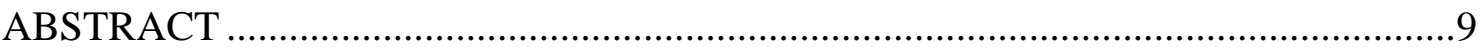

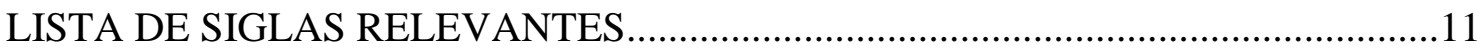

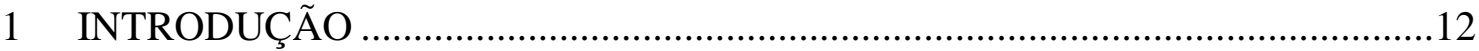

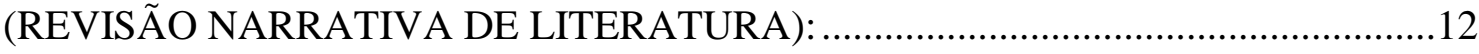

1.1. De que saúde, doença e adoecimento estamos falando? .....................................12

1.2. Espiritualidade na prática clínica: Por que abordá-la? .......................................15

1.3. O que vem a ser a dimensão espiritual da pessoa? .............................................19

1.4. Como inserir a abordagem da espiritualidade na prática clínica? .......................22

1.5. Consolidação da abordagem da espiritualidade na prática clínica: qual o impacto dos valores e barreiras pessoais do médico? ............................................................25

2 DELIMITAÇÃO E JUSTIFICATIVA: Autoconhecimento e espiritualidade do profissional de saúde: como podemos caminhar? .........................................................29

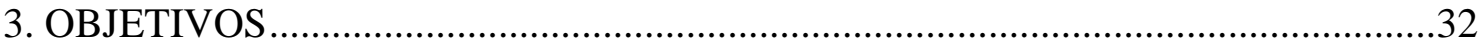

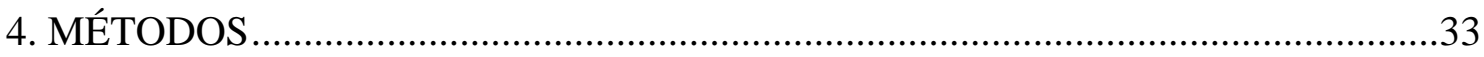

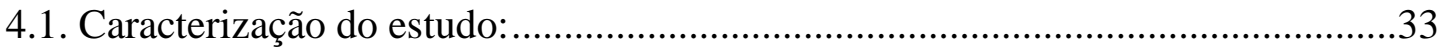

4.2. Caracterização do universo e amostra da pesquisa: ............................................33

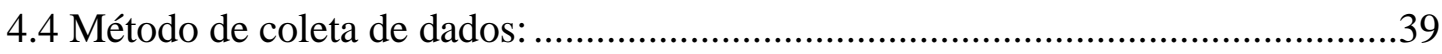

4.5 Caracterização do questionário da pesquisa: ...................................................40

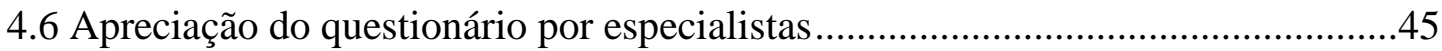

4.7 Avaliação do questionário em projeto piloto ........................................................46

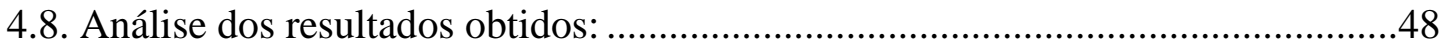

4.9. Modelo para estudo da R/E do MFC e sua interface com a prática da abordagem

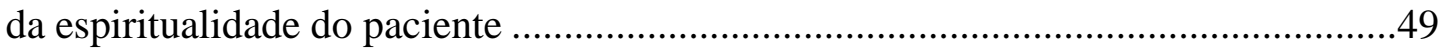

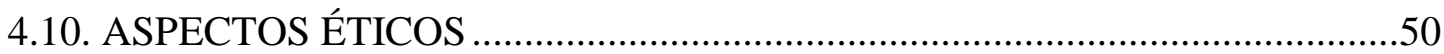

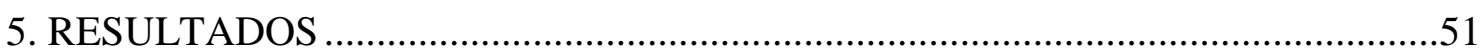

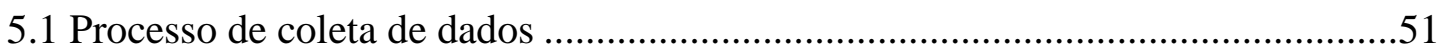

5.2 Seleção da amostra a partir das variáveis de inclusão e exclusão .........................52

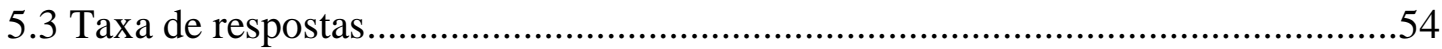

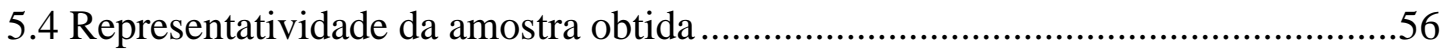

5.5 Caracterização demográfica da amostra do estudo ..............................................60

5.6 Caracterização da amostra conforme atuação profissional ..................................63

5.7 Caracterização da amostra conforme a inserção da abordagem da religiosidade/espiritualidade na prática clínica 
5.8 Caracterização da amostra conforme a religiosidade e espiritualidade do profissional.....

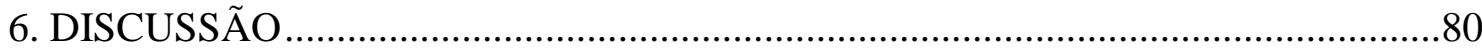

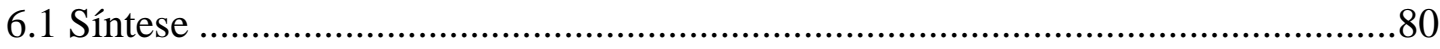

6.2 Interpretação e implicações dos resultados ............................................................. 81

6.2.1 Dados demográficos: Quem somos nós e os "outros"? ......................................81

6.2.2. Que espiritualidade é essa abordada pelos MFC? ............................................87

6.2.3 Valores pessoais do profissional: desdobramentos no cuidado integral ............93

6.2.4 Inserção na prática clínica: cuidado centrado na pessoa, família e comunidade98

6.2.5. Se treinamento é uma necessidade, como está o ensino? ...............................103

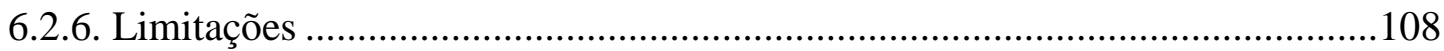

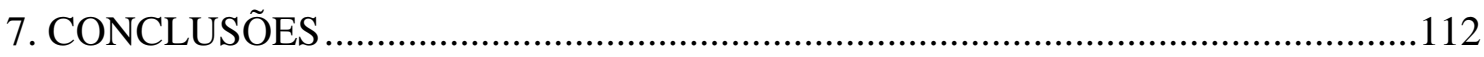

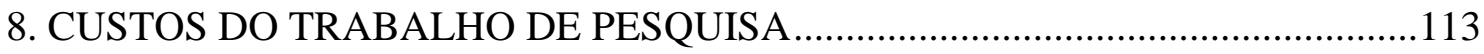

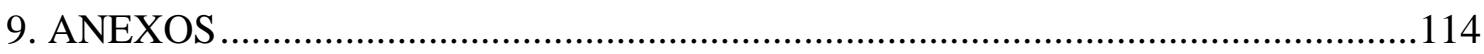

9.1. ANEXO 1: Livre tradução da ferramenta FICA para abordagem da espiritualidade:

9.2. ANEXO 2: Livre tradução da ferramenta HOPE para abordagem da espiritualidade:

9.3. ANEXO 3: Livre tradução da ferramenta SPIRITualHistory para abordagem da espiritualidade:

9.4. ANEXO 4: Os quatro componentes do Método Clínico Centrado na Pessoa: ..117

9.5. ANEXO 5: Versão preliminar do questionário de participação na pesquisa: ....118

9.6. ANEXO 6: QUADRO 2: Instrumentos de abordagem da E/R na clínica 123

9.7. ANEXO 7: Functional Assessment of Chronic Illness Therapy - Spiritual Well-

Being, na versão modificada para "non-illness" (FACIT-SP - Non Illness):

9.8. ANEXO 8: Versão final do questionário de participação na pesquisa, incluindo o termo de consentimento livre e esclarecido 130

9.9. ANEXO 9: Parecer do Comitê de Ética em Pesquisa 140

9.10. ANEXO 10: Carta de apoio da SBMFC, disponibilizando banco de contatos de e-mails 143

9.11. ANEXO 11: Licença para utilização da FACIT Non Illness 145

10. REFERÊNCIAS: 147 


\section{RESUMO}

Oliveira JAC. Desafios do cuidado integral em saúde: a dimensão espiritual do médico se relaciona com sua prática na abordagem espiritual do paciente? [dissertação]. São Paulo: Faculdade de Medicina, Universidade de São Paulo; 2018.

A literatura demonstra que a dimensão espiritual tem impacto na saúde biopsicossocial, sendo associada à preservação da saúde mental, qualidade de vida e redução da mortalidade global e cardiovascular. Contudo, são descritas várias barreiras para a abordagem clínica da espiritualidade do paciente, como a falta de tempo ou treinamento sobre o assunto, além dos valores pessoais e religiosos do profissional. A abordagem da espiritualidade na prática clínica de médicos de família e comunidade (MFC) ainda é um desafio e, com isso, a presente dissertação descreve aspectos da dimensão espiritual e religiosa de MFC brasileiros, com residência médica na área, além de apresentar aspectos sobre a inserção do tema da espiritualidade/religiosidade (E/R) na prática clínica desse grupo de profissionais. Para tanto, foi realizado um estudo observacional transversal por meio de questionário online. Os dados foram analisados quantitativamente por meio de medidas de frequência numérica, percentual e de tendência central. A frequência e temática abordadas pelos $\mathrm{MFC}$ em relação à $\mathrm{E} / \mathrm{R}$ foram aferidas por meio de constructo que agregou os questionários FICA, HOPE e SPIRITual History. Os escores de bem-estar espiritual e religiosidade dos médicos foram aferidos por meio de escalas bem avaliadas na literatura (respectivamente, FACIT-SpNI e DUREL-P). O inquérito online obteve taxa de resposta de 15,8\%, sendo a amostra de maioria do sexo feminino $(65,1 \%)$, com idade média de 35,8 anos e média de tempo de trabalho na área de 7,9 anos. A atuação profissional se dá em assistência clínica $(87,7 \%)$ e ensino $(67,1 \%)$. A maioria $(78,4 \%)$ declara identificação com uma matriz religiosa, sendo 21,6\% católicos, 13,7\% espíritas e 11,3\% evangélicos. Grande parte da amostra $(21,6 \%)$ se identificou com mais de uma religião. Os MFC apresentam baixa religiosidade organizacional (49,3\% raramente ou nunca frequentam instituições), porém, forte prática de religiosidade não organizacional $(65,4 \%$ declaram práticas pessoais no mínimo semanais). O escore de religiosidade intrínseca médio foi de 10,6 (padrão: 3 a 15) e o de bem-estar espiritual foi de 35,7 (padrão: 0-48). Para a prática 
clínica, houve maior concordância com o conceito de espiritualidade de Puchalski, que apresenta amplitude moderada quando comparado aos conceitos de Anandarajah e Koenig. O grau de concordância apontou no sentido de diferenciação do conceito de espiritualidade em relação à definição de religiosidade. Embora a grande maioria acredite que a $\mathrm{E} / \mathrm{R}$ influencie muito a saúde $(88,4 \%)$ e que essa abordagem seja pertinente à prática clínica do $\operatorname{MFC}(81,2 \%)$, apenas $35,0 \%$ da amostra se sentia preparada para abordar o tema e a maioria o faz com frequência moderada $(50,3 \%)$. As principais barreiras para essa abordagem seriam falta de tempo $(53,4 \%)$, treinamento $(39,7 \%)$ e valores pessoais, como medo de impor sua religião $(27,7 \%)$ ou medo de ofender o paciente $(23,6 \%)$. As áreas mais frequentemente discutidas pelos MFC com os pacientes tratam da rede de suporte social (discutido por $42,8 \%$ dos médicos) e resiliência (40,2\%). Os temas menos discutidos seriam a relação médico-paciente (não discutido por $74,0 \%)$ e as implicações para o plano terapêutico $(64,7 \%)$.

Descritores: espiritualidade; comunicação em saúde; atenção primária à saúde; integralidade em saúde; medicina de família e comunidade; estudos transversais. 


\section{ABSTRACT}

Oliveira JAC. Challenges of comprehensiveness health care: does the physician's spiritual dimension relate to the clinical practice in approaching patient's spirituality? [dissertation]. São Paulo: "Faculdade de Medicina, Universidade de São Paulo"; 2018.

Researches show that the spiritual dimension influences the biopsychosocial health, being associated with the preservation of mental health, quality of life and reduction of global and cardiovascular mortality. However, there are several barriers for approaching patient's spirituality in clinical practice, such as the lack of time or training on this subject and personal values of the professionals, as religiosity. Approaching spirituality is still a challenge for Brazilian Family Physicians (BFP). Then, the present research describes aspects of the spiritual and religious dimensions of Brazilian Family Physicians who had completed medical residency programs in this area. It also shows aspects about the insertion of spirituality/religiosity (S/R) in the clinical practice of this group of professionals. For this reason, we carried out a cross-observational study by means an online questionnaire. We analyzed the data quantitatively by means of simple distribution and frequency measurements. The frequency and thematic discussed by $\mathrm{BFP}$ in relation to $\mathrm{S} / \mathrm{R}$ were measured by an instrument developed using the questionnaires FICA, HOPE and SPIRITual History. We evaluated the doctors' scores of spiritual- wellbeing and religiosity by means of well-evaluated scales (respectively, FACIT-SpNI and Durel-P). The online survey obtained response rate of $15.8 \%$. The sample had most female $(65.1 \%)$, average age of 35.8 years-old and average working time in the area of 7.9 years. Most of the professionals works in clinical assistance $(87.7 \%)$ and teaching $(67.1 \%)$. The majority $(78.4 \%)$ declares identification with one religion, being $21.6 \%$ Catholics, $13.7 \%$ Spiritists and $11.3 \%$ Protestants. A large portion of the sample (21.6\%) identified itself with more than one religion. The BFP showed low organizational religiosity (49.3\% rarely or never attend to institutions), but high practice of non-organizational religiosity $(65.4 \%$ declare personal practices at least weekly). The average of intrinsic religiosity score was 10.6 (standard: 3-15) and the spiritual-wellbeing average score was 35.7 (standard: 0-48). About the clinical practice, 
there was greater agreement with the concept of spirituality carried out by Puchalski, which presents moderate amplitude when compared to Anandarajah's or Koenig's concepts. The concordance degree showed same tendency to the sense of differentiation of the concepts of spirituality and religiosity. While $88.4 \%$ of BFP believe that the S/R influences a lot the health and $81.2 \%$ believe that this approach is pertinent to their clinical practice, only $35.0 \%$ of the sample felt prepared to address this topic and most do it sometimes $(50.3 \%)$. The main barriers to this approach were lack of time $(53.4 \%)$, training (39.7\%) and personal values, such as fear of imposing their religion $(27.7 \%)$ or fear of offending the patient $(23.6 \%)$. The themes most often discussed by BFP with patients deal with the social support network (discussed by $42.8 \%$ of doctors) and resilience (40.2\%). The less discussed subjects were the doctor-patient relationship (not discussed by $74.0 \%)$ and the implications for the therapeutic plan $(64.7 \%)$.

Descriptors: spirituality; health communication; primary health care; integrality in health; family practice; cross-sectional studies. 


\section{LISTA DE SIGLAS RELEVANTES}

APS: atenção primária à saúde

CRE: coping religioso-espiritual

DUREL: Índice de Religiosidade da Universidade Duke

ESF: Estratégia Saúde da Família

E/R: Espiritualidade / Religiosidade

FACIT-SpNI: Functional Assessment of Chronic Illness Therapy - Spiritual WellBeing - Non Illness

IBGE: Instituto Brasileiro de Geografia e Estatística

MCCP: Método clínico centrado na pessoa

MFC: Médico(s) de Família e Comunidade

SBMFC: Sociedade Brasileira de Medicina de Família e Comunidade

FICA, HOPE e SPIRITual History: acrósticos que denominam instrumentos utilizados para realização da denominada anamnese espiritual 


\section{INTRODUÇÃO}

\section{(REVISÃO NARRATIVA DE LITERATURA):}

\subsection{De que saúde, doenca e adoecimento estamos falando?}

As áreas da saúde constituem ciências aplicadas, ou seja, devem reunir e ordenar elementos das ciências gerais, buscando melhorar a qualidade de vida dos seres humanos. Nesse contexto, as necessidades de cuidado em saúde vêm sendo revistas à luz da experimentação, da filosofia e das relações humanas, psicológicas ou sociais. Novos achados vêm convidando os profissionais da saúde a reflexões acerca do paradigma adotado para compreender doença, pessoa e a saúde como um todo.

Ao descrever a estrutura das revoluções científicas em sua obra, Thomas Kuhn (2003) traz o conceito de paradigma, ou seja, a visão sobre a qual estruturamos nossas explicações e concepções de verdade e realidade em um determinado período dentro da história da ciência. Para o campo da epistemologia, Kuhn nos leva a refletir sobre as limitações intrínsecas ao método científico, em cada período paradigmático, chamado por ele de "ciência normal".

Embora na comunidade acadêmica atual prevaleça o método científico cartesiano, há autores que questionam as limitações desse paradigma na área da saúde (Anderson e Rodrigues, 2012). Advém a tensão entre o modelo de causalidade linear e a proposta de uma visão de mundo globalmente interligado. Para essa última concepção, fenômenos biológicos, psicológicos, sociais e ambientais são e estão todos interdependentes, caracterizando a visão sistêmica ou mesmo complexa. Dessa tensão decorreria uma crise, por buscarmos novas explicações para nossa realidade, porém, permanecermos aplicando conceitos obsoletos, baseando-nos em uma visão de mundo linear e cartesiana (Boff, 2013).

Acompanhando essa tendência de crise e revisão de valores e conceitos, as ciências da saúde vivenciam uma série de questionamentos: Como prover real cuidado abordando aspectos biopsicossociais-espirituais? Como aliar a excelência técnica ao humanismo filosófico? Como desenvolver uma prática sustentável e custo-efetiva?

As noções de doença, adoecimento e cura vêm sendo redimensionadas, uma vez que o modelo explicativo do processo saúde-adoecimento tem evoluído do clássico modelo biomédico ou anatomopatológico para o paradigma da integralidade 
biopsicossocial. Essa última visão afirma que os fatores que afetam o cuidado em saúde são multidimensionais, se inter-relacionam e interpenetram, caracterizando um fenômeno complexo (Anderson e Rodrigues, 2012).

Nesse sentido, a atenção primária à saúde (APS), tem percebido que, para enfrentar a crescente complexidade no cuidado, é preciso buscar modelos não lineares de pensamento, aceitar o imprevisível ou incerto, respeitar e utilizar a autonomia e a criatividade e adotar postura flexível frente aos diferentes contextos e indivíduos ou grupos (Plsek e Greenhalgh, 2001). Essa visão sobre as necessidades em saúde prestadas pela APS também tem encontrado eco na produção científica e políticas públicas brasileiras, orientando o modelo de cuidado ampliado (Brasil, MS, 2004).

Organizador dos princípios da especialidade médica dirigida para atuação no contexto da atenção primária à saúde, Ian McWhinney (2010) ratifica essa visão sob a ótica da Medicina de Família e Comunidade quando coloca que "A doença [...] não é algo que vem de fora e se superpõe ao homem, é sim um modo peculiar de as pessoas se expressarem em circunstâncias adversas". Para o autor, os seres humanos são vistos como sistemas auto organizados, ou seja, são seres independentes que, porém, interagem buscando o equilíbrio em conjunto, a interdependência. Sendo assim, McWhinney (2010) considera que cada sistema ou ser humano

Tem tanto a capacidade de se renovar quanto de transcender a si mesmo. A cura é um exemplo de auto renovação, em que algumas partes do sistema são renovadas enquanto a integridade do sistema organizado [ser] é mantida. [...] A chave para promover a cura pode ser o fortalecimento das defesas do organismo, a mudança do fluxo de informações ou o encorajamento da auto transcendência no lugar da neutralização de um agente.

Desse modo, o ser humano passa a ser visto, sob o prisma da teoria sistêmica, como um ser singularmente complexo. Perante essas novas visões, as competências exigidas do profissional para dar resposta às necessidades de saúde das pessoas também se ampliam (Plsek e Greenhalgh, 2001; Ayres, 2009).

Nessa perspectiva, o conceito de saúde também passa a ser dinâmico. Retomando a definição adotada pela Organização Mundial da Saúde (OMS, 1946), 
observamos o caráter de avanço paradigmático, ao afirmar-se que "Saúde é um estado de completo bem-estar físico, mental e social, e não consiste apenas na ausência de doença ou de enfermidade".

Apesar das muitas críticas à intangibilidade da atual definição da OMS (1946), muitos autores têm proposto a ampliação desse conceito, sugerindo a inserção de aspectos relativos à autonomia da pessoa, autocuidado e espiritualidade ou relação com a esfera transcendente do ser humano e seu propósito de vida (Reed, 1991).

Uma vez que a noção de saúde avança em complexidade, o mesmo ocorre com o conceito de cuidado. Sob o ponto de vista da ontologia existencial, o filósofo Heidegger (1995) defende a ideia de que o conceito de cuidado se refere à capacidade de centrar-se no projeto de ser do ser humano. Voltar-se para a experiência de cada pessoa seria uma ação de buscar compreender a pessoa, seu mundo e a si mesmo. Para Boff (2013) essa proposta exige que se extrapole o cuidado em saúde para o campo das relações. Ou seja, de modo sistêmico, interligado e ecológico, busca-se o entendimento do modo de agir e interagir do ser e, assim, se inicia a compreensão de seu processo saúde-adoecimentocuidado.

Para Ayres (2004), remetendo-se a Heidegger (1995), o cuidado tem uma dimensão radicalmente auto reflexiva, constituindo o próprio ato de ser do ser humano, na busca de seu "projeto de felicidade". Segundo o autor, é convidativo

$$
\begin{aligned}
& \text { Pensar o modo de ser dos humanos como uma contínua } \\
& \text { concepção/realização de um projeto, a um só tempo } \\
& \text { determinado pelo contexto onde estão imersos, antes e para } \\
& \text { além de suas consciências, e aberto à capacidade de } \\
& \text { transcender essas contingências e, a partir delas e interagindo } \\
& \text { com elas, reconstruí-las. }
\end{aligned}
$$

É desse modo que o cuidado passa a assumir o sentido de ser do humano para Heidegger, ainda segundo Ayres (2004). A própria pessoa desenvolve a autonomia para o processo de "curadoria" que exerce sobre sua própria existência e a de seu mundo: o autocuidado vem da autorreflexão, contudo, não constitui ato inteiramente consciente, intencional ou controlável. Antes, porém, trata-se de uma vivência pessoal resultante e retro alimentadora da auto compreensão e de ação transformadora. 
Desse modo, a dimensão de significado da existência do ser humano ganha foco no âmbito das necessidades do cuidado em saúde.

\subsection{Espiritualidade na prática clínica: Por que abordá-la?}

René Descartes, filósofo francês, é o principal idealizador do método cartesiano, paradigma caracterizado pela concepção de causalidade linear, que deu origem a visão anátomo-clínica e grande produção de conhecimento na ciência médica. Embora tenha sido de importância vital e ainda seja hegemônica, essa visão tem se mostrado insuficiente perante a complexidade do cuidado exigido na atenção primária à saúde.

Nesse sentido, novos modelos, como a visão complexa e sistêmica, aliados ao paradigma da integralidade biopsicossocial-espiritual, têm se mostrado mais consistentes para a explicação e gestão do processo saúde-adoecimento (Plsek e Greenhalgh, 2001). Esses novos paradigmas nos despertam para a compreensão da funcionalidade, empoderamento e resiliência da pessoa, exigindo do profissional uma nova postura de cuidado.

Frente à complexidade das dimensões do cuidado em saúde encontradas na APS, o profissional, muitas vezes, tem a percepção de ser impotente perante várias situações e precisa lidar com determinantes incertos e multifatoriais.

Ante esse impasse, surge a pergunta sobre qual o papel do médico de família e comunidade (MFC) na abordagem da pessoa, no contexto do paradigma da integralidade biopsicossocial. Para Anderson e Rodrigues (2012),

O MFC pode ser capaz de contribuir, por um lado, identificando e (re)significando agentes estressores (situações, ações, comportamentos, hábitos) que produzem sofrimento e desequilíbrio e, por outro lado, identificando e (re)valorizando as condições individuais, familiares e sociais - associadas à resiliência, que permitem a superação em novo e mais avançado padrão de equilíbrio.

Starfield (2002) coloca que a integralidade, um dos valores primordiais da APS, exige que a atenção reconheça, adequadamente, a variedade completa de necessidades relacionadas à saúde e disponibilize os recursos para abordá-las. Para Ayres (2009), o conceito de integralidade é polissêmico e capaz de aglutinar diferentes conjuntos de 
ideias e sujeitos interessados na melhoria da qualidade, democracia e justiça da atenção à saúde. Para o autor, a integralidade se relaciona com as fronteiras das necessidades de saúde e nos desafia “ ' a saber e fazer o 'que' e 'como' pode ser realizado em saúde para responder universalmente às necessidades de cada um”.

Sob essa ótica, muitas evidências já corroboram para que o domínio espiritual seja incorporado ao cuidado em saúde junto às dimensões física, psicológica e social e se observa que a produção científica na área vem apresentando grande crescimento (Lucchetti et al., 2014a).

Há diversos trabalhos mostrando associação de crenças e práticas religiosas e/ou espirituais com a maior preservação e recuperação da saúde mental, inclusive no que se refere a situações complexas, como risco de suicídio e transtornos alimentares (Gonçalves JP et al., 2015; Lawrence et al., 2015; Akrawi et al., 2015). Benefícios sobre qualidade de vida, impacto sobre a saúde social e sobre a qualidade das relações interpessoais também já tem sido demonstrados em diferentes populações (Sawatzky et al., 2005; Unterrainer et al., 2014; Sherman et al., 2015). Além disso, há trabalhos demonstrando melhor controle pressórico (Gillum et al., 2006) e menor mortalidade cardiovascular (Hummer et al., 1999) e geral (Chida et al., 2009). Para situações específicas, como em populações portadoras de HIV, observa-se discordância sobre o impacto dimensão espiritual e religiosa do paciente, podendo haver associações a desfechos considerados positivos ou negativos (Lassiter et al., 2015).

A revisão de Koenig (2015) resume recentes investigações sobre os efeitos da religião e espiritualidade $(\mathrm{R} / \mathrm{E})$ na saúde. $\mathrm{O}$ autor discute associações descritas no contexto de saúde mental, bem-estar, propósito na vida, esperança, otimismo, autoestima, depressão, ansiedade, suicídio e abuso de substâncias. Além disso, aborda impacto sobre os comportamentos de exercício de saúde, dieta, tabagismo e atividade sexual de risco. Temas relevantes como o impacto da $E / R$ sobre doença arterial coronariana, câncer e mortalidade por qualquer causa também são abordados. Ainda nessa revisão, o autor examina pesquisas sobre a prevalência de necessidades espirituais entre os indivíduos com doenças graves ou terminais, as consequências de ignorar essas necessidades, e os resultados dos ensaios clínicos que examinaram os efeitos das avaliações espirituais por médicos. 
Por outro lado, trabalhos como o de Pargament et al. (2001) demonstram a associação da angústia espiritual com aumento do risco de morte em idosos americanos, além do impacto negativo sobre o bem-estar decorrentes de sentimentos como culpa ou abandono relacionados às crenças religiosas. Um estudo de amostra populacional nos Estados Unidos (Abu-Raiya et al, 2015) encontrou correlação significativa entre a presença de angústia espiritual e sintomas depressivos e de ansiedade generalizada, além da menor percepção de satisfação com a vida e felicidade. Esses achados levam a uma questão paradoxal, na qual a vivência religiosa pode configurar tanto fonte de angústia, quanto recurso para lidar com problemas da vida (Abu-Raiya et al, 2016). Inclusive para associação a desfechos negativos, a temática se torna relevante para o cuidado em saúde, uma vez que o sofrimento ou angústia espiritual gera impacto biopsicossocial e seu reconhecimento passa a ser parte do cuidado integral à pessoa.

As evidências nesse campo parecem ser tão robustas que a Association of American Medical Colleges (AAMC) recomenda que já há evidências suficientes para indicar a abordagem de tópicos em espiritualidade e religiosidade na prática clínica (AAMC, 1999). Do mesmo modo, a Associação Mundial de Psiquiatria também já se posicionou a respeito da importância da abordagem do tema no cuidado em saúde mental (Moreira-Almeida et al., 2016).

Por outro lado, também existe dúvida sobre a percepção dos pacientes em relação a receberem uma abordagem de conteúdo espiritual de seus profissionais de saúde, uma vez que esse tema pode mobilizar questões éticas, culturais e religiosas (Lucchetti et al., 2014b). Vários estudos, sintetizados na revisão sistemática de Best et al. (2015), avaliaram o interesse dos pacientes em discutir assuntos ligados a espiritualidade no contexto do atendimento em saúde. Na revisão, foram avaliados 54 estudos compreendendo 12.327 pacientes. Foi demonstrado que, na maioria dos estudos, mais da metade da amostra considerava que era apropriado para o médico para saber sobre as necessidades espirituais do paciente, em pelo menos algumas circunstâncias. Para o autor, esta avaliação demonstrou que muitos pacientes têm um forte interesse em discutir espiritualidade na consulta médica e que os médicos deveriam se esforçar para identificar quais pacientes gostariam de receber essa abordagem. Contudo, a revisão identifica um impasse relevante: enquanto a maioria dos pacientes manifesta interesse na discussão da religião e espiritualidade em consultas 
médicas, há uma incompatibilidade entre a percepção de pacientes e médicos sobre o que constitui essa discussão e em que momento ela deve acontecer. Aponta-se a necessidade de estudos nessa temática.

Do ponto de vista das necessidades de saúde centradas na pessoa, o fato de muitos pacientes desejarem tal abordagem é forte razão para que os profissionais se capacitem nessa área (Koenig et al., 2005). No cenário da APS, evidências apontam que as pessoas desejam que sua dimensão espiritual seja abordada por seu médico. McCord et al. (2004) observou que mais de $85 \%$ das pessoas desejavam que seus médicos conversassem sobre suas crenças, independentemente da fé pessoal do médico. Além disso, as pessoas consideravam como características de um bom médico a escuta compreensiva, a compaixão e a capacidade de prover esperança.

Em relação ao interesse dos pacientes, dados semelhantes foram encontrados no Brasil. Um estudo com 110 idosos em reabilitação observou que 94\% deles declaravam alguma afiliação religiosa e $69,5 \%$ consideravam como muito importante o impacto de sua fé e religiosidade para sua reabilitação. Nesse mesmo estudo, 87,3\% dos entrevistados indicaram que gostariam que seus médicos lhes perguntassem sobre fé e religiosidade, contudo, apenas 8,2\% deles haviam sido questionados sobre essa temática por seus médicos (Lucchetti et al., 2011). A discrepância entre o desejo dos pacientes e a atitude dos médicos também é uma área que aponta necessidade de estudos.

Além do impacto do binômio espiritualidade-religiosidade (E/R), bem como do interesse dos pacientes sobre essa temática, um terceiro grupo de evidências corrobora para o estudo da abordagem da dimensão espiritual da pessoa na prática clínica, ao demonstrar que essa prática pode trazer impacto para os próprios profissionais de saúde.

Um estudo qualitativo avaliou retrospectivamente a narrativa da experiência de 17 trabalhadores de cuidados paliativos em um hospice. O estudo explorou a dimensão orientada para o crescimento da personalidade e a preparação da psique dos trabalhadores do hospice para a morte e o morrer. Observou-se que esses profissionais vivenciavam uma transformação pessoal, um alargamento da consciência com, por vezes, avanço no nível de empatia e transcendência da existência (Dearmond, 20122013). Também no contexto dos cuidados paliativos, há estudos avaliando a percepção do profissional acerca de sua espiritualidade individual e sobre como a mesma se associa a um sentimento comum de espiritualidade da equipe (Sinclair et al., 2006). 
Outro estudo buscou estudar o impacto da espiritualidade sobre aspectos pessoais e profissionais de médicos paliativistas. Para isso, utilizaram a análise qualitativa fenomenológica do discurso de 10 médicos, entre um e vinte anos de prática. Os profissionais responderam a entrevistas semiestruturadas contendo perguntas tais como "Que impacto você sente que sua própria espiritualidade teve na sua prática de cuidados paliativos?" e "Que impacto você sente que a sua prática médica teve em sua própria espiritualidade?". A análise dos discursos observou que os médicos consideraram a abordagem da dimensão espiritual como fundamental para que tivessem a percepção de prestar cuidados paliativos integrais e compassivos. Além disso, observou-se que a espiritualidade pessoal do médico estava indissoluvelmente entrelaçada a sua prática profissional, bem como a prática trazia impacto para a sua espiritualidade intrínseca (Seccareccia e Brown, 2009).

\subsection{O que vem a ser a dimensão espiritual da pessoa?}

No contexto de abordagem clínica da dimensão espiritual do paciente, o entendimento do conceito de espiritualidade torna-se fundamental, para que ele não seja reduzido ou confundido com conceitos de religião ou religiosidade. Embora a definição de espiritualidade não seja consensual na literatura (Koenig, 2008), para a construção do presente trabalho, partimos dos conceitos de espiritualidade apresentados pelos autores que propõem as principais ferramentas de abordagem da espiritualidade na prática clínica, no contexto da atenção primária à saúde, que constitui o principal objeto de nosso estudo (Lucchetti et al., 2013a). As ferramentas citadas serão descritas no próximo item deste trabalho.

Segundo a definição de Maugans (1996), que é bem próxima da de Koenig et al. (2001), espiritualidade poderia ser definida como um sistema de crenças, com foco em elementos intangíveis, que dariam vitalidade e significado aos eventos da vida e, podendo ser expressa por meio de religiões formalizadas ou não. Esse conceito avançou bastante ao longo dos últimos anos. Puchalski (2014a) defende que a espiritualidade é um aspecto dinâmico e intrínseco da experiência humana, por meio do qual se busca e expressa o significado, propósito e transcendência da existência. Tal estado perpassa a vivência da pessoa em suas relações consigo mesma, com a família, com os outros, a comunidade, a natureza e com aquilo que é significativo e sagrado. Já para Anandarajah 
e Hight (2001), essa é a dimensão em que obtemos significado, conexão, conforto e paz para as nossas vidas. Esse significado pode ser buscado não apenas na religião, como se pensa mais comumente, mas também na música, na arte, na natureza ou mesmo em valores e princípios pessoais ou científicos.

As duas últimas definições nos parecem mais interessantes para a aplicabilidade clínica por médicos de família e comunidade, por permitirem mais amplamente a inclusão das percepções religiosas e não religiosas que compõem a dimensão espiritual da pessoa, contribuindo, assim, para a visão integral do paciente. Além disso, os próprios autores dessas definições apontam para a importância da abordagem da espiritualidade de modo centrado na pessoa (Puchalski, 2014a; Anandarajah et al., 2010). Essa prática vai ao encontro das competências previstas para médicos de família e comunidade no Brasil pela Sociedade Brasileira de Medicina de Família e Comunidade (SBMFC, 2015), que será abordada em outra sessão do presente trabalho.

Ainda no cenário das definições, cabe destacar que o conceito de espiritualidade difere dos domínios da religião e religiosidade. Para Koenig et al. (2001), a religião constitui um sistema organizado de crenças, práticas e simbolismos que catalisam a aproximação da pessoa com o sagrado. Já a religiosidade é o modo como a pessoa vivencia sua fé ou religião. Ou seja, são matrizes da visão de mundo da pessoa, e que podem ou não integrar a sua dimensão espiritual.

Para Vasconcelos (2009), dar ênfase ao conceito de espiritualidade, ao invés de religiosidade, pode ajudar a temática a se tornar mais acessível para profissionais e pacientes, uma vez que a espiritualidade é uma dimensão intrínseca ao ser humano, enquanto o domínio religioso pode ou não ser significativo para a pessoa abordada. Para o autor, espiritualidade é um conceito que ressalta a dinâmica de aproximação com o eu profundo, prática que não necessariamente corresponde ao caminho proposto pelas hierarquias religiosas. Sendo assim, a noção de espiritualidade teria papel inclusivo perante a diversidade sociocultural e, além disso, permitiria salientar a dimensão da vivência pessoal em detrimento da dimensão formal de ligação a uma instituição.

Esse processo de aproximação com o conceito da espiritualidade não pode, contudo, desprezar a importância da dimensão da religiosidade, que tem sido o foco da maior parte das pesquisas científicas na área. Além disso, a religiosidade tem forte inserção no cenário nacional, tanto por sua prevalência $(92,6 \%$ dos brasileiros declaram 
possuir uma religião segundo o IBGE, 2010) como por sua importância e significado na vida das pessoas e nos desfechos em saúde já discutidos no item 1.2.

Independentemente da abordagem da dimensão da espiritualidade e/ou da religiosidade, a experiência da pessoa tem ganhado cada vez mais destaque tanto na conceituação filosófica do cuidado (Ayres, 2004) quanto em sua aplicação prática em saúde, por exemplo, a partir do método clínico centrado na pessoa (Stewart et al., 2014).

A doença e a experiência de adoecimento trazem as pessoas a diferentes graus de reflexão e ressignificação sobre sua vida, relações, escolhas e planos, pois consiste em uma experiência de crise (Stewart et al., 2014; Kübler-Ross, 1987). Não é infrequente que, nesse processo, a pessoa reveja valores e busque significado para sua existência, passando a valorizar, assim, sua dimensão espiritual na construção de suas estratégias de resiliência. Na elaboração subjetiva profunda, consciente e inconsciente, de sua experiência de adoecimento a pessoa constrói novos sentidos e significados para sua vida. Essa mobilização passa a constituir recurso interno capaz de mobilizar a pessoa na difícil tarefa de reorganização do viver exigida pelo adoecimento (Vasconcelos, 2011).

Com a transição epidemiológica de distribuição de doenças no Brasil desde a segunda metade do século XX, observa-se a prevalência crescente de doenças crônicodegenerativas, cujo enfrentamento não pode ser pontual. Retomando Vasconcelos (2009), a abordagem dessas condições clínicas

Exige modificações profundas do modo de vida que só acontecem se é mobilizada uma grande "garra" nos pacientes e nos grupos [...] Encontra-se aí a força da espiritualidade como instrumento de promoção da saúde, na medida em que lida com as dimensões pouco conscientes do ser em que se assentam os valores, motivações profundas e sentidos últimos da existência individual e coletiva.

Desse modo, retomando-se o conceito de Heidegger (1995) acerca do cuidado como o suporte ao projeto de Ser da pessoa, percebe-se a ligação da questão espiritual com as necessidades de saúde e bem-estar. A conceituação da abordagem da dimensão espiritual como prática auto reflexiva existencial pode tornar essa dimensão uma potente ferramenta do cuidado em saúde. A atenção espiritual em saúde pode ser facilitadora para processos de recuperação do projeto existencial da pessoa, permitindo 
o fortalecimento do vínculo e da ação terapêutica do profissional. Nesse sentido, é possível resgatar essa prática como intervenção que se aproxima da conceituação de cuidado proposta por Ayres (2004):

Cuidado como designação de uma atenção à saúde imediatamente interessada no sentido existencial da experiência do adoecimento, físico ou mental, e, por conseguinte, também das práticas de promoção, proteção ou recuperação da saúde.

Desse modo, a abordagem da espiritualidade parece vir ao encontro da visão integral que se busca na APS e consiste em ferramenta para trabalhar o significado das vivências (Elwyn et al., 1999), as estratégias de enfrentamento ou coping (Panzini et al., 2007), o desenvolvimento da resiliência (Kent et al., 2015) e o reenquadramento de situações disfuncionais vivenciadas, rotinas do médico de família e comunidade (MFC) brasileiro em sua prática.

\subsection{Como inserir a abordagem da espiritualidade na prática clínica?}

Considerando-se que a espiritualidade impacta na saúde, tanto de modo positivo quanto negativo (Panzini et al., 2007) e que muitos pacientes gostariam que seu médico conversasse sobre esse assunto (McCord et al., 2004), não abordar essa temática com a pessoa pode resultar em fragmentação no cuidado, piora da qualidade de vida e até iatrogenias.

A literatura sobre diferentes metodologias de abordagem da dimensão espiritual do paciente, a denominada "anamnese espiritual", é bastante extensa. A revisão sistemática de Luchetti et al. (2013a) encontrou 25 métodos propostos para abordagem da espiritualidade da pessoa e os avaliou. Os autores analisaram as 25 ferramentas por meio da pontuação em um score desenvolvido para a revisão. Dentre as cinco ferramentas com melhor pontuação, três foram desenvolvidas para utilização no âmbito da atenção primária à saúde: FICA (Puchalski e Romer, 2000), SPIRITual History (Maugans, 1996) e HOPE (Anandarajah e Hight, 2001). Apenas cinco dentre as 25 ferramentas avaliadas pela revisão passaram por processos de validação, sendo que o FICA foi uma delas (Borneman et al., 2010).

Tais métodos propõem a abordagem de certos aspectos fundamentais da dimensão espiritual dos indivíduos que repercutem em maior ou menor grau em seu 
estado de saúde, tais como identificação dos elementos de fé ou crença; percepção de sentido ou significado na vida da pessoa; construção de estratégias de suporte da pessoa, incluindo a vivência da espiritualidade e rede de apoio; avaliação da importância de crenças e práticas da pessoa em sua vida, incluindo sua repercussão em seu estado de saúde-doença ou no plano terapêutico; e possibilidade de incluir demandas espirituais que possam ser abordadas no contexto terapêutico de cuidado integral multidimensional. As perguntas descritas para cada uma das três ferramentas podem ser visualizadas nos ANEXOS 1, 2 e 3 .

Para os autores da revisão sistemática citada, mesmo com o bom desempenho dos questionários FICA, HOPE e SPIRITual History para a realização da anamnese espiritual, cada um deles deve ser utilizado clinicamente de modo individualizado, de acordo com a realidade de cada profissional, tempo disponível, perfil do paciente e definições adotadas.

Várias fontes da literatura destacam a importância de que a abordagem da dimensão espiritual possa ser centrada nas necessidades da pessoa (Puchalski e Romer, 2000; Saguil e Phelps, 2012). De modo especial, dentre as competências descritas como essenciais ao médico de família e comunidade egresso de um programa de residência médica na área, se encontram conhecimentos, habilidades e atitudes para aplicação do método clínico centrado na pessoa (SBMFC, 2015).

O método clínico centrado na pessoa (MCCP), metodologia proposta por Stewart et al. (2014), teve origem em pesquisas dos mesmos autores (Stewart, 2001) que observaram que as pessoas buscavam atendimentos médicos que avaliassem a razão principal da sua consulta, como suas necessidades e preocupações; procurassem um entendimento integrado do seu mundo, considerando necessidades emocionais e questões existenciais; chegassem a um consenso com a pessoa sobre problemas e propostas terapêuticas; proviessem fatores de prevenção e promoção de saúde; e fossem capazes de qualificar o relacionamento entre pessoa e médico.

A partir dessas premissas, o MCCP foi estruturado, a princípio, em seis e, após, em quatro componentes, que se encontram resumidos no ANEXO 4 (Stewart et al., 2014). Esses componentes ou passos são estruturados de modo a explorar a doença e a experiência de doença, ou seja, como cada pessoa, individualmente, vivencia seu processo único de adoecimento, trazendo à tona seus sentimentos, ideias, expectativas e 
impacto funcional acerca de uma enfermidade ou condição de vida. Para isso, o método busca entender a pessoa como um todo, ou seja, abordar a pessoa em suas dimensões biopsicossociais-espirituais e suas relações. A preocupação com essas dimensões da pessoa ganha relevância ao se elaborar um plano comum de manejo dos problemas, buscando ajustar as condutas às necessidades integrais manifestadas pela pessoa, a partir daquilo que é significativo para ela em seu plano terapêutico. Para o bom desempenho dessa prática, é preciso que o profissional de saúde busque incorporar prevenção e promoção de saúde ao atendimento; ser realista em termos de tempo e recursos; e intensificar o relacionamento entre pessoa e médico, construindo vínculo e uma relação terapêutica pautada na compaixão, horizontalidade das relações de poder e no processo de autoconhecimento e autoconsciência do médico. A efetividade da aplicação clínica e ensino desse método já vem sendo observada em diferentes estudos na literatura, inclusive com evidências para o aspecto de autoconhecimento do profissional na prática clínica (Smith et al., 1999), como será discutido na sequência.

Como produto da presente dissertação de mestrado, foi publicado artigo original na literatura (Oliveira et al., 2018) que propõe a realização da abordagem da espiritualidade da pessoa de modo integrado ao método clínico centrado na pessoa. Para essa aplicação metodológica, para além das perguntas diretas sobre religiosidade ou espiritualidade, busca-se compreender a experiência da pessoa com essa dimensão de sua vida, incluindo ideias e sentimentos que estejam relacionados a suas perspectivas pessoais. Desse modo, é possível integrar à anamnese a identificação de fontes de apoio, estratégias de resiliência ou mesmo o sentimento de sofrimento espiritual. Além disso, o método considera as expectativas do paciente e o impacto de sua E/R em sua vida e no próprio cuidado em saúde, observando-se tanto o contexto de crença pessoal quanto a visão familiar, a rede de suporte social e o contexto cultural, conforme esses fatores tiverem maior ou menor importância para a vivência da pessoa. O impacto dessa metodologia sobre a prática clínica de residentes de medicina de família e comunidade foi estudado qualitativamente (Stange, 2018), tendo-se observado maior inserção dessa temática na prática clínica após a capacitação na metodologia. 


\subsection{Consolidacão da abordagem da espiritualidade na prática clínica: qual o impacto dos valores e barreiras pessoais do médico?}

Apesar das várias ferramentas consistentes disponíveis para a anamnese espiritual e do próprio treinamento na prática centrada na pessoa, a abordagem da dimensão espiritual do paciente ainda parece ser um desafio para a prática do médico de família e comunidade (MFC) brasileiro. Essa percepção desperta a dúvida sobre como fatores profissionais e pessoais podem interferir com a decisão de realizar ou não essa abordagem.

No estudo de Koenig et al. (2005) foram elencadas barreiras para a abordagem da espiritualidade do paciente, tais como a falta de tempo (concordância de 95,0\% dos respondedores), conhecimento ou treinamento sobre o assunto $(69,0 \%)$ e diversos desconfortos com o tema, como preocupação de atuar em área não médica $(64,0 \%)$, medo de ofender $(57,0 \%)$ ou de impor pontos de vista religiosos ao paciente $(51,0 \%)$, conforme a FIGURA 1.

FIGURA 1. Percentual de acordo com concordância com as barreiras para abordagem da E/R na prática clínica - Koenig et al., 2005

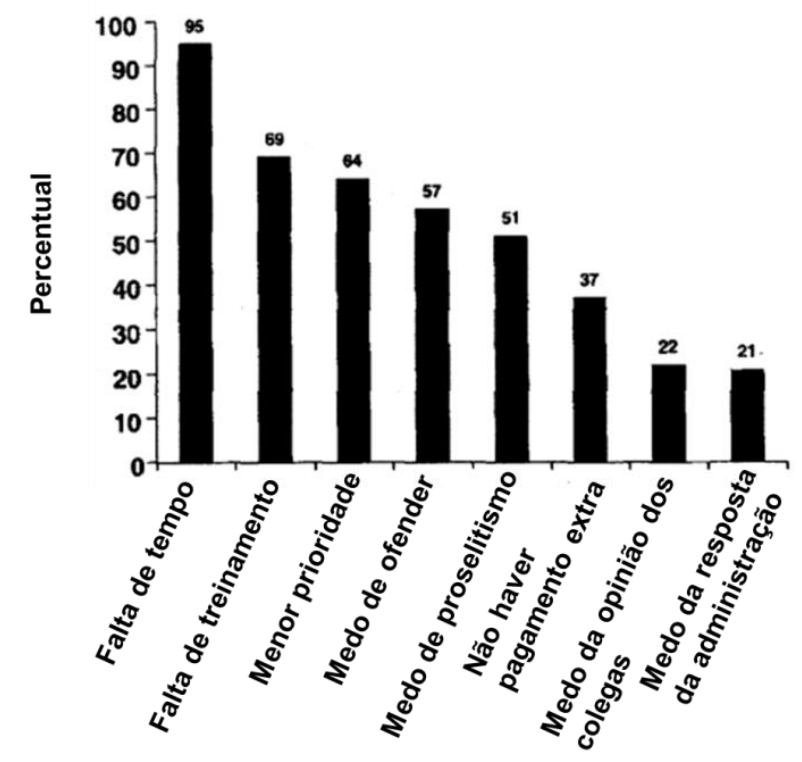

FONTE: Koenig et al., 2005

Sobre a temática específica da interferência de valores pessoais do médico na abordagem clínica da espiritualidade do paciente, Curlin et al. (2006) realizou um estudo transversal com 2000 médicos americanos, de diferentes especialidades. Por 
meio de questionário não validado, o autor avaliou a espiritualidade e religiosidade (assumidas como sinônimos para o autor) auto referidas dos profissionais e constatou que aqueles que se declaravam como mais religiosos ou espiritualizados $(17,0 \%)$ tinham tendência significativamente maior de abordar $\mathrm{E} / \mathrm{R}$ do paciente na prática clínica $(63,0 \%$ vs. $18,0 \%, p<0,001)$. Médicos com baixo escore de $\mathrm{E} / \mathrm{R}$ também relatavam com maior frequência a percepção de desconforto em discutir questões religiosas com pacientes $(44,0 \%$ vs. $3,0 \%, \mathrm{p}<0,001)$, além de declararem terem menor conhecimento ou treinamento na área $(41,0 \%$ vs. $7,0 \%$, p<0,001). Após o ajuste para características religiosas e outras variáveis codependentes, a falta de conhecimento ou treinamento não permaneceu associada a nenhum comportamento específico. Por outro lado, nessa análise, a percepção de desconforto com o tema por parte do profissional se manteve associada com a menor tendência do médico de realizar anamnese espiritual (OR 0,6, IC 95,0\% 0,4-0,9).

Em outro estudo com a mesma amostra de médicos americanos, o autor avaliou a associação da $\mathrm{E} / \mathrm{R}$ dos profissionais com as observações e interpretações que eles faziam sobre a relação entre saúde e E/R (Curlin et al., 2007a). Foi observado que a maior parte dos médicos $(56,0 \%)$ acreditava que a $E / R$ tivessem muita ou muitíssima influência na saúde, seja por ajudar os pacientes nas estratégias de enfrentamento $(76,0 \%)$, dar ao paciente um estado de mente positiva $(75,0 \%)$ ou prover suporte emocional e prático a partir da comunidade religiosa $(55,0 \%)$. Ficou claro, no entanto, que, independentemente de sua religião, médicos com maior $\mathrm{E} / \mathrm{R}$ eram substancialmente mais propensos a reportarem que os pacientes mencionam temáticas sobre $E / R$ frequentemente (36 vs 11,0\%, p<0,001); acreditarem que $\mathrm{E} / \mathrm{R}$ influencia fortemente a saúde (82 vs 16\%, p<0,001) e interpretar a influência da $E / R$ na saúde mais como positiva que negativa (OR: 4,5, IC 95,0\% 2,8-7,3).

As dificuldades e barreiras para a abordagem da espiritualidade do paciente também são encontradas no âmbito da medicina de família e comunidade. Vermandere e Lepeleire (2011) avaliou 113 artigos em uma revisão qualitativa da literatura sobre fatores facilitadores e barreiras para a abordagem da espiritualidade na atenção primária. Dentre os fatores limitantes dessa prática, a partir da análise temática, foram descritos: a insegurança do profissional sobre iniciar a discussão sobre questões espirituais; medo de que os pacientes interpretassem mal a discussão sobre 
espiritualidade; a preocupação com a invasão da privacidade dos pacientes; medo de causar desconforto ao paciente; dificuldade em utilizar a linguagem espiritual; percepção de que as questões espirituais têm prioridade mais baixa do que outras preocupações médicas; a crença de que as discussões espirituais não vão influenciar o cuidado dos pacientes; a existência de sistemas de crenças diferentes entre médico e paciente; e, por fim, a falta de consciência espiritual médico.

No Brasil, os dados sobre opinião de profissionais de saúde em relação à temática da E/R no cuidado em saúde são mais restritos. O estudo SBRAME (Spirituality and Brazilian Medical Education), realizado com estudantes de medicina, avaliou a percepção sobre a importância da abordagem da espiritualidade na prática clínica, bem como sua percepção sobre treinamento na área (Lucchetti et al. 2013c). Observou-se que a maioria dos estudantes desejava perguntar aos pacientes sobre religiosidade e espiritualidade em sua prática clínica $(58,0 \%$ dos respondedores) e consideravam essa abordagem relevante $(75,3 \%)$, embora menos da metade dos estudantes se sentissem preparados para realizar essa abordagem $(48,7 \%)$. Na área da enfermagem, Tomasso et al. (2011) observou, entre estudantes e docentes da Universidade Estadual de Marília, que 96,0\% acreditavam que a espiritualidade influenciava muito na saúde do paciente e $77,0 \%$ sentiam vontade de abordar o assunto. Entretanto, somente $36,0 \%$ julgavam-se preparados para realizar essa abordagem na assistência em enfermagem. Assim como nos estudos internacionais, as principais barreiras para abordar o assunto foram medo de impor as próprias crenças, falta de tempo e medo de ofender os pacientes.

Buscando compreender melhor a interferência da $\mathrm{E} / \mathrm{R}$ de médicos e a atuação das barreiras dos valores pessoais na prática do profissional, o estudo de Campbell et al. (2002) entrevistou MFC americanos ( $N=14)$ sobre sua prática de abordagem espiritual, com análise qualitativa dos resultados. Observou-se que metade realizava abordagem regular e outra metade não costumava realizar. Dentre os que relatavam prática regular da abordagem espiritual, as motivações apresentadas foram as evidências científicas e a importância da dimensão espiritual em suas próprias vidas. Como fatores que dificultavam a abordagem, foram elencadas questões culturais, educacionais, o grau de abertura da pessoa à espiritualidade ou tomada de consciência, a resistência a expor crenças pessoais e a percepção de que a abordagem não traria impacto clínico. A 
abordagem foi descrita como facilitada pela disponibilidade do profissional de saúde, bem como por seus hábitos de vida, equilíbrio pessoal e maturidade espiritual.

Desse modo, observa-se que os valores pessoais do médico podem ter impacto sobre sua decisão de realizar ou não a anamnese espiritual em sua prática clínica. Do mesmo modo, a revisão de Vermandere e Lepeleire (2011) descreve fatores profissionais e pessoais do médico que podem atuar como facilitadores dessa prática, tais como: a ação do médico de comunicar sua vontade de se envolver em discussões espirituais e reservar tempo para isso; habilidade em técnicas de comunicação verbais e não verbais; capacidade de transmitir à pessoa a segurança de que confidências espirituais serão recebidas sem julgamento; estar consciente do cuidado necessário para não abusar da sua posição como profissional; habilidade para realizar uma abordagem diplomática quando as crenças espirituais do médico e do paciente diferirem; a própria inclinação espiritual do médico; e, finalmente, a habilidade do profissional de ser centrado na pessoa.

Observa-se na literatura que, apesar das técnicas e estratégias de abordagem da dimensão espiritual diferirem entre médicos de família e comunidade, esses profissionais buscam prover suporte integral e centrado na pessoa em sua prática de cuidado, o que atua como um favorecedor para o manejo das necessidades espirituais do paciente (Campbell et al., 2002; Anandarajah et al., 2011). Nesse sentido, retomando Campbell et al. (2002), essa abordagem parece advir, dentro do método clínico centrado na pessoa, a partir da resposta singular da pessoa frente a sua experiência de adoecimento crônico, terminalidade da existência e reação a estressores do ciclo de vida. Contudo, para que a avaliação da dimensão espiritual possa ser realizada com sensibilidade e integridade pelo profissional, é preciso que ele leve em consideração as barreiras do paciente, mas também suas resistências pessoais ao tema ou às demandas que possam advir da abordagem. Para Lucchetti et al. (2010), essas barreiras seriam quebradas à medida que o médico se aprofundasse no tema e se desvencilhasse de seus próprios medos e preconceitos.

O quarto componente do método clínico centrado na pessoa (MCCP), que trata da intensificação do relacionamento entre médico e pessoa, propõe a reflexão sobre autoconhecimento e a pessoa do médico. Sobrevém a importância de se atentar para o contexto pessoal do médico e seu processo de tomada de consciência dentro de sua 
prática. Para a realização de abordagens integrais, como é o cunho da abordagem da dimensão espiritual, o médico precisa ter clareza de suas crenças e valores para que elas não interfiram em sua abordagem terapêutica (NHG, 2002). Isso exige autoconhecimento do profissional, tanto para reconhecer e trabalhar com sua frustração, quanto para gerir os processos de transferência e contratransferência, enquanto busca auxiliar a pessoa a encontrar as próprias respostas (Stewart et al., 2014).

\section{DELIMITAÇÃO E JUSTIFICATIVA: Autoconhecimento e espiritualidade do profissional de saúde: como podemos caminhar?}

No sentido de se capacitar para abordar temas que impactem sobre seus valores pessoais, como a abordagem da espiritualidade e religiosidade, o médico precisa manter uma prática reflexiva sobre si mesmo. O encontro clínico ocorrido na consulta traz repercussões para a pessoa e o profissional. Para melhor desempenhar essa tarefa, na visão de Balint (1988), o médico deve trabalhar a sua função apostólica, ou seja, não usar de proselitismo para com suas próprias ideias. Essa postura é reforçada por Puchalski (2014a) na esfera da abordagem espiritual. Para atingir tal desempenho, é fundamental que o profissional se atente às reflexões subjetivas advindas da consulta e aos seus próprios valores pessoais.

Nesse sentido, a dimensão do autoconhecimento do médico é um dos campos de desenvolvimento profissional esperado, segundo o consenso americano que norteia as competências para a abordagem da espiritualidade na prática clínica (Puchalski, 2014 b). Encontrar um consenso que homogeneíze e norteie essa prática reflexiva e de autoconhecimento do médico, no entanto, parece ser difícil perante a multiplicidade dos valores espirituais e religiosos, dentre outros valores, que podem interferir com a decisão clínica (Curlin et al., 2007a). No Brasil, embora as Diretrizes Curriculares Nacionais do Curso de Medicina (Brasil, 2014) tragam destaque para a importância do exercício do cuidado integral em saúde, não há menção direta à dimensão espiritual do cuidado. Em relação ao egresso do curso de medicina, é esperado que o profissional seja ético, crítico e reflexivo, eixos que fazem alusão ao profissionalismo e desenvolvimento pessoal. Em relação à residência médica no país, não há menção à espiritualidade ou religiosidade nos documentos da Comissão Nacional de Residência Médica. Em 
levantamento feito por nosso grupo de pesquisa e que aguarda publicação, a única especialidade médica que orienta a importância da religiosidade na prática clínica em seu conteúdo programático é a psiquiatria.

Os estudos demonstrando a interferência dos valores pessoais, sobretudo religioso-espirituais, dos médicos trazem questionamento sobre como isso interfere nas decisões clínicas e éticas, além da possibilidade de impactar a autonomia do paciente e dificultar consensos dentro das sociedades médicas. Movidos por essas questões, o grupo de Hvidt et al. (2017) construiu o questionário NERSH, um data pool que agrega dados de cinco continentes e busca compreender melhor como os valores pessoais (religiosidade, boa vontade e senso de vocação) influenciariam condutas éticas e práticas. Embora o grupo já tenha dados brasileiros, esses dados vêm de uma amostra de enfermeiras da Universidade Estadual de Marília e da Universidade Nove de Julho, ambas do estado de São Paulo, além de inquérito com 180 médicos do Hospital de Clínicas da Faculdade de Marília. Desse modo, não há dados expressivos sobre a opinião de médicos, no cenário nacional, havendo características que necessitam ser mais bem estudadas no contexto de um país continental como o Brasil.

Pesquisadores do grupo NERSH também consideram que ainda existe necessidade de compreender melhor as características de $\mathrm{E} / \mathrm{R}$ dos profissionais e suas percepções (Hvidt et al., 2017), além de estudar melhor diferentes grupos, a fim de se reconhecer as diferenças nacionais, culturais, étnicas e religiosas que permeiem o processo de tomada de decisão clínica de abordar ou não a dimensão espiritual do paciente (Lucchetti et al., 2016).

Nesse sentido, a pergunta sobre como lidar com as dimensões subjetivas do profissional, em especial a dimensão religiosa-espiritual, surge como um grande desafio a ser mais bem estudado e delineado na prática clínica. A ausência de estudos brasileiros que avaliem o impacto da religiosidade e espiritualidade do médico em sua postura clínica de abordar ou não a dimensão espiritual do paciente limita a capacidade de compreendermos melhor o médico brasileiro e suas necessidades de capacitação e consenso sobre a atuação na área.

Desse modo, o presente estudo realizou essa análise com médicos brasileiros, de modo a contribuir para o esclarecimento desse campo no cenário nacional. A fim de homogeneizar a amostra entre as especialidades médicas, foi escolhido trabalhar com a 
percepção de médicos de família e comunidade que tenham concluído residência médica na área. A escolha por trabalhar com essa especialidade médica se deu pela sua posição estratégica para a estruturação do sistema de saúde e formação de recursos humanos em saúde no Brasil. Além disso, a especialidade tem distribuição regional abrangente no país e as competências de formação desse grupo de profissionais já são orientadas para comunicação, prática centrada na pessoa e autoconhecimento, como descreveremos na metodologia do presente estudo. 


\section{OBJETIVOS}

O objetivo geral é descrever como a espiritualidade e a religiosidade auto referidas de médicos de família e comunidade com residência médica na área estão relacionadas à prática desses profissionais em abordar a dimensão espiritual do paciente.

Objetivos específicos:

- Descrever aspectos da dimensão espiritual e religiosa de médicos de família e comunidade, com residência médica na área;

- Conhecer aspectos sobre a inserção do tema da espiritualidade na prática clínica rotineira referida por esse grupo de profissionais;

- Discutir como os aspectos da prática clínica de médicos de família e comunidade podem ser impactados pela espiritualidade e religiosidade desses profissionais. 


\section{MÉTODOS}

\subsection{Caracterização do estudo:}

Realizou-se estudo transversal observacional descritivo, com análise quantitativa de dados demográficos e da percepção do médico de família e comunidade brasileiro (MFC) sobre sua espiritualidade e religiosidade (E/R) intrínsecas. Também foram avaliadas a percepção auto referida dos MFC sobre a inserção da temática da $E / R$ no contexto da prática clínica e a frequência com que esse grupo de médicos costuma abordar a dimensão espiritual do paciente em suas consultas rotineiras. Fatores associados à realização ou não da abordagem $E / R$ nas consultas também foram avaliados.

\subsection{Caracterização do universo e amostra da pesquisa:}

O universo do estudo foi constituído por médicos de família e comunidade brasileiros que tivessem concluído residência médica na área até setembro de 2017. Obter dados sobre o número total de médicos que compõem esse universo, no entanto, foi bastante difícil, dado o contexto histórico da especialidade e a falta de dados sobre egressos de residência médica no Brasil.

Os primeiros programas de residência médica, na época na especialidade denominada medicina geral e comunitária, datam de 1975. A Sociedade Brasileira de Medicina de Família e Comunidade (SBMFC) foi fundada em 1981 e é a entidade nacional que congrega os médicos que atuam em serviços de Atenção Primária em Saúde (APS), incluindo a Estratégia Saúde da Família (ESF), prestando atendimento médico geral, integral e de qualidade a indivíduos, famílias e comunidades. Inclui também professores, preceptores, pesquisadores e outros profissionais que atuam ou estão interessados nesta área.

Desde a criação do então Programa Saúde da Família pelo governo federal, em 1994, a APS vem ganhando força como porta de entrada e ordenadora da atenção à saúde no país. A especialidade Medicina de Família e Comunidade passou por um processo de expansão, contudo, dada a grande necessidade de profissionais médicos para atuarem nesse setor, as vagas da APS brasileira foram ocupadas, em sua maioria, por médicos que não possuem formação especializada na área. 
Os dados sobre a atuação de médicos na APS do país não são precisos. $\mathrm{O}$ levantamento publicado por Malta et al. (2016) aponta que, segundo dados do Departamento da Atenção Básica do Ministério da Saúde, o Brasil possuía 33.404 equipes de Estratégia Saúde da Família em 2012, ocasião em que a cobertura do serviço alcançava 55,0\% dos brasileiros. A cobertura de APS vinha em franca expansão no período, registrando aumento de $10,0 \%$ da cobertura nos últimos dez anos. Não conhecemos a taxa de ocupação dessas equipes por médicos, contudo, no ano de 2013, o governo federal disponibilizou mais de 11 mil vagas para o Programa "Mais Médicos", sob a justificativa de não preenchimento das vagas oferecidas nas ESF. Em 2011, em levantamento realizado por encomenda da SBMFC (2011), médicos espanhóis produziram relatório estimando que apenas 5,0\% das equipes de estratégia saúde da família eram preenchidas por médicos especialistas na área.

Nesse sentido, embora a medicina de família e comunidade seja reconhecida como especialidade médica desde 2002 pela Associação Médica Brasileira (AMB), dado o contexto nacional de necessidade de profissionais para atuação na APS muito superior ao número de especialistas no país, a SBMFC associa diferentes categorias profissionais. Podem se associa à instituição médicos reconhecidos como especialistas em medicina de família e comunidade por terem concluído residência médica na área (cujo nome oficial da especialidade e de seus programas de residência médica foi Medicina Geral Comunitária até abril de 2002); médicos reconhecidos como especialistas na área por terem quatro anos ou mais de experiência na área e terem sido aprovados em concurso de prova de título de especialista promovido pela SBMFC; além de associar estudantes de medicina, médicos residentes ou médicos generalistas atuantes na estratégia saúde da família ou interessados nessa área.

A SBMFC reconhece como especialistas em medicina de família e comunidade médicos que tenham tanto concluído residência médica na área, como médicos titulados especialistas pela sociedade, por meio de concurso. De modo a avaliar dados de médicos com formação mais homogênea na área, a amostra principal para análise em nosso estudo foi constituída pelo grupo de especialistas que tivessem concluído residência médica em Medicina de Família e Comunidade até setembro de 2017. A escolha por egressos de programas de residência médica se deu porque, de acordo com as competências esperadas pela SBMFC (2015), esse grupo de profissionais deve ser 
capacitado para a utilização do método clínico centrado na pessoa (MCCP), método que apresenta potencial para estimular o autoconhecimento e tomada de consciência de percepções e valores por parte do profissional em sua prática clínica, como já discutido.

Como a SBMFC agrega uma vasta gama de profissionais, possui membros com diferentes modalidades de formação ou treinamento. Como é esperado que egressos dos programas de residência médica na especialidade tenham conhecimento e treinamento específicos na área do método clínico centrado na pessoa, foi adotado como critério de inclusão na amostra principal da pesquisa que o profissional tenha concluído programa de residência médica na área de Medicina de Família e Comunidade ou Medicina Geral e Familiar (designação prévia a 2002), no momento da aplicação do questionário. Os questionários respondidos por especialistas em medicina de família e comunidade titulados por concurso promovido pela SBMFC também foram arquivados e serão analisados de modo a poder gerar dados comparativos com a amostra principal em outras pesquisas, no futuro.

Como critérios de exclusão foram definidos: 1) profissional que não informou seu número de registro geral por unidade federativa $(\mathrm{RG})$, como forma de evitar duplicidades de preenchimento; 2) profissional que declarou não ter concluído residência médica em Medicina de Família e Comunidade; 3) participante que não tenha respondido o questionário na íntegra.

Os médicos foram recrutados a partir de cadastro feito na SBMFC ou por contato direto com programas de residência médica do país. O cadastro da SBMFC não distingue, dentre os associados, médicos que tenham concluído residência médica na área, dos demais associados. Desse modo, na etapa de planejamento da pesquisa, foi levantado que a SBMFC dispunha de banco de cadastro com quase 8000 endereços eletrônicos de e-mails, contudo a estimativa era de que, dentre esses contatos, seria esperado um universo de cerca de 4000 médicos especialistas em medicina de família e comunidade, por titulação ou residência médica, de acordo com dados da Demografia Médica no Brasil (Scheffer et al., 2015). Desse modo, dada a impossibilidade de filtrar os contatos dos especialistas, os e-mails de convite para participação na pesquisa foram disparados para todos os contatos relacionados. Dentre os 4000 especialistas na área, era esperado que cerca de metade (2000 médicos) atenderiam ao critério da amostra 
principal de ter concluído residência médica em medicina de família e comunidade. A carta da SBMFC autorizando uso dos contatos segue no ANEXO 10.

Para dar uma ideia comparativa da representatividade da amostra, nos Estados Unidos, o estudo de Curlin et al. (2006), que avaliou a relação entre a religiosidade de médicos e suas atitudes auto referidas sobre a abordagem dessa temática na prática clínica, alcançou taxa de resposta de 63,0\% dos contatados. Com isso, o estudo obteve resposta de 2000 médicos americanos, sendo 126 deles MFC (em um universo estimado de 100.000 MFC no país). No entanto, a terceira chamada para resposta ao questionário por e-mail oferecia contrapartida de 20 dólares aos participantes.

Quanto à taxa de resposta ao questionário online esperada, uma revisão sistemática (Basílio et al., 2018) avaliou as respostas de médicos de família e comunidade portugueses a pesquisas realizadas a distância (telefone, e-mail, postagem). A taxa de resposta encontrada dentre os 37 estudos incluídos na revisão foi de $56,0 \%$ (IC95,0\%, 47,0-64,0\%), contudo, houve heterogeneidade importante dentre os estudos incluídos (I2=99,0\%). Já existem estudos brasileiros realizados com amostragem de médicos de família e comunidade após conclusão da residência médica, contatados por correio eletrônico para aplicação de questionário online. Um programa de residência médica de Porto Alegre contatou 180 egressos por correio eletrônico, obtendo resposta de $93(51,7 \%)$ egressos (Farias et al., 2004). Outro estudo, contatando 100 médicos egressos de um curso de especialização em saúde da família no Espírito Santo obteve 47 $(47,0 \%)$ respostas por meio eletrônico (Maciel et al., 2010). Em ambos os casos, o fato de os médicos contatados serem egressos das instituições que realizaram as pesquisas pode ter interferido para o aumento da taxa de resposta.

\subsection{Planejamento de poder amostral do estudo e universo}

\section{populacional de médicos de família e comunidade no Brasil}

Os dados sobre especialistas em medicina de família e comunidade no Brasil são escassos, sendo difícil obter dados que diferenciem egressos de programas de residência médica (população alvo deste estudo) de médicos que obtiveram título de especialista.

A comissão nacional de residência médica disponibiliza para consulta pública os dados de Consulta a Certificados de Residência Médica em seu site (CNRM, 2017). De acordo com as informações disponíveis em novembro de 2017, 557 médicos foram 
registrados como egressos de programas de residência em Medicina de Família e Comunidade no Brasil. Não há informação sobre o período da última atualização desses dados.

Para o planejamento do presente trabalho de pesquisa, foi utilizada como fonte de dados sobre a especialidade os dados disponibilizados pelo estudo Demografia Medica no Brasil (Scheffer et al., 2015). De modo a garantir a melhor atualização possível, os dados utilizados foram os disponibilizados pelo site de consulta pública da pesquisa, o qual teria sido atualizado em 29/11/2016. Os dados de registro de especialidades médicas que alimentam esse banco de dados são os decorrentes do cadastro dos egressos dos programas de residência médica como especialistas junto aos Conselhos Regionais de Medicina. Como esse cadastro não é obrigatório no Brasil, é estimado que haja subnotificação do registro de egressos dos programas de residência na área no Brasil.

De acordo com as informações do estudo Demografia Médica no Brasil em seu site de consulta pública, o Brasil possui 4.022 médicos especialistas em Medicina de Família e Comunidade. Deste total, $648(16,1 \%)$ médicos têm registro de conclusão de residência média na área. Os demais são titulados pela Sociedade Brasileira de Medicina de Família e Comunidade.

Já o contexto de crescimento da especialidade e a expansão de vagas para residência médica na área nos fizeram questionar os dados oficiais das pesquisas. Para o ano de 2015, por exemplo, foram disponibilizadas pelo Ministério da Educação e Cultura (MEC) 1537 vagas para programas de residência médica em Medicina de Família e Comunidade. Deste total, 400 vagas foram preenchidas $(26,0 \%)$. Não havia dados sobre quantos desses ingressantes teriam concluído os dois anos de residência médica na área até 2017.

Dada a dificuldade de obtenção dos dados, na etapa de planejamento do estudo, foi realizado cálculo de poder amostral considerando-se um universo desconhecido, em função da proporção esperada de médicos que abordariam ou não a dimensão da espiritualidade e religiosidade (E/R) em suas consultas médicas, estimada a partir de estudos internacionais. O modelo explicativo de distribuição amostral esperado se encontra esboçado na FIGURA 2. 
FIGURA 2. Modelo teórico orientador da estimativa da amostra a partir da proporção de médicos que abordam ou não E/R em suas consultas, no universo dos MFC brasileiros - 2017

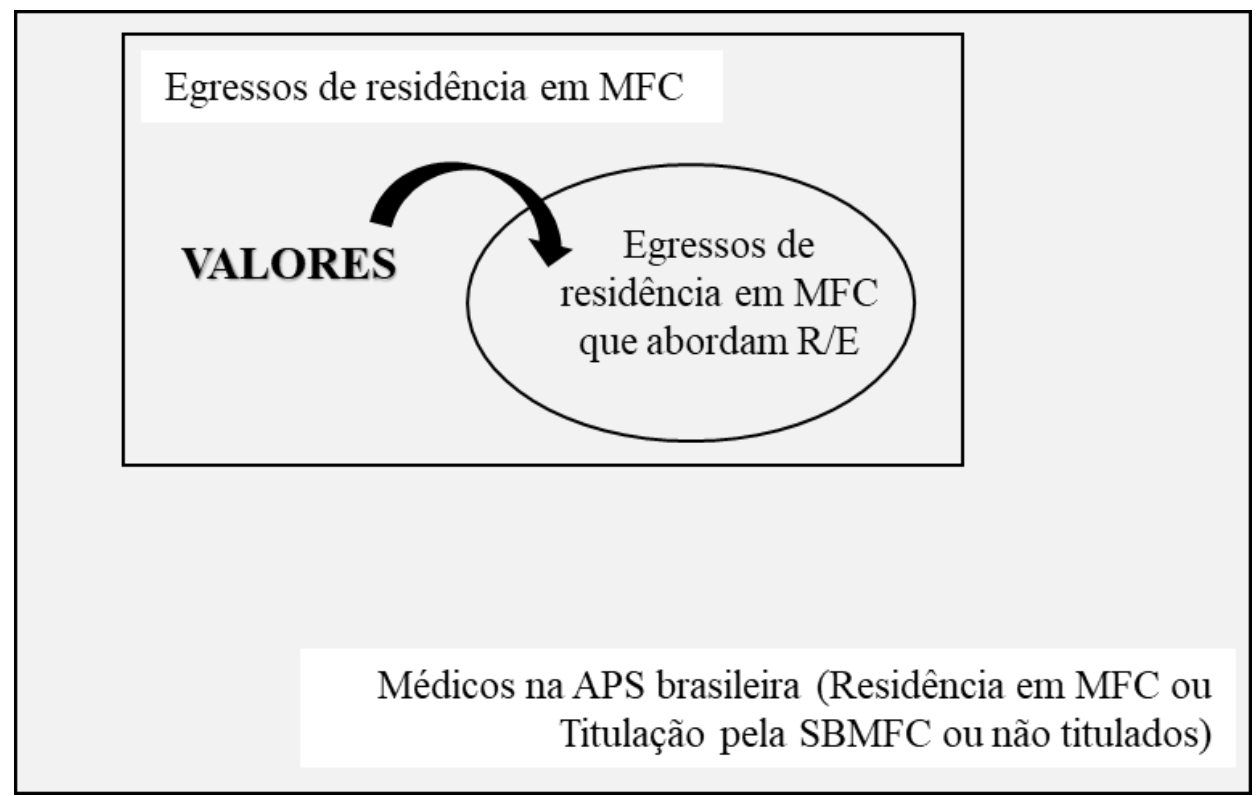

Embora não haja dados brasileiros, a literatura internacional permite estimar o quanto médicos de família e comunidade abordam ou não essa temática com os pacientes. Em relação a médicos de diferentes especialidades, incluindo MFC, o estudo de Curlin et al. (2006) mostrou que apenas 10,0\% dos médicos declaravam sempre perguntar sobre E/R. No questionário NERSH, de Hvidt et al. (2017), esse mesmo grupo somou $25,0 \%$ dos respondedores. Nos dez anos de intervalo entre os estudos, houve grande crescimento da temática da $\mathrm{E} / \mathrm{R}$ no meio científico, o que pode ter impactado na distribuição.

Para o cálculo de poder amostral no planejamento do presente estudo, foi utilizado o método de proporção de população esperada, conforme disposto por Peacock e Peacock (2011), cujo cálculo é realizado pela seguinte fórmula:

$$
\mathrm{N}=\alpha^{2} \times 4 \mathrm{p} .(1-\mathrm{p}) / \mathrm{d}^{2}
$$

Sendo: N: amostra esperada

$\alpha$ : intervalo de confiança, assumido como 95,0\% neste estudo ( $\mathrm{IC}=1.96)$

p: proporção esperada na população (Culin: 10,0\%, NERSH: 25,0\%) 
d: variação do intervalo de confiança (padrão $=0,10$ )

Assumindo-se as proporções encontradas na literatura de 10,0\% e 25,0\%, até a posição mais conservadora para o teste (proporção de 50,0\%, valor máximo da distribuição normal invertida), a expectativa de amostragem para o presente estudo segue disposta no QUADRO 1. A presente dissertação de mestrado se ateve à análise descritiva do banco de dados, ficando a análise estatística associativa reservada a futuros trabalhos de pesquisa.

QUADRO 1 - Cálculo de tamanho amostral em função da proporção de MFC que abordar R/E de modo rotineiro (frequente ou sempre) em suas consultas

\begin{tabular}{|l|l|l|l|l|}
\hline $\mathbf{N}$ estimado & 138 & 288 & 290 & 384 \\
\hline $\mathbf{P}$ & $0,1($ Curlin) & 0,25 (NERSH) & 0,5 (Conservador) & 0,5 (Conservador) \\
\hline $\mathbf{D}$ & 0,1 & 0,1 & 0,115 (expandido) & 0,1 \\
\hline $\boldsymbol{\alpha}(\mathbf{I C})$ & 1,96 & 1,96 & 1,96 & 1,96 \\
\hline
\end{tabular}

NOTA: Valor de N obtido para amostra no presente estudo: 292

\subsection{Método de coleta de dados:}

Os profissionais elegíveis para a pesquisa foram contatados via e-mail, a partir dos dados do cadastro da SBMFC ou pela lista de e-mails mantida pela Sociedade, e convidados para participação na pesquisa. Caso aceitasse participar, o profissional deveria preencher Termo de Consentimento Livre e Esclarecido (TCLE) online. Caso o participante se declarasse de acordo com o termo, seria convidado a responder questionário para preenchimento por meio de formulário online, utilizando software de acesso livre (Google Formulários@). Embora não fosse a estratégia principal de coleta de dados, os participantes também foram ser recrutados por meio de e-mail enviado diretamente a programas de residência médica na área e sensibilizados por meio de redes sociais. O processo de divulgação da pesquisa por e-mail e mídias sociais se encontra detalhadamente descrito no capítulo Resultados, item 5.1, intitulado "Processo de coleta de dados". 


\subsection{Caracterização do questionário da pesquisa:}

O modelo piloto do questionário aplicado na pesquisa se encontra disponível como ANEXO 5 e é constituído por três domínios, dispostos do seguinte modo:

I. Aspectos demográficos: Caracterizam a amostra por meio de variáveis categóricas em relação à idade, sexo, atuação profissional e afiliação religiosa, seguindo o padrão do estudo multicêntrico SBRAME, que avaliou aspectos de religiosidade e espiritualidade de estudantes de medicina de diferentes regiões do Brasil (Lucchetti et al., 2013c).

II. Espiritualidade e prática clínica: Esse eixo aborda:

i. Auto percepção do profissional sobre o desenvolvimento da prática centrada na pessoa, por meio de perguntas diretas.

ii. Mensuração da temática e frequência de perguntas relacionadas à abordagem espiritual realizadas de modo rotineiro pelos profissionais em sua prática clínica. Para essa mensuração, construímos um conjunto de perguntas a partir dos instrumentos de abordagem espiritual que obtiveram os melhores índices de avaliação na revisão sistemática de Luchetti et al. (2013a) e que foram descritos na mesma revisão como instrumentos pertinentes para aplicação no contexto da Medicina de Família e Comunidade e APS. Desse modo, foram selecionados os instrumentos FICA, HOPE e SPIRITual History, já mencionados na introdução do presente trabalho. O primeiro instrumento (FICA) se encontra validado, em inglês, na literatura acadêmica. Nenhum dos três tem validação em língua portuguesa. Assim, os questionários foram traduzidos de modo livre, somando-se 44 questões oriundas dos três questionários, que seriam interessantes aos médicos inserirem em suas consultas para abordar a espiritualidade do paciente. Em seguida, a autora de presente dissertação realizou análise de conteúdo das 44 questões e, por similaridade e saturação de conteúdo, a autora identificou oito eixos temáticos. Assim, as 44 questões pertencentes aos questionários foram 
categorizadas por temas, como se encontra detalhado no ANEXO 6 (QUADRO 2). Em seguida, para cada um dos oito eixos temáticos, foram selecionadas duas perguntas a serem utilizadas em nosso questionário. A seleção das perguntas foi realizada por meio dos critérios de evitar repetição de conteúdos e privilegiar as perguntas de conteúdo mais abrangente, sendo selecionadas duas perguntas por área temática. A escolha das perguntas também buscou manter o número total de perguntas semelhante entre os três instrumentos e, desse modo, foram inseridas cinco perguntas do FICA e SPIRTual e seis perguntas originárias do HOPE. O conjunto final de 16 perguntas (duas para cada um dos dois eixos temáticos) segue disposto no QUADRO 3. A frequência de realização das perguntas na prática clínica foi aferida por meio de frequência autodeclarada pelos MFC, com escala de cinco itens (sempre, frequentemente, razoavelmente, pouco ou nunca). A proposta do constructo não é ser analisada por meio de nenhum escore ou ponto de corte, pois não busca avaliar se os médicos abordam mais ou menos temas sobre E/R em sua prática clínica. O propósito da utilização do constructo é de conhecer os temas mais frequentemente discutidos pelos médicos com seus pacientes, a respeito relação entre espiritualidade, religiosidade e cuidado em saúde.

iii. Avaliação da percepção do profissional sobre a importância da abordagem da espiritualidade e religiosidade na prática clínica e barreiras que limitem essa prática. Essa aferição será realizada por meio de perguntas aplicadas no estudo multicêntrico brasileiro SBRAME (Lucchetti et al., 2013c). As perguntas desse estudo, por sua vez, foram traduzidas do estudo de Curlin et al. (2006) e do questionário NERSH, de Hvidt e Curlin et al. (2017), trabalhos que tem se tornado referência na literatura para a avaliação da percepção e médicos em relação à temática de espiritualidade e religiosidade. Originalmente, o estudo de Curlin foi realizado com médicos de diversas especialidades, nos Estados Unidos da América e, com o NERSH, foi ampliado para os cinco continentes. 


\section{QUADRO 3 - Eixos temáticos das questões sobre R/E categorizadas a partir dos instrumentos FICA, HOPE e SPIRITual History}

\begin{tabular}{|c|c|}
\hline Área temática & Pergunta \\
\hline \multirow[t]{2}{*}{ Religião organizada } & Você tem alguma afiliação religiosa? \\
\hline & $\begin{array}{l}\text { Você tem alguma crença espiritual além da sua } \\
\text { religião? }\end{array}$ \\
\hline \multirow{2}{*}{$\begin{array}{l}\text { Significado da religiosidade e/ou } \\
\text { espiritualidade para a pessoa }\end{array}$} & O que te dá significado na vida? \\
\hline & $\begin{array}{l}\text { O que a sua espiritualidade / religião significa para } \\
\text { você? }\end{array}$ \\
\hline \multirow[t]{2}{*}{ Coping religioso espiritual } & $\begin{array}{l}\text { Você tem crenças espirituais ou religiosas que te } \\
\text { ajudam a lidar com problemas? }\end{array}$ \\
\hline & $\begin{array}{l}\text { Em que aspectos a religião o ajuda e em quais não o } \\
\text { ajuda muito? }\end{array}$ \\
\hline \multirow[t]{2}{*}{ Espiritualidade e resiliência } & $\begin{array}{l}\text { Quais são as suas fontes de esperança, força, conforto e } \\
\text { paz? }\end{array}$ \\
\hline & O que o sustenta e o faz seguir adiante? \\
\hline \multirow[t]{2}{*}{ Rede de suporte social } & $\begin{array}{l}\text { Comunidades como igrejas, templos, centros, grupos } \\
\text { de apoio são fontes de suporte importante? }\end{array}$ \\
\hline & $\begin{array}{l}\text { Existe algum grupo de pessoas que você "realmente" } \\
\text { ama ou que seja importante para você? }\end{array}$ \\
\hline Práticas e estilo de vida & $\begin{array}{l}\text { Você tem práticas específicas realizadas como parte de } \\
\text { sua vida religiosa ou espiritual (por exemplo, oração, } \\
\text { meditação, serviço)? } \\
\text { Ficar doente afetou sua habilidade de fazer coisas que } \\
\text { o ajudam espiritualmente? }\end{array}$ \\
\hline \multirow{2}{*}{$\begin{array}{l}\text { Relação da religiosidade/ } \\
\text { espiritualidade com o projeto } \\
\text { terapêutico }\end{array}$} & $\begin{array}{l}\text { Você tem alguma crença específica que pode afetar } \\
\text { decisões médicas ou o seu tratamento? }\end{array}$ \\
\hline & $\begin{array}{l}\text { Em suas crenças, há alguma prática ou restrição sobre } \\
\text { seu tratamento médico que eu deveria saber? }\end{array}$ \\
\hline \multirow{2}{*}{$\begin{array}{l}\text { Impacto da religiosidade/ } \\
\text { espiritualidade na relação médico- } \\
\text { paciente }\end{array}$} & $\begin{array}{l}\text { Que conhecimento ou entendimento sobre isso você } \\
\text { acha que fortaleceria nossa relação médico-paciente? }\end{array}$ \\
\hline & $\begin{array}{l}\text { Que aspectos da sua religião / espiritualidade você } \\
\text { gostaria que eu considerasse em seu cuidado? }\end{array}$ \\
\hline Total: & $\begin{array}{l}\text { Perguntas selecionadas FICA: } 5 \\
\text { Perguntas selecionadas HOPE: } 6 \\
\text { Perguntas selecionadas SPIRITual: } 5\end{array}$ \\
\hline
\end{tabular}

III. Espiritualidade e Religiosidade do profissional de saúde: A partir de revisões sistemáticas que avaliam instrumentos de aferição da espiritualidade e religiosidade disponíveis na literatura internacional (Monod et al., 2011) e em língua portuguesa (Lucchetti et al., 2013b), foram escolhidos dois instrumentos: FACIT-SpNI: Functional Assessment of Chronic Illness Therapy - Spiritual Well-Being - Non Illness e DURELP: Índice de religiosidade de Duke). 
A escolha dos instrumentos se deu pelo fato de ambos serem descritos como algumas das ferramentas mais amplamente utilizadas na literatura por ambas as revisões sistemáticas e por sua aplicabilidade, em termos de constituírem instrumentos de breve aplicação. Além disso, o escore DUREL-P já se encontra validado em língua portuguesa. O instrumento FACIT-Sp12 também já foi validado em língua portuguesa, contudo, é aplicado a populações portadoras de agravos crônicos à saúde. A escala utilizada pela presente pesquisa, FACIT-SP Non Illness, aplicada para pessoas saudáveis, é semelhante à FACIT-SP12, porém, ainda não foi validada em português.

A avaliação da auto percepção de religiosidade foi realizada a partir do instrumento Índice de Religiosidade da Universidade Duke (DUREL), também traduzido e validado no Brasil (Lucchetti et al., 2012a). A subescala de religiosidade intrínseca e o escore geral da escala demonstram consistência interna adequada ( $\alpha$ de Cronbach de 0,758 e 0,733, respectivamente), além de validade discriminante moderada (correlação de Spearman variando de 0,36 a 0,46). Para efeitos de análise, a DUREL é composta por cinco itens que avaliam as três dimensões da religiosidade que mais tem se relacionado com desfechos em saúde encontrados na literatura (Moreira-Almeida, 2008), a saber: religiosidade organizacional (aferida pela pergunta relacionada à frequência de ida à igreja, templo ou encontro religioso), religiosidade não organizacional (aferida pela pergunta a respeito da frequência de atividades individuais, como leitura de textos sagrados, orações ou meditação) e religiosidade intrínseca, que é dada pela análise conjunta de três assertivas. As assertivas que compõem o domínio da religiosidade intrínseca questionam sobre o quanto a pessoa sente a presença de Deus (ou do Espírito Santo) em sua vida, o quanto a religiosidade é determinante do modo de viver da pessoa e o quanto a pessoa se esforça para viver sua religião nos diferentes aspectos da sua vida. Ainda segundo Moreira-Almeida et al. (2008), os dois primeiros itens se mostram relacionados a indicadores de saúde física, mental ou suporte social em estudos epidemiológicos americanos. Já os itens relacionados à religiosidade 
intrínseca são itens que se relacionam com suporte social e desfechos em saúde. É importante observar que, na avaliação da DUREL, cada uma dessas três dimensões deve ser analisada separadamente. Seus escores não devem ser somados em um escore total. O domínio da religiosidade intrínseca (três últimas questões) pode ser avaliado de modo agrupado, sendo atribuída pontuação de 1 a 5 para cada uma das assertivas (escore total variando de 3 a 15).

O instrumento de bem-estar espiritual (FACIT-SP-12) foi traduzido e validado no Brasil para pacientes portadores de condições psiquiátricas, encontrando boas propriedades psicométricas, como confiabilidade testereteste $(r=0,99)$, consistência interna ( $\alpha$ de Cronbach=0,92) e validades discriminante e convergente (Lucchetti et al., 2015). Contudo, como a amostra de nossa pesquisa se caracteriza por médicos de família e comunidade em atividade, é esperado que a maior parte da amostra se aproxime da população geral e não sofra de uma doença crônica, como foi o caso da amostra de validação utilizada no Brasil. Desse modo, a escala utilizada em nosso questionário de pesquisa será a FACIT-SP-Non Illness, na qual, das 12 assertivas da FACIT-Sp12, as duas últimas assertivas são modificadas, para se adequarem a uma população geral (portadora ou não de doença crônica). A tradução a ser utilizada na presente pesquisa, será a tradução oficial disponibilizada pela FACIT para o português. A escala FACIT-SP-Non Illness se encontra em validação para português brasileiro, conforme autorização da instituição FACIT (ANEXO 11). O ponto de interesse de nossa pesquisa nessa escala é por ser esse um instrumento que avalia de modo mais amplo a dimensão da espiritualidade da pessoa (para além do âmbito da religiosidade), pois se relaciona com a percepção subjetiva de bem-estar espiritual, independentemente da prática ou não de uma crença ou religião.

Em termos de análise, a escala é composta por 12 assertivas, divididas em três domínios de bem-estar espiritual: significado (considerado o domínio filosófico ou cognitivo da espiritualidade), paz (aspecto emocional ou afetivo da espiritualidade) e fé (dimensão da espiritualidade 
relacionada a crenças). Os participantes foram orientados a indicar o quanto concordavam (de nem um pouco a muitíssimo) com cada uma das assertivas, considerando o período dos últimos sete dias antes da aplicação do questionário. O modelo de análise da escala segue um cálculo para cada um dos domínios, com assertivas que somam e outras que subtraem ao escore. A escala completa, com sua assertivas e modo de cálculo, se encontram disponíveis no ANEXO 7.

\subsection{Apreciacão do questionário por especialistas}

Durante o mês de junho de 2017, o questionário da pesquisa foi submetido para apreciação de quatro especialistas, sendo dois pesquisadores do tema saúde e espiritualidade (Prof. Dr. Giancarlo Lucchetti, da Universidade Federal de Juiz de Fora, e Mary Ruth Gomes Esperandio, da Pontifícia Universidade Católica do Paraná) e dois especialistas na área de metodologia de pesquisa científica (Prof. Dr. José Eluf Neto, do Departamento de Medicina Preventiva da Universidade de São Paulo, e Daiana Bonfim, do Hospital Israelita Albert Einstein).

A versão preliminar do questionário, disponível no ANEXO 5 desta dissertação, foi enviado aos referidos especialistas por meio de documento editável de texto por email, com prazo de resposta em até duas semanas.

Dentre as modificações do questionário inicial destacam-se: 1) Sugestão de mudança da ordem de aplicação dos eixos do questionário, levando o eixo sobre dados demográficos para o final do questionário, de modo a priorizar que as questões mais reflexivas do questionário fossem respondidas no início, evitando o viés de informação devido ao cansaço do respondedor; 2) Padronização do modo de apresentação das respostas às assertivas, adotando-se o padrão de Likert, com respostas por extenso em vez de numerais, para melhor comunicação visual; 3) Revisão da tradução das assertivas sobre perguntas feitas aos profissionais de saúde a seus pacientes (item 3 do eixo I); 4) Acréscimo de questão sobre o conceito de espiritualidade dos respondedores; 5) Supressão da questão sobre conhecimento de instrumentos de abordagem da espiritualidade na prática clínica, uma vez que era questão restrita ao conhecimento da existência dos questionários e pouco agregaria quanto ao conhecimento da prática clínica. Nesse sentido, essa questão foi substituída pela questão sobre o conceito de 
espiritualidade descrito pelos autores desses questionários (sendo o conceito de Maugans et al. 1999 substituído pelo de Koenig et al., 2001); 6) Revisão das estratégias de aplicação do questionário online (proposta de contato direto com programas de residência médica); 7) Revisão dos objetivos geral e específicos da pesquisa, para adequação metodológica.

A versão final do questionário se encontra disponível como ANEXO 8 na presente dissertação.

\subsection{Avaliacão do questionário em projeto piloto}

No mês de agosto de 2017, após aprovação do projeto pelo Comitê de Ética em Pesquisa, foi realizada aplicação do questionário de pesquisa em modelo piloto, em formato online pelo Google Formulários ${ }^{\circledR}$. O questionário foi respondido online por seis residentes de medicina de família e comunidade e realizada apreciação em grupo a fresco (em até 24 horas após a resposta do questionário online).

A apreciação do questionário piloto foi realizada em grupo, sendo que todas as questões foram discutidas quanto à clareza, compreensão e facilidade de preenchimento. Os participantes também foram solicitados a avaliar o questionário de modo global, quanto ao tempo levado para realização, esforço necessário e dificuldades que pudessem limitar o preenchimento completo do questionário.

Dois residentes responderam ao questionário utilizando computadores, três usando aparelhos celulares e uma respondeu utilizando tablet, todos com conexão com a internet. Nenhum dos residentes teve problema para acessar o link para o questionário. O tempo médio dispendido para responder ao questionário completo foi de 14,2 minutos.

Embora dois residentes tenham relatado que o questionário ficou um pouco cansativo, consideramos o tempo para preenchimento adequado. Algumas modificações de apresentação foram realizadas para melhorar a experiência de preenchimento, tais como, apresentação de grupos de questões em modelo de quadro em vez de múltipla escolha, melhora da visualização das escalas de likert, troca da ordem de algumas perguntas e adequação de algumas palavras nos enunciados das questões.

Algumas perguntas modificadas merecem comentários a parte: 
1. As assertivas da questão sobre o conceito de espiritualidade foram reordenadas mediante sorteio, para que não guardassem uma ordem de gradação de um conceito menos amplo para um mais amplo.

2. Além da questão sobre se o médico costuma perguntar sobre espiritualidade, foi acrescentada a questão, também de declaração subjetiva, sobre com que frequência a dimensão é abordada.

3. Na questão sobre fatores que desencorajam o médico a abordar o tema, foi inserida a opção "Não me sinto desencorajado" e um campo em texto livre para outros.

4. A questão que pergunta se o médico se enquadra em uma afiliação religiosa ou sistema de crenças foi, de longe, a que mais despertou a atenção do grupo. Entre os presentes, alguns adotam pontos de vista filosóficos ou práticos de religiões da qual não se declaram adeptos. Foi muito destacada a importância de ser considerado o pluralismo e sincretismo religioso, situação que ocorreu com três dos seis respondedores (um ateu, uma da umbanda e outra que pratica meditação). Embora a amostra seja pequena, 50,0\% dos respondedores apontarem dificuldade em relatar seu real sentimento / postura perante essa questão. Mediante a consulta de referências importantes na literatura, observamos que, no questionário de Curlin et al. (2006) para médicos americanos, se pergunta: "Qual sua afiliação religiosa?" e as possíveis assertivas são: católico, judeu, outra religião (incluindo budista, hindu, mórmon, muçulmano, ortodoxo ou outra), protestante e nenhuma (inclui ateu, agnóstico e nenhum). O questionário NERSH (Hvidt et al., 2017), que analisou médicos de 5 continentes do mundo, também perguntou sobre afiliação religiosa, mas trazendo mais opções: Nenhuma afiliação (incluindo ateu, agnóstico e nenhum), budista, hindu, judeu, mórmon, muçulmano, protestante, católico, cristão ortodoxo, outro cristão, outro ou não respondeu.

Nossa formulação inicial se encontrava do seguinte modo: "Você se enquadra em alguma dessas filiações religiosas ou sistemas de crenças?", sendo dadas as seguintes opções (sendo possível assinalar apenas uma): Católica Apostólica Romana, Evangélica, Espírita, Não tenho religião e não 
acredito em Deus, Não tenho religião mas acredito em Deus, Não me enquadro. Para lidarmos com essa questão, considerando o contexto cultural do nosso país, foram inseridas diversas opções de filiação religiosa, para além das praticadas pelo IBGE; o termo utilizado passou a ser de "matriz religiosa", segundo discussão com uma antropóloga; foi permitido que o participante assinalasse mais de uma opção na questão; e foi acrescentada a opção "Outros" em campo aberto.

A versão final da questão ficou formulada do seguinte modo: "Escolha abaixo uma ou mais afiliação(ões) religiosa(s) ou sistema(s) de crenças no qual(is) você julgue se enquadrar": Católico, Evangélico, Espírita, Outra crença de matriz cristã, Religiões de matriz africana (como umbanda e candomblé), Religiões de matriz budista, Religiões de matriz hindu, Religiões de matriz judaica, Religiões de matriz muçulmana, Acredito em Deus e não tenho religião, Não acredito em Deus e não tenho religião, Não me enquadro em nenhum dos descritos, Outros (campo aberto). Essa nova formulação foi reavaliada pelos especialistas, com aceite de todos.

\subsection{Análise dos resultados obtidos:}

A análise dos resultados foi realizada por meio da descrição da frequência numérica e percentual e medidas de tendência central como média, mediana, desvio padrão e valores máximos e mínimos das variáveis demográficas e relacionas aos vínculos de trabalho e prática clínica, bem como pelos escores das escalas de aferição de religiosidade e bem-estar espiritual do profissional (respectivamente, DUREL e FACIT Non-Illnes). As análises foram realizadas a partir do banco de dados criado a partir do software de acesso livre utilizado (Google Formulários@) e do software Excel@ 2014.

A inserção da abordagem da religiosidade e espiritualidade na prática clínica dos profissionais também foi analisada por meio da declaração de frequência de perguntas que o profissional costuma realizar e barreiras identificadas para a prática da abordagem espiritual. Essas variáveis categóricas, com respostas em escala Likert, foram avaliadas também se utilizando medidas de frequência numérica e percentual analisadas pelo software Excel@ 2014. 


\subsection{Modelo para estudo da R/E do MFC e sua interface com a prática da abordagem da espiritualidade do paciente}

Embora a prioridade do presente estudo não seja a análise associativa, mas sim descritiva, o raciocínio que orientou a presente pesquisa de mestrado foi um modelo explicativo que considerou a identificação de variáveis dependentes e independentes, o desfecho esperado (sucesso) e o raciocínio sobre a determinação biológica e temporal que afetem o desfecho (Victora et al., 1997).

Foram assumidas como variáveis dependentes as relacionadas ao desfecho (sucesso) abordagem clínica da espiritualidade do paciente. A ocorrência de abordagem clínica foi aferida no estudo de modo objetivo como variável categórica binária, sendo distribuída entre sim (respostas sempre ou frequentemente) ou não (às vezes/razoavelmente, pouco, nunca) à pergunta sobre com que frequência o profissional aborda essa temática em sua prática clínica rotineira.

Para composição do modelo explicativo, foram consideradas variáveis independentes, ou seja, que possam estar associadas ao desfecho: religiosidade do profissional (Escores na DUREL), bem-estar espiritual do profissional (FACIT-Sp-Non illness), religião ou crença do profissional, barreiras apontadas pelos profissionais de saúde para a inserção da R/E na prática clínica e tempo de trabalho na APS. Uma variável independente que pode ter ação mais horizontal ao desfecho prática clínica, atuando como variável confundidora, é a utilização frequente ou sempre do método clínico centrado na pessoa nas consultas clínicas. A proposta da modelagem de estudo segue sintetizada na FIGURA 3.

FIGURA 3. Modelo explicativo do presente estudo - 2017 


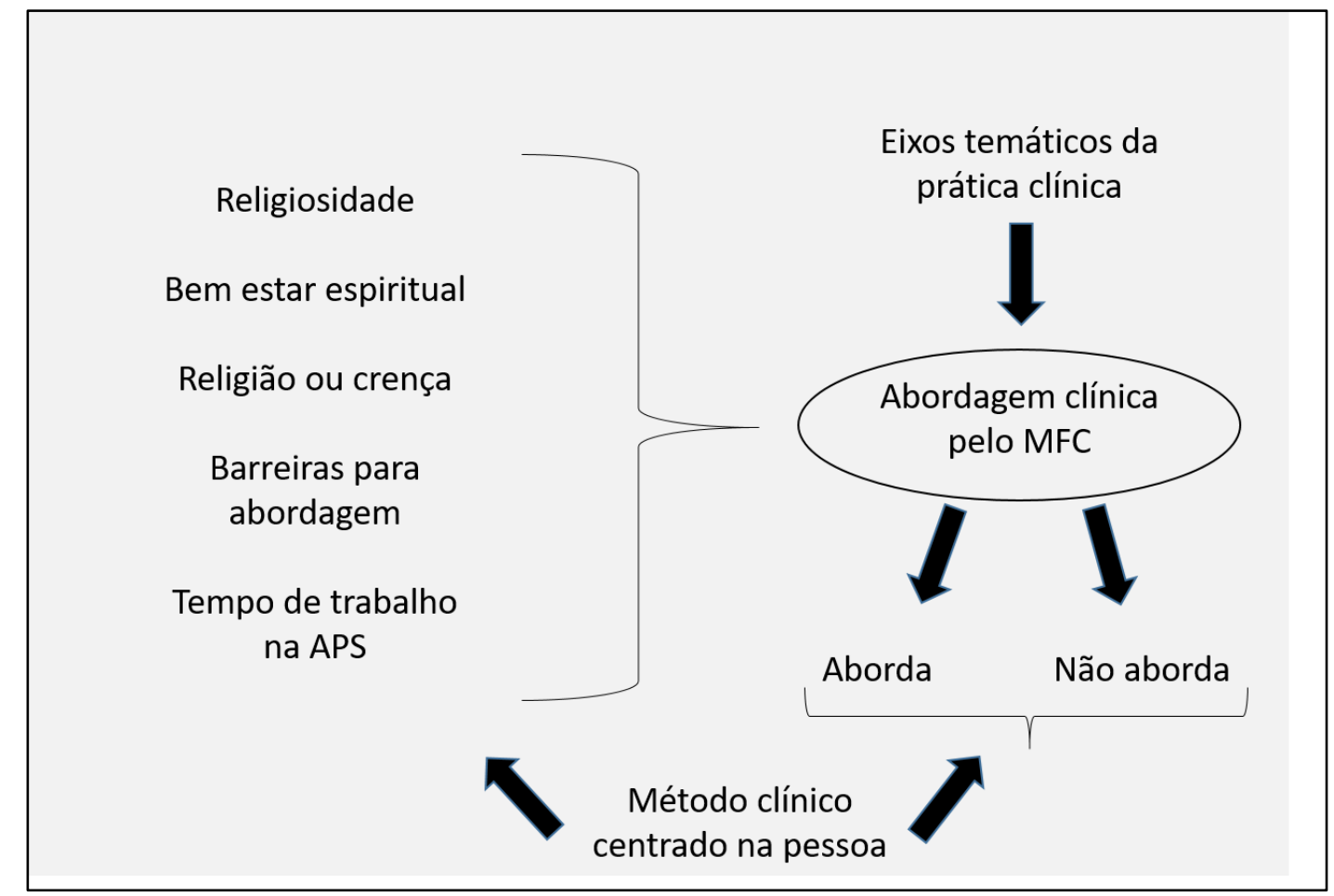

NOTA: À esquerda: grupo de variáveis independentes. À direita: variável dependente (abordagem da E/R). Abaixo: variável com potencial confundidor.

\subsection{ASPECTOS ÉTICOS}

A modalidade de pesquisas transversais com uso de questionários online vem apresentando crescimento e já é estudada dentro de metodologias de pesquisa, inclusive em relação a vieses e aspectos éticos (Gunther et al., 2002). Em relação ao possível viés de seleção, por restringir a pesquisa a pessoas com acesso à internet, julgamos que a população alvo da pesquisa teria acesso a esse meio, uma vez que é a modalidade de cadastro utilizada pela própria SBMFC.

Atendendo à resolução $n^{\circ} 466 / 2012$, o presente projeto foi submetido à avaliação pelo Comitê de Ética em Pesquisa da Faculdade de Medicina da Universidade de São Paulo e aprovado segundo o parecer 2.178.587, conforme ANEXO 9. O Termo de Consentimento Livre e Esclarecido (ANEXO 8) foi enviado precedente o questionário de pesquisa e teve aceite ou negação eletrônica online pelo participante. A concordância com o termo foi disposta como critério obrigatório para seguir respondendo ao questionário da pesquisa. 


\section{RESULTADOS}

\subsection{Processo de coleta de dados}

O questionário foi disparado ao público-alvo por meio de e-mail. A Sociedade Brasileira de Medicina de Família e Comunidade disponibilizou, mediante nosso compromisso de sigilo dos dados, uma lista de 7.995 endereços de e-mail. Essa lista continha contatos de médicos associados (médicos com residência médica em medicina de família e comunidade, residência médica em outras áreas, título de especialista em medicina de família e comunidade e profissionais que atuam na rede de atenção primária à saúde no Brasil, sem titulação ou especialização), residentes, estudantes e outros profissionais de saúde que frequentem os espaços da SBMFC, tais como seu congresso bienal.

Os questionários foram enviados por e-mail a todos os contatos da lista entre os dias 04 e 10 de setembro de 2017. Dos 7.995 e-mails disponibilizados para envio, 954 $(11,9 \%)$ se referiam a endereços inválidos. Na primeira semana de envio, foram obtidas 194 respostas ao questionário. Com a queda na taxa de respostas a partir da segunda semana, foi iniciada uma segunda onda de disparo de questionários. Em 20 de setembro de 2017, enviamos e-mails aos respondedores da pesquisa solicitando que encaminhassem o questionário para outros MFC com quem tivessem contato, especialmente egressos de programas de residência médica. O questionário também foi divulgado na lista de e-mails da SBMFC. Até 30 de setembro já havíamos alcançado 285 respostas.

Como terceira onda de divulgação, a partir de 02 de outubro de 2017, a pesquisa foi divulgada por aplicativo de rede social (Whatsapp@). Os questionários não foram enviados pelo aplicativo. Foi feita apenas uma divulgação da pesquisa e enviado um link do Google Formulários $@$ para que os MFC interessados em responder a pesquisa nos enviassem seus endereços de e-mails. Os contatos foram enviados por meio de grupos relacionados à medicina de família e comunidade e atenção primária à saúde. A pesquisa não foi divulgada em grupos especificamente relacionados à temática da espiritualidade/religiosidade. Nessa etapa, foram obtidos 72 endereços eletrônicos de pessoas que se disponibilizaram a participar e, assim, receberam o questionário para preenchimento online. Até 20 de outubro, alcançamos 419 respostas. Foi então feita 
tentativa de divulgação por outra rede social (Facebook@), por meio de perfil pessoal, sem uso de grupos temáticos. Foram obtidos apenas seis novos endereços de e-mails para contato. Em 30 de outubro, a pesquisa foi divulgada pela página do $14^{\circ}$ Congresso Brasileiro de Medicina de Família e Comunidade, alcançando-se 457 respostas até 06 de novembro de 2017 (término do congresso).

Foi realizada, então, uma segunda onda de envio de questionários a toda a lista de e-mails disponibilizada pela SBMFC, além de contato direto com 205 e-mails institucionais de programas de residência médica do Brasil. Por meio do aplicativo Whatsapp $\bigodot$, foi realizada uma chamada em 10 de novembro, comunicando que o prazo de coleta de dados para pesquisa iria se encerrar em 48 horas. Até 12 de novembro às 23:50 horas, obtivemos 604 respostas totais, sendo 83 enviadas nas últimas 48 horas.

Em nenhuma das etapas da pesquisa foi oferecida qualquer forma de contrapartida pela participação. Os respondedores que desejassem poderiam enviar seus endereços de e-mail para receberem notícias sobre publicações e dados da pesquisa.

\subsection{Seleção da amostra a partir das variáveis de inclusão e exclusão}

Das 604 respostas recebidas, apenas oito pessoas não concordaram com os termos de pesquisa e recusaram sua participação após a leitura do termo de consentimento livre e esclarecido. Desses oito, três pessoas nos enviaram e-mail justificando sua recusa (37,5\% das negativas), sendo apontados os seguintes motivos:

1. "É com prazer que dou minha negativa a mais uma pauta globalista!"

2. "Trata-se de uma pesquisa de mestrado que procura compreender melhor a relação entre a prática clínica da medicina de família e comunidade e a abordagem da dimensão espiritual do paciente. Inclua que permeiam o relacionamento entre enfermeiro e família. Para se instituir a assistência de médico e de enfermagem humanizada".

3. "Não possuo residência em medicina de família e comunidade e, portanto, não me enquadro nos critérios de inclusão da pesquisa".

Dentre os 596 respondedores que aceitaram participar da pesquisa por meio de aceite do TCLE, 49 não enviaram suas respostas a nenhuma das questões do questionário da pesquisa. Pode ter havido falha eletrônica no Google Formulário®, pois a página do TCLE era diferente da página do questionário. A possibilidade de que os 
participantes tenham desistido de responder ao questionário por cansaço, indisponibilidade de tempo ou outros fatores é menos provável, uma vez que não houve envio de nenhum dado para todos os 49 casos em que houve essa ocorrência.

Das 547 respostas completas recebidas, $252(46,1 \%)$ não se enquadravam no critério de inclusão da pesquisa, pois os respondedores não haviam concluído residência médica em medicina de família e comunidade. Obtivemos 108 respostas de pessoas que possuíam título de especialista na área, mas não haviam cursado residência médica e 144 respostas de pessoas que não possuía nenhuma das duas titulações (residência médica ou título de especialista em medicina de família e comunidade). Como o banco de contatos da SBMFC era misto (não incluía apenas pessoas com residência em medicina de família e comunidade), a questão sobre a titulação foi inserida no questionário para poder ser aplicada como critério de exclusão. Após aplicação dos critérios de exclusão, o banco de dados foi checado quanto à duplicidade de respostas, sendo encontradas 11 respostas repetidas por meio do número de registro geral por unidade federativa, utilizado no estudo como identificador. Para todas as respostas duplicadas, foi mantida no presente estudo apenas a última resposta enviada pelo participante.

Desse modo, a amostra estudada pela pesquisa foi de 292 (53,4\% das respostas recebidas), amostra que contém médicos que concluíram residência em medicina de família e comunidade. O processo de seleção das respostas válidas segue na FIGURA 4.

FIGURA 4. Definição do banco de dados com as respostas válidas para os objetivos da pesquisa - 2017

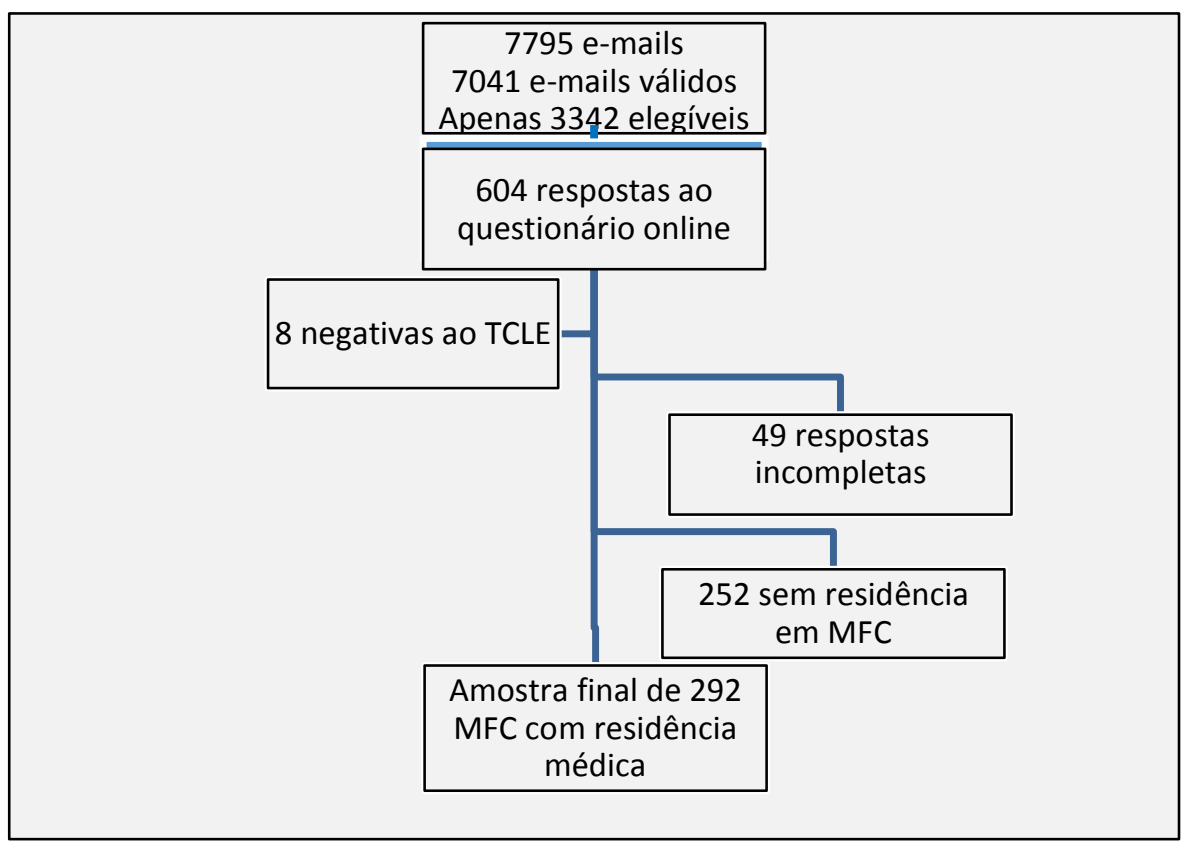




\subsection{Taxa de respostas}

Dentre os 7.041 e-mails válidos disparados com o convite para participação na pesquisa por meio da resposta ao questionário online, a taxa de resposta foi de 8,6\% (604 respostas). Contudo, dentre esses contatos, não era possível prever duplicidades (a mesma pessoa pode ter sido contatada por mais de um endereço de e-mail válido) e o universo de especialistas em medicina de família e comunidade (título ou residência) era desconhecido. Muitas pessoas podem ter deixado de responder por não se enquadrarem no critério de ser especialista na área, uma vez que, considerando os dados da demografia médica (Scheffer et al., 2015) teríamos 4.022 especialistas na área no Brasil. Ou seja, quase metade do total de e-mails contidos no cadastro da SBMFC $(\mathrm{N}=7.995)$ poderia ser de pessoas que não se enquadravam no critério de especialista na área (residência médica ou título).

Posto isso, a partir dos dados da Demografia Médica, seria possível estimar que, considerando o universo total de 4.022 especialistas brasileiros, a taxa de resposta mínima para os 604 questionários respondidos seria de 15,0\%. Contudo, não é possível saber quantos desses especialistas teriam recebido o convite para participação na pesquisa, nem quantos não especialistas estariam incluídos no cadastro dos contatados.

Conforme o item 4.2 do presente trabalho (Universo e Amostra da pesquisa), em pesquisa semelhante, com médicos americanos, Curlin et al. (2006) alcançou taxa de resposta de 63,0\% dentre 2000 médicos selecionados de modo aleatório no cadastro de uma base de dados que incluiria todos os médicos americanos (American Medical Association Physician Masterfile) e contatados por meio de postagem via correios e contato telefônico. Para melhor avaliar a taxa de respostas em função da elegibilidade dos médicos convidados para a pesquisa, o grupo de pesquisadores fez contato por email com 30 dos 809 não respondedores de sua pesquisa e encontrou que 17,0\% dos não respondedores não atendiam ao critério de elegibilidade de sua pesquisa. Com isso, a taxa de resposta foi recalculada conforme as recomendações da American Association for Public Opinion Research, conforme a fórmula:

Taxa $=\mathrm{N}$ respostas $/ \mathrm{N}$ respostas $+(\mathrm{P} \%$ de elegíveis $* \mathrm{~N}$ não respondedores $)$ 
Diante da dificuldade em estimar o número real de convidados para a pesquisa que fossem elegíveis para responder e, portanto, calcular a real taxa de resposta, optamos por utilizar a mesma fórmula de Curlin et al. (2006). Partimos da prerrogativa de que quase 50,0\% dos 7.995 contatos de e-mails não são pertencentes a especialistas em medicina de família e comunidade $(\mathrm{N}=4.022$ ou $50,3 \%$ dos contatos de e-mails teriam residência médica ou título na área).

Assim, nosso cálculo de taxa de resposta estimado seria de:

$$
\text { Taxa de resposta }=604 / 604+(0,5 * 6437)=15,8 \%
$$

Essa estimativa pode ser respaldada por meio de dois cuidados metodológicos tomados em nosso estudo. O primeiro é a observação de que, embora o termo de consentimento livre e esclarecido de nossa pesquisa deixasse claro que a pesquisa se destinava a médicos de família e comunidade com residência médica na área, 252 das respostas foram dadas por pessoas que não se enquadravam nesse critério $(41,7 \%$ dos respondedores). A segunda iniciativa tomada para apurar a real elegibilidade dos contatos da pesquisa foi a de contatar pessoas que não tenham respondido ao questionário, nem com aceite, nem com negativa do TCLE.

Durante a etapa de coleta de dados, recebemos espontaneamente e-mails de pessoas que encaminharam justificativas para a não participação na pesquisa, categorizadas no QUADRO 4.

\section{QUADRO 4 - Justificativas espontâneas de não respondedores da pesquisa}

\begin{tabular}{|l|l|l|}
\hline Categoria de resposta dos contatados & $\mathbf{N}$ & Justificativas enviadas \\
\hline $\begin{array}{l}\text { Não possui residência em medicina de família e } \\
\text { comunidade }\end{array}$ & 4 & $\begin{array}{l}\text { "Trabalho na APS, mas não fiz residência" } \\
\text { "Curso mestrado em saúde da família, mas } \\
\text { não sou MFC" }\end{array}$ \\
\hline $\begin{array}{l}\text { Residência em medicina de família e } \\
\text { comunidade não concluída na ocasião }\end{array}$ & 3 & --- \\
\hline $\begin{array}{l}\text { Não se enquadrava nos critérios da pesquisa } \\
\text { Outros }\end{array}$ & 5 & $\begin{array}{l}\text { "Não pratico MFC" } \\
\text { "Sou pediatra" } \\
\text { "Só dou aulas, não clinico" }\end{array}$ \\
\hline
\end{tabular}


Em maio de 2018, foi realizado contato por e-mail com 30 endereços eletrônicos captados de modo aleatório no banco de contatos da SBMFC, dentre os que não haviam registrado resposta ao questionário da pesquisa. Segundo notificação automática, a mensagem não pôde ser entregue a quatro deles. Apenas um respondeu ao nosso contato, relatando trabalhar na área da atenção primária à saúde, mas não possuir título de especialista nem residência médica. Como o contato foi enviado de modo individual, pessoal e não relacionado à pesquisa em si, interrogamos que a baixa resposta possa estar relacionada ao não recebimento do e-mail e não somente ao interesse pela área temática da pesquisa ou não.

\subsection{Representatividade da amostra obtida}

Como disposto no QUADRO 1, a amostra alvo calculada para a pesquisa seria entre 288 (seguindo a estimativa NERSH) e 290 (cenário mais conservador, mas com ampliação do intervalo de confiança) médicos de família com residência médica na área. Embora tenham sido obtidas 604 respostas, se enquadram no critério de inclusão do presente estudo 292 respondedores que haviam concluído residência médica em medicina de família e comunidade até o momento da resposta ao questionário. Essa foi a amostra adotada para estudo na presente dissertação.

Para análise em cenário mais conservador (quando se espera menor conhecimento sobre a amostra), seriam necessárias 384 respostas. Somando-se os grupos de MFC com residência médica e título de especialista na área $(\mathrm{N}=400)$ o número de respostas se mostra potente para análise estatística em futuros trabalhos.

Para além do poder estatístico do estudo, a obtenção de dados sobre a demografia de médicos de família no Brasil se mostrou um resultado potente do presente estudo, uma vez que não encontramos fontes confiáveis sobre esses dados na literatura.

A população total de médicos de família e comunidade que haviam concluído residência médica até a data de coleta de dados do presente estudo (setembro a novembro de 2017) era desconhecida. Havia sido adotada a população descrita pela Demografia Médica no Brasil, com um universo de $\mathrm{N}=648$ médicos, sendo que a amostra obtida pela pesquisa foi de $\mathrm{N}=292$, o que alcançaria $45,1 \%$ dos médicos de família egressos de residência médica no Brasil. Considerando-se a expectativa a partir 
do banco de dados da SBMFC, que parecia mais próxima da realidade brasileira (cerca de 2000 egressos de residência), a presente pesquisa teria obtido participação de $14,6 \%$ do universo total de médicos elegíveis para a pesquisa no país.

Após o período de coleta de dados e análise da pesquisa, no entanto, em dezembro de 2017, o Sistema de Informação da Comissão Nacional de Residência Médica (SIS-CNRM) publicou dados de ingresso e conclusão dos programas de residência médica em Medicina de Família e Comunidade de 1980 a setembro de 2017. De acordo com esses dados, no Brasil, concluíram residência médica na área um total de 3.342 médicos. Segundo o banco de dados da SBMFC, havia registro de 2.593 médicos que obtiveram título de especialista em medicina de família e comunidade. Desse modo, excluindo-se as duplicidades (médicos com residência médica e título de especialista), temos um total de 5.438 especialistas na área no Brasil.

A partir de banco de dados elaborado pela SBMFC, é possível observar o crescimento da distribuição de vagas nos programas de residência médica na especialidade no FIGURA 5.

FIGURA 5. Distribuição e taxa de ocupação de vagas de residência médica em medicina de família e comunidade no Brasil - SBMFC - 2017

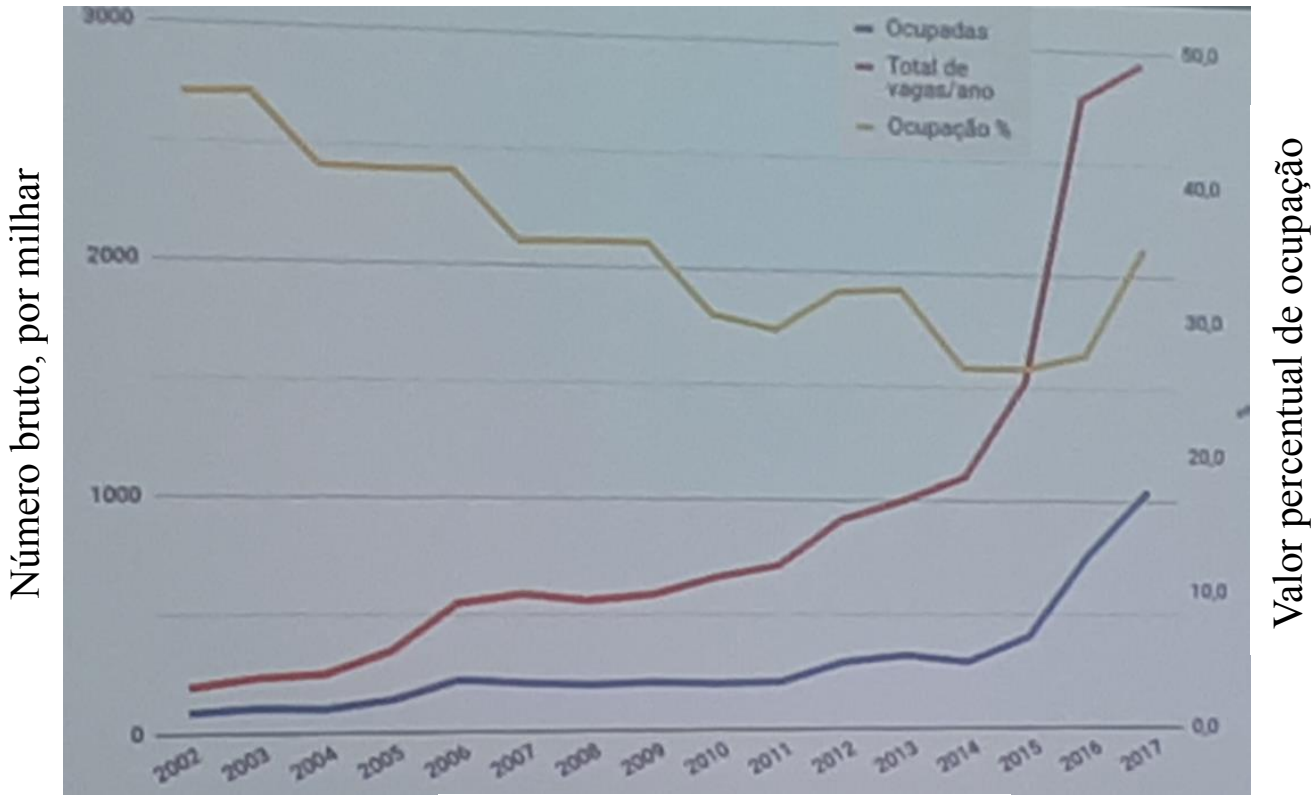

Evolução por tempo em anos

FONTE: Banco de dados da Sociedade Brasileira de Medicina de Família e Comunidade (SBMFC), 2017. LEGENDA: Vide página 58. 
LEGENDA: Linha superior (amarela): Vagas ocupadas

Linha central (vermelha): Total de vagas/ano

Linha inferior (azul): Percentual de ocupação das vagas

Adotando-se o cálculo amostral conservador realizado na etapa de planejamento do presente estudo, o novo cenário não impacta na análise dos dados amostrais obtidos. Embora agora o cenário de formação de MFC no Brasil seja melhor conhecido, para efeitos de análise demográfica dos médicos de família e comunidade brasileiros, fica mantida como referência o Estudo Demografia Médica (Scheffer et al., 2015), pois ainda não há outros dados publicados na área.

De acordo com esse estudo, a população de MFC ( $\mathrm{N}=4022$, dentre egressos de programas de residência médica e titulados pela SBMFC) é caracterizada por idade média de 41,0 anos (com desvio padrão de 8,7 anos para IC de 95,0\%), sendo o tempo médio de graduado em Medicina de 15,7 anos (DP: 8.5 anos, IC 95,0\%). A maioria dessa população é constituída pelo sexo feminino (56,9\%). A distribuição do total percentual de médicos por estado e região pode ser melhor visualizada nas FIGURAS 6 e 7, a seguir.

FIGURA 6. Número de médicos Especialistas em MFC no Brasil, em distribuição percentual por Unidade Federativa - 2015

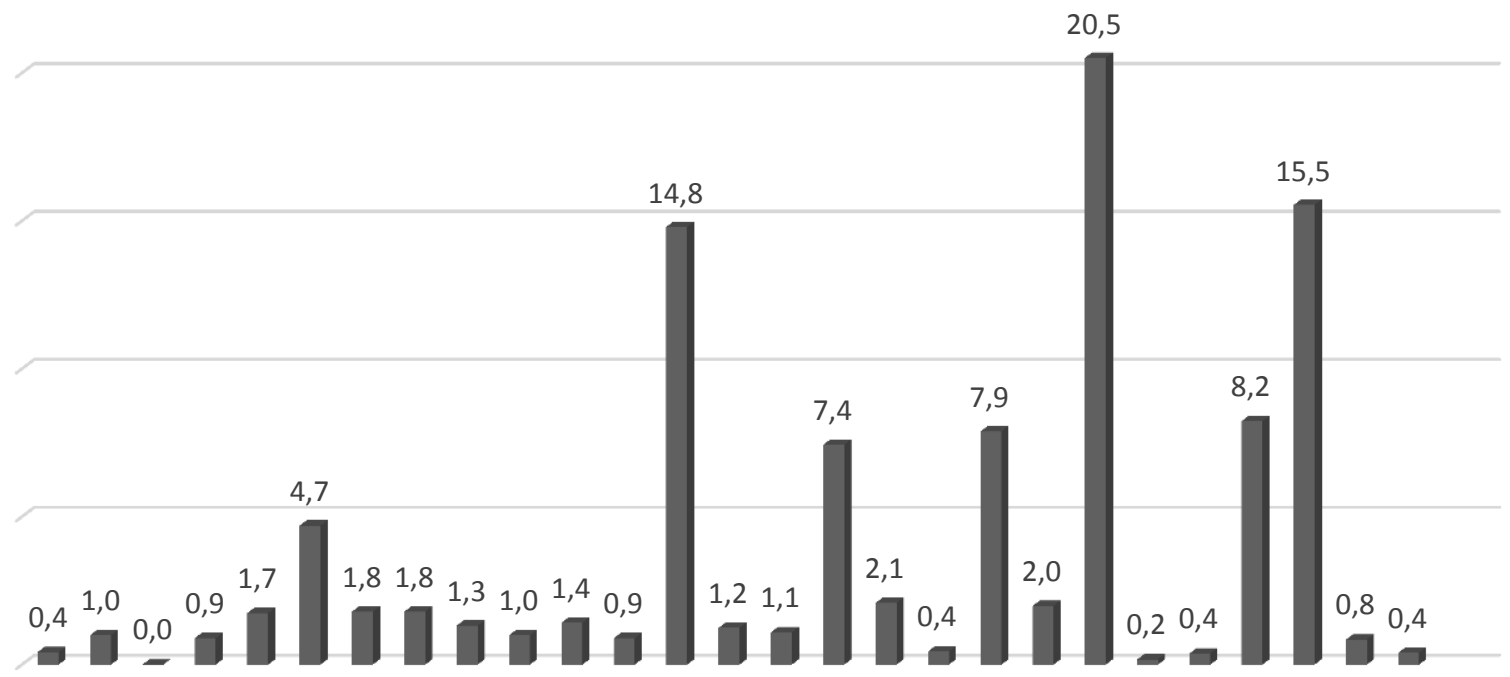

AC AL AP AM BA CE DF ES GO MA MT MS MG PA PB PR PE PI RJ RN RS RO RR SC SP SE TO 
FONTE: Gráfico construído a partir dos dados brutos do número de médicos em cada estado no país disponíveis na Demografia Médica Brasileira (Scheffer, 2015). Valor percentual calculado em função do total de especialistas no país segundo a fonte.

FIGURA 7. Número de médicos Especialistas em MFC no Brasil, em distribuição percentual por Região Geográfica - 2015

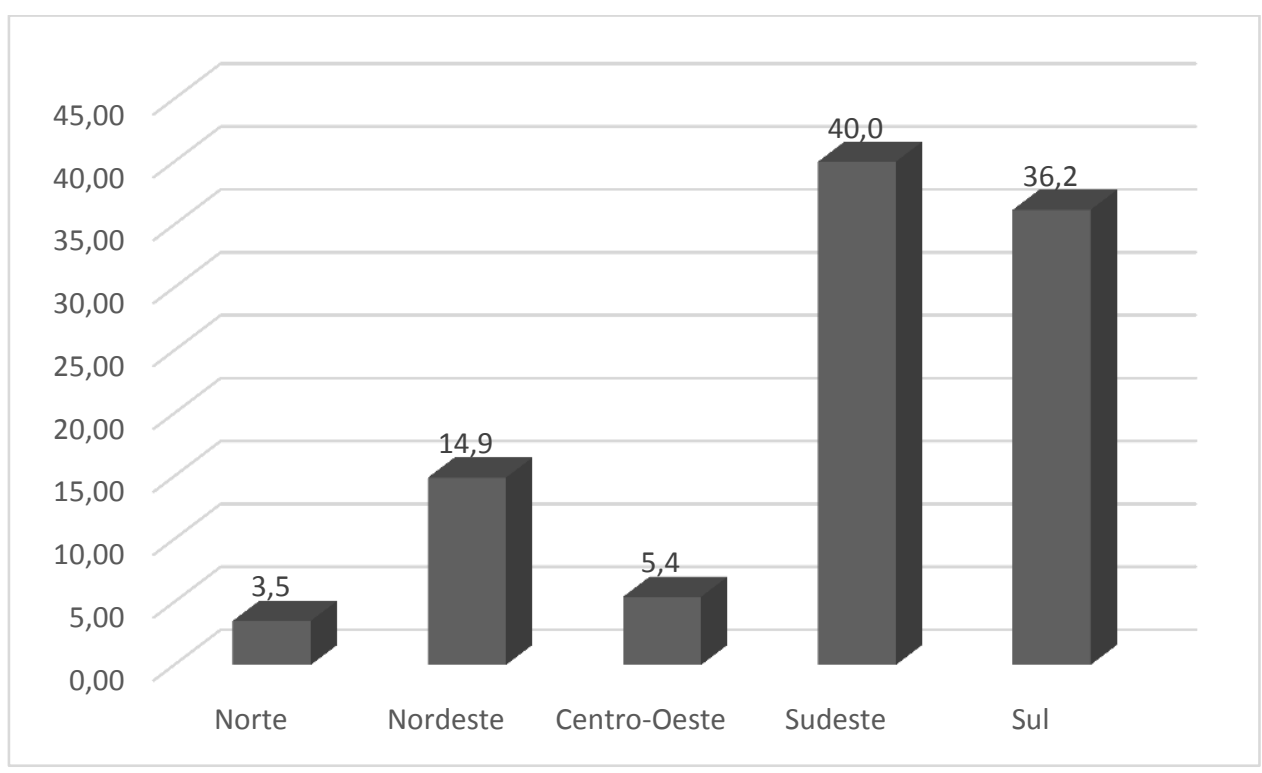

FONTE: Gráfico construído a partir dos dados brutos do número de médicos em cada estado no país disponíveis na Demografia Médica Brasileira (Scheffer, 2015). Valor percentual calculado em função do total de especialistas no país segundo a fonte. 


\subsection{Caracterização demográfica da amostra do estudo}

A distribuição da amostra por frequência numérica, percentual e tendência central dos dados demográficos pode ser visualizada na TABELA 1.

TABELA 1 - Caracterização demográfica da amostra do estudo (N = 292) - 2017

\begin{tabular}{l|r}
\hline Sexo (N / \%) & $102(34,9 \%)$ \\
\hline Masculino & $190(65,1 \%)$ \\
\hline Feminino & 35,8 anos / 34 anos \\
\hline Idade em anos (Média / Mediana) & \\
\hline Distribuição regional (N / \%) & $9(3,1 \%)$ \\
Região Norte & $37(12,7 \%)$ \\
Região Nordeste & $24(8,2 \%)$ \\
Região Centro-Oeste & $144(49,5 \%)$ \\
Região Sudeste & $77(26,5 \%)$ \\
Região Sul & \\
Religião (N / \%) & $63(21,6 \%)$ \\
Católicos & $40(13,7 \%)$ \\
Espíritas & $33(11,3 \%)$ \\
Evangélicos ou Protestantes & $9(3,1 \%)$ \\
Budistas & $9(3,1 \%)$ \\
Matriz africana (Ex: umbanda e candomblé) & $20(6,8 \%)$ \\
Outros & $35(12,0 \%)$ \\
Acredito em Deus e não tenho religião & $20(6,8 \%)$ \\
Não acredito em Deus e não tenho religião & $63(21,6 \%)$ \\
Duas ou mais identificações ou filiações religiosas & \\
& \\
\hline & \\
\hline &
\end{tabular}

A amostra de 292 médicos com residência médica em medicina de família e comunidade concluída na área apresenta 190 pessoas do sexo feminino $(65,1 \%)$ e 102 do sexo masculino (34,9\%). A idade média dos respondedores foi de 35,76 anos, com mediana de 34 anos e desvio padrão de 6,7 anos, sendo a idade máxima de 63 e a 
mínima de 24. Quanto à distribuição entre os sexos, a média de idade entre as mulheres foi de 35,98 anos (DP: 7,04 anos) e em homens foi de 35,33 anos (DP: 6,05).

Quanto à distribuição da amostra em relação à região geográfica, todas as cinco macrorregiões brasileiras foram representadas, conforme a TABELA 1. Em relação à distribuição entre as unidades federativas, três das 27 unidades não tiveram nenhum participante na amostra: Amapá (que não possui especialistas registrados na Demografia Médica), Piauí (18 especialistas registrados) e Roraima (15 especialistas registrados).

Em relação à afiliação religiosa ou sistema de crenças declarado, o participante podia escolher entre nove matrizes religiosas nominalmente enumeradas, além de estarem disponíveis as opções "Acredito em Deus e não tenho religião", "Não acredito em Deus e não tenho religião", "Não me enquadro em nenhum dos descritos" e "Outros", opção que permitia ao participante utilizar a escrita livre, em campo aberto. Era possível assinalar mais de uma assertiva nessa questão.

Dentre os MFC, 229 (78,4\%) julgaram enquadrar-se em ao menos uma filiação religiosa ou sistema de crenças dentre os enumerados ou preenchidos livremente no campo outros. Optaram pela opção “Acredito em Deus e não tenho religião" $53(18,2 \%)$ participantes, embora, dentre esse grupo, 19 (35,9\%) tenham declarado que também possuíam identificação com pelo menos uma religião, embora não se enquadrem por completo na denominação religiosa. Do total de 292 participantes da amostra, $20(6,9 \%)$ MFC declararam não acreditar em Deus e não possuir religião, porém, dentre esse grupo, uma pessoa apontou outro sistema de crença na opção em texto livre ("Crença em seres extra físicos").

Dentre aqueles $229(78,4 \%)$ que declararam se identificar com alguma religião ou crença específicos, 147 (64,2\%) declararam-se pertencentes a um único sistema de crenças ou afiliação religiosa. Um percentual de 21,6\% (63) declara identificação com duas ou mais religiões. Esse percentual sobre para 35,8\% (82) quando se inclui a opção "Acredito em Deus e não tenho religião" como possibilidade de sistema de crenças, Em relação ao grupo que apresenta pluralismo religioso, 58 (25,3\% do total de pessoas com ao menos um sistema de crenças) apontaram identificação com dois sistemas de crenças e 24 (10,5\% do total) assinalaram três ou mais opções de crenças, incluindo a opção “Acredito em Deus e não tenho religião" para ambos os subgrupos. 
A frequência numérica e percentual de filiação religiosa para o grupo que declara identificação com apenas um sistema de crenças pode ser visualizada na TABELA 1. Quando se analisa a filiação religiosa acrescentando-se o grupo dos que declaram identificação com mais de uma matriz religiosa, o chamado pluralismo religioso, a distribuição simples dentre as diferentes religiões passa a ter uma proporção bastante diferente da observada na amostra de declarantes de seguidores de uma única matriz religiosa, conforme pode ser observado na TABELA 2.

TABELA 2 - Caracterização da amostra conforme identificação com um único sistema de crenças, comparada à distribuição considerando-se o pluralismo religioso de médicos de família e comunidade - 2017

\begin{tabular}{|c|c|c|}
\hline Religião declarada & $\begin{array}{c}\text { Uma religião } \\
\qquad(\mathrm{N} / \%)\end{array}$ & $\begin{array}{c}\text { Pluralismo } \\
\text { (N / \%) }\end{array}$ \\
\hline Católicos & $63(21,6)$ & $105(36,0)$ \\
\hline Espíritas & $40(13,7)$ & $89(30,5)$ \\
\hline Evangélicos ou Protestantes & $33(11,3)$ & $38(13,0)$ \\
\hline Budistas & $9(3,1)$ & $29(9,9)$ \\
\hline Matriz africana (Ex: umbanda e candomblé) & $9(3,1)$ & $24(8,2)$ \\
\hline Outros & $20(6,8)$ & $23(7,9)$ \\
\hline Acredito em Deus e não tenho religião & $35(12,0)$ & $53(18,2)$ \\
\hline Não acredito em Deus e não tenho religião & $20(6,8)$ & $20(6,9)$ \\
\hline Duas ou mais identificações ou filiações religiosas* & $63(21,6)$ & $82(35,8)$ \\
\hline
\end{tabular}

*NOTA: No caso de duas ou mais identificações religiosas, o percentual sobre para $35,8 \%$ quando se agrega à religião apontada a possibilidade de assinalar, além da denominação religiosa assinalada, a frase "Acredito em Deus e não tenho religião".

Embora tenha sido pouco prevalente, destacamos que duas pessoas $(0,9 \%)$ da amostra se declararam indígenas. Em um país cuja origem populacional contempla essa etnia, não havíamos incluído essa opção de matriz de crença dentre as denominações religiosas enumeradas no questionário. Transcrevemos aqui a declaração das duas pessoas, pela importância de seu conteúdo cultural e antropológico: "Católica, Espírita, 
Sou indígena e muito das minhas crenças vieram da minha intimidade com a mãe natureza, porém fomos catequizados e hoje vivo os dois mundos. Acredito em um Deus Tupã que interage através da mãe terra, sol, água, a natureza em si" e "Sigo acreditando no Deus Tupã que rege rios terra, floresta e nós".

Outra declaração transcrita na íntegra é a de um participante que discorreu sobre a interação entre sua vivência espiritual e sua prática clínica: "Não sou capaz de afirmar ou negar a existência de Deus. Frequento religiões por interesses filosófico, social, antropológico, etc. Acho que contribui com minha prática médica no sentido de compreender (prender em mim) as pessoas e melhorar o relacionamento médicopaciente e com a sociedade em geral. Também creio que meditação/oração são positivas para a condução da vida". Essa declaração foi escolhida por ter sido a única que abordou a inteiração com a clínica, embora não fosse o direcionamento da questão.

\subsection{Caracterização da amostra conforme atuacão profissional}

O perfil de atuação profissional da amostra, distribuído por frequência numérica e percentual, se encontra disponível na TABELA 3.

TABELA 3. Caracterização da amostra conforme atuação profissional $(\mathbf{N}=292)$ 2017

\begin{tabular}{|l|r|}
\hline Atuação profissional (N / \%) & \\
\hline Assistência & $256(87,7 \%)$ \\
\hline Ensino & $196(67,1 \%)$ \\
\hline Gestão & $46(15,8 \%)$ \\
Outros & $17(5,8 \%)$ \\
\hline Funções em seus vínculos de trabalho (N / \%) \\
\hline Uma função & $91(31,2 \%)$ \\
\hline Duas funções & $172(58,9 \%)$ \\
\hline Três ou mais funções & $29(9,9 \%)$ \\
\hline Carga horária de trabalho semanal (N / \%) & $92(31,5 \%)$ \\
Menos de 40 horas & $123(42,1 \%)$ \\
40 horas & $77(26,4 \%)$ \\
\hline Mais de 40 horas & \\
\hline
\end{tabular}




\section{Percepção sobre preparo para aplicar o MCCP (N / \%)}

Muitíssimo

$48(16,4 \%)$

Muito

$170(58,2 \%)$

Moderadamente

$68(23,3 \%)$

Pouco

$4(1,4 \%)$

Nada

$2(0,7 \%)$

Frequência com que utiliza o MCCP (N / \%)

Sempre

$130(44,5 \%)$

Frequentemente

$123(42,1 \%)$

Razoavelmente

$34(11,6 \%)$

Pouco

$4(1,4 \%)$

Não utilizam

$1(0,3 \%)$

Percepção sobre preparo para abordar R/E (N / \%)

Muitíssimo

$17(5,8 \%)$

Muito

$85(29,1 \%)$

Moderadamente

$147(50,3 \%)$

Pouco

$40(13,7 \%)$

Nada

$3(1,0 \%)$

\section{Frequência com que aborda R/E (N / \%)}

Sempre

Frequentemente

$101(34,6 \%)$

Razoavelmente

$111(38,0 \%)$

Pouco

$61(20,9 \%)$

Não utilizam

Em relação ao número de modalidades de função no trabalho (Assistência, Ensino, Gestão ou Outros), a maioria dos MFC participantes (172 ou 58,9\%) possui dois vínculos funcionais. Dentre as áreas de atuação dos MFC, a maioria (256 ou $87,7 \%$ ) declara realizar assistência clínica no setor público ou privado como ao menos uma de suas atividades trabalhistas e também possuem alguma atividade relacionada ao 
ensino (total de 196 ou 67,1\% da amostra). Quanto à distribuição da carga horária, a maior parte dos MFC declara trabalhar 40 horas semanais (123 ou 42,1\%).

Em relação ao tempo de exercício na área da medicina de família e comunidade, os participantes declaram média de atuação de 7,85 anos (DP: 5,84 anos), com tempo de atuação na área variando de nenhum a 35 anos completos.

Quanto à percepção sobre sua atuação clínica, a maioria dos MFC analisados se consideram muito (170 ou 58,2\%) ou muitíssimo (48 ou 16,4\%) preparados para aplicar o método clínico centrado na pessoa em sua prática. De modo semelhante, quando questionados sobre a frequência com que costumam utilizar o método clínico centrado na pessoa em sua prática médica, a maioria respondeu que costuma utiliza-lo sempre (130 ou 44,5\%) ou frequentemente (123 ou 42,1\%).

Já quando questionados sobre o quanto se consideram preparados para abordar aspectos religiosos e/ou espirituais com seus pacientes, os MFC demonstraram menor segurança. A maioria limítrofe (147 ou 50,3\%) se considerou moderadamente preparado, porém, poucos se consideraram nada ( 3 ou 1,0\%) ou pouco (40 ou 13,7\%) preparados.

Os MFC também foram convidados a responder sobre sua percepção subjetiva em relação à interface entre saúde e espiritualidade. Os resultados estão sumarizados na TABELA 4.

TABELA 4 - Caracterização da amostra conforme percepções sobre a interface entre saúde e espiritualidade $(\mathrm{N}=292)$ - 2017

\begin{tabular}{|c|c|}
\hline 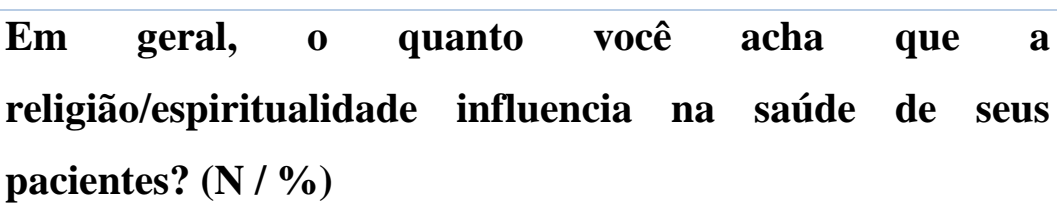 & $72(24,7 \%)$ \\
\hline Extremamente & $186(63,7 \%)$ \\
\hline Muito & $33(11,3 \%)$ \\
\hline Mais ou menos & $1(0,3 \%)$ \\
\hline Pouco & 0 \\
\hline Nenhuma & \\
\hline $\begin{array}{l}\text { A influência da religião/espiritualidade na saúde } \\
\text { geralmente é positiva ou negativa? }(\mathrm{N} / \%)\end{array}$ & \\
\hline
\end{tabular}




\begin{tabular}{|c|c|c|}
\hline Geralmente positiva & & $29(78,4 \%)$ \\
\hline Igualmente positiva e negativa & & $59(20,2 \%)$ \\
\hline Geralmente negativa & & $4(1,4 \%)$ \\
\hline Não tem influência & & 0 \\
\hline O quanto você acha pertinente tal abordagem? (N / \%) & & \\
\hline Muitíssimo & & $85(29,1 \%)$ \\
\hline Muito & & $52(52,0 \%)$ \\
\hline Moderadamente & & $49(16,8 \%)$ \\
\hline Pouco & & $5(1,7 \%)$ \\
\hline Nada & & $1(0,3 \%)$ \\
\hline $\begin{array}{l}\text { Em sua opinião, com com que intensidade a E/R dos } \\
\text { médicos interfere no entendimento do processo saúde- } \\
\text { doença e na relação médico-paciente? }(\mathrm{N} / \%)\end{array}$ & & \\
\hline Enorme intensidade & 32 & $(11,0 \%)$ \\
\hline Grande intensidade & 123 & $(42,1 \%)$ \\
\hline Moderada intensidade & 94 & $(32,2 \%)$ \\
\hline Pequena intensidade & 34 & $(11,6 \%)$ \\
\hline Não interfere & 9 & $(3,1 \%)$ \\
\hline $\begin{array}{l}\text { Quais fatores desencorajam você a discutir religião ou } \\
\text { espiritualidade com seus pacientes? }(\mathrm{N} / \%)\end{array}$ & & \\
\hline Falta de tempo & 156 & $(53,4 \%)$ \\
\hline Falta de treinamento & 116 & $(39,7 \%)$ \\
\hline Falta de conhecimento & 81 & $(27,7 \%)$ \\
\hline Medo de impor sua religião & 81 & $(27,7 \%)$ \\
\hline Medo de ofender o paciente & 69 & $(23,6 \%)$ \\
\hline Desconforto com o tema & 22 & $(7,5 \%)$ \\
\hline Aborda conforme necessidades da pessoa* & 12 & $(4,1 \%)$ \\
\hline Medo de desaprovação dos colegas & 9 & $(3,1 \%)$ \\
\hline Medo de ser julgado por sua crença* & 6 & $(2,0 \%)$ \\
\hline Não relevante para o médico & 4 & $(1,4 \%)$ \\
\hline Não se sentiriam desencorajados & 80 & $(27,4 \%)$ \\
\hline
\end{tabular}


* Categorias agrupadas a partir da opção "Outros”, campo de texto livre no questionário.

Quando questionados sobre o quanto acreditam que o binômio religiosidadeespiritualidade $(\mathrm{R} / \mathrm{E})$ influencia na saúde de seus pacientes, a grande maioria considera que a R/E influencia extremamente (72 ou $24,7 \%$ ) ou muito a saúde (186 ou $63,7 \%$ ). Ninguém considerou que não haveria influência. Quando questionados sobre o perfil da influência exercida pela R/E sobre a saúde, a grande maioria (229 ou 78,4\%) consideraram que a influência, em geral, é positiva.

Ao serem questionados se julgam a abordagem da $\mathrm{R} / \mathrm{E}$ pertinente à prática clínica, a grande maioria considerou a abordagem muito (152 ou 52,1\%) ou muitíssimo (85 ou 29,1\%) pertinente ao seu contexto de trabalho. Apesar da importância atribuída pela maioria dos MFC à abordagem da temática da religiosidade e espiritualidade nas consultas de rotina, a frequência com que declaram realizá-la segue uma proporção menor, sendo que a maioria afirmou abordar a temática de modo razoavelmente frequente (111 ou 38,0\%) ou frequente (101 ou 34,6\%). 20,9\% (61 respondedores) da amostra consideram abordar pouco a temática.

Os MFC foram questionados quanto a possíveis barreiras com que se deparam em seu exercício profissional e que possam limitar a abordagem da temática da $\mathrm{R} / \mathrm{E}$ em sua prática clínica. Cada médico poderia escolher quantas opções julgasse necessárias e também poderia utilizar o campo outros para texto livre. A distribuição percentual das barreiras apontadas pelos 292 médicos de família e comunidade respondedores da pesquisa se encontra sumarizada na TABELA 4.

O grupo de barreiras para a abordagem que mais se destacou foi o que se refere à falta de tempo (156 ou 53,4\%), falta de treinamento (116 ou 39,7\%) e falta de conhecimento (81 ou 27,7\%). A partir da categorização temática dos discursos e análise do conteúdo de texto livre do campo "outros", um novo grupo foi delimitado, relacionado a necessidades de saúde. Esse último grupo somou 12 respondedores $(4,1 \%)$ e foi agregado pelo conteúdo das respostas estarem relacionados à competência clínica centrada na pessoa. Dentro desse campo foram agrupados seis profissionais que referiam abordar a dimensão espiritual conforme a complexidade clínica ou tipo de queixa (por exemplo, saúde mental, abordagem familiar, estratégia de enfrentamento 
negativa ou cuidados paliativos); três profissionais que relatavam abordar a espiritualidade de modo não sistematizado, por exemplo, questionando o paciente sobre questões existenciais, significado ou de sentido da vida; e três que relatavam abordar conforme o entendimento ou aceitação do paciente e sua expectativa em relação às atribuições do médico. Desse modo, agregando esses quatro grupos (tempo, conhecimento, treinamento e necessidades de saúde) como motivações não diretamente relacionadas aos valores pessoais do médico, esse grupo foi enumerado como uma barreira por $65,7 \%$ dos MFC entrevistados.

Embora o subgrupo que relata a importância de observar a necessidade de saúde da pessoa para a decisão sobre a realização da abordagem seja pequeno (12 ou 4,1\% da amostra), essa categoria merece ser mais bem explorada por não ser relatada na literatura em trabalhos prévios (Vermandere e Lepeleire, 2011). Com isso, para contribuir com a compreensão desse campo, apresentamos alguns trechos de discursos dos MFC para ilustrar algumas das percepções desses profissionais sobre a abordagem da E/R do paciente:

1. "Estar atento ao que dá sentido e significado é uma forma de olhar para Espiritualidade do paciente, mesmo que sem esse objetivo específico ou de forma sistematizada. A sistematização da abordagem depende do contexto, e é de fundamental importância nos momentos críticos da vida daqueles que cuidamos".

2. "Não me sinto desencorajado a discutir esse tema. Abordo questões existenciais e de sentido de vida, praticamente sempre. Entendo isso como trabalhar espiritualidade".

3. "Não acredito que seja necessário perguntar tudo em todas as consultas. Reservo essa discussão, por exemplo, para situações em saúde mental”.

O grupo de barreiras que se refere a motivações diretamente relacionadas aos valores pessoais do médico foi citado por $34,4 \%$ dos participantes da pesquisa. Dentre esse grupo, foram enumeradas como barreiras o medo de impor sua religião ao paciente ( 81 ou $27,7 \%$ ), medo de ofender o paciente (69 ou 23,6\%), desconforto com o tema (22 ou 7,5\%), medo de ser desaprovado por colegas médicos (9 ou 3,1\%) e não achar que o tema é relevante para o conhecimento médico ou não faz parte do trabalho deste profissional (4 ou 1,4\%). A esse grupo também foram somados os MFC que, no campo outros, forneceram respostas em texto livre relacionadas ao medo de serem julgados por 
sua crença ou filosofia de vida, como o ateísmo (6 ou 2,1\% do total de MFC). A título de ilustração, transcrevemos um trecho que relaciona a crença do profissional à inserção da temática em sua prática clínica:

1. "Sou atéia e como isso assusta o paciente prefiro não discutir, mas geralmente concordo e respeito seus pontos de vista, apesar de achar que há muita auto sugestão envolvida.

Dentre todos os respondedores, $80(27,4 \%)$ afirmaram não se sentirem desencorajados a abordarem a temática da religiosidade ou espiritualidade em sua prática clínica rotineira. Desses, 51 (63,8\%) não apontaram nenhum fator limitante para a realização dessa abordagem.

A distribuição da amostra por grupos agregados a partir do tipo de barreira assinalada pelos MFC se encontra disponível na TABELA 5. O detalhamento da distribuição de cada categoria de barreira enumerada conforme classificação em grupos segue disponível na FIGURA 8.

TABELA 5 - Distribuição dos fatores listados como barreiras para abordagem da E/R segundo categorial grupal de barreiras - 2017

\begin{tabular}{|l|c|}
\hline Barreiras diretamente dependentes dos valores & 31 \\
pessoais do MFC & $(10,6 \%)$ \\
(Medo de impor pontos de vista religiosos, de ofender o & \\
paciente, de ser julgado por sua crença ou por colegas, & \\
desconforto com o tema ou julgar que ele não é & \\
relevante) & 105 \\
\hline Barreiras dependentes de fatores externos ao & $(36,0 \%)$ \\
profissional & \\
(Falta de tempo, treinamento, conhecimento ou aborda & \\
conforme necessidade da pessoa) & 104 \\
\hline MFC enumera barreiras de ambas as categorias & $(35,6 \%)$ \\
\hline Não se sentem desencorajados & 52 \\
\hline
\end{tabular}


NOTA: Para essa distribuição, foram considerados como "Não se sentem desencorajados" os MFC que assinalaram somente essa opção, sem declarar nenhuma outra barreira.

Figura 8. Distribuição percentual das barreiras para abordagem da E/R, conforme relação com valores pessoais do médico de família e comunidade - 2017

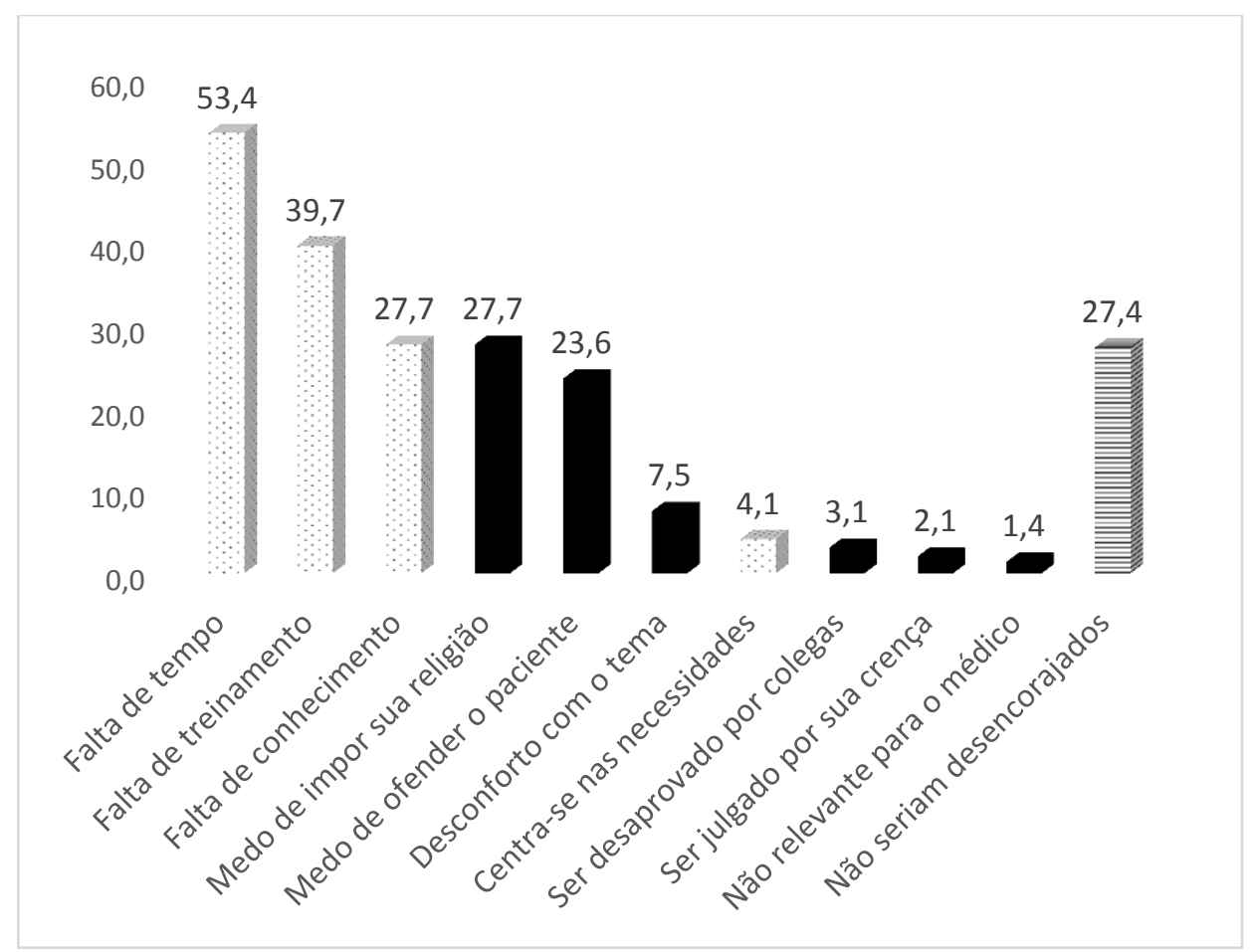

NOTA: O percentual de "Não se sentem desencorajados" da figura 8 é diferente do apresentado na tabela 5 porque o gráfico da figura considera todos os MFC que assinalaram essa assertiva, tendo ou não enumerado outra barreira.

LEGENDA: Barras com preenchimento em pontos correspondem a barreiras dependentes de fatores externos ao profissional. Preenchimento sólido em preto corresponde a barreiras diretamente dependentes dos valores pessoais do MFC. Preenchimento em linhas é relativo aos MFC que enumeraram barreiras de ambas as categorias. 


\subsection{Caracterização da amostra conforme a inserção da abordagem da religiosidade/espiritualidade na prática clínica}

Os MFC também foram questionados quanto ao conceito de espiritualidade que lhes parecia ser o mais próximo da concepção que buscam adotar em sua prática clínica. Para isso, foi avaliada escala de concordância em Likert, variando de "Concordo totalmente" a "Discordo totalmente", para quatro assertivas. Três assertivas apresentavam conceitos de espiritualidade adotados pelos autores dos instrumentos de abordagem da espiritualidade melhor avaliados pela revisão sistemática de Lucchetti et al. (2013a), a saber:

- "Aspecto da humanidade que lida com a maneira como os indivíduos buscam significado, propósito e expressam sua conexão consigo próprios, com os outros, com a natureza e com o sagrado” (Puchalski, 2014a).

- "Busca pessoal para entender questões relacionadas ao fim da vida, seu sentido e as relações com o sagrado ou transcendente. Pode levar ao desenvolvimento de práticas religiosas ou não” (Koenig et al., 2001).

- "Dimensão humana que inclui a busca por significado, propósito e conexão. Pode se dar por meio da religião, da relação com o divino, com a arte, natureza e valores pessoais ou cientificos" (Anandarajah e Hight, 2001).

Como variável de checagem, foi disponibilizada uma quarta assertiva para julgamento, contendo o conceito de religiosidade (e não de espiritualidade) de um dos autores:

- "Espiritualidade" [Religiosidade] "é o quanto um indivíduo acredita, segue e pratica uma religião, seja de modo organizacional (ida a igreja ou templo) ou não (prece, meditação, hinos)" (Koenig et al., 2001).

Em relação ao grau de concordância dos MFC em relação às assertivas, observou-se que a grande maioria concordou total ou parcialmente com a proposta de 
Puchalski (2014a) (281 ou 96,3\%), seguida pelo conceito de Anandarajah e Hight (2001) (257 ou 88,0\%) e o de Koenig et al. (2001) (250 ou 85,6\%). Por outro lado, os participantes se dividiram quanto ao grau em que o conceito de religiosidade pudesse ser expresso como a sua visão da espiritualidade do paciente. Para essa assertiva, a maior parte (143 ou 49,0\%) expressou discordância parcial $(24,3 \%)$ ou completa $(24,7 \%)$; contudo, $123(42,1 \%)$ pessoas expressaram concordância parcial $(28,1 \%)$ ou total $(14,0 \%)$ com essa assertiva. A distribuição completa para cada uma das assertivas pode ser visualizada na TABELA 6 .

TABELA 6 - Grau de concordância com assertivas que expressassem o conceito de espiritualidade adotado na prática do $\mathrm{MFC}(\mathrm{N}=292)-2017$

Puchalski, 2014a (N / \%)

Concordo plenamente

$218(74,7 \%)$

Concordo parcialmente

$63(21,6)$

Nem concordo nem discordo

$4(1,4 \%)$

Discordo parcialmente

$6(2,0 \%)$

Discordo totalmente

$1(0,3 \%)$

Anadarajah, 2001 (N / \%)

Concordo plenamente

$186(63,7 \%)$

Concordo parcialmente

$71(24,3 \%)$

Nem concordo nem discordo

$12(4,1 \%)$

Discordo parcialmente

$17(5,8 \%)$

Discordo totalmente

$6(2,1 \%)$

Koenig, 2001 (N/ \%)

Concordo plenamente

$153(52,4 \%)$

Concordo parcialmente

$97(33,2 \%)$

Nem concordo nem discordo

$14(4,8 \%)$

Discordo parcialmente

$17(5,8 \%)$

Discordo totalmente

$11(3,8 \%)$

Religiosidade, Koenig, 2001 (N / \%)

Concordo plenamente

$41(14,0 \%)$

Concordo parcialmente

$82(28,1 \%)$ 
Nem concordo nem discordo

Discordo parcialmente

$71(24,3 \%)$

Discordo totalmente

$72(24,7 \%)$

A FIGURA 9 permite melhor comparação visual entre os graus de concordância dos MFC em relação aos quatro conceitos de espiritualidade propostos.

FIGURA 9. Grau de concordância dos MFC com o conceito de espiritualidade de diferentes autores $\mathbf{- 2 0 1 7}$

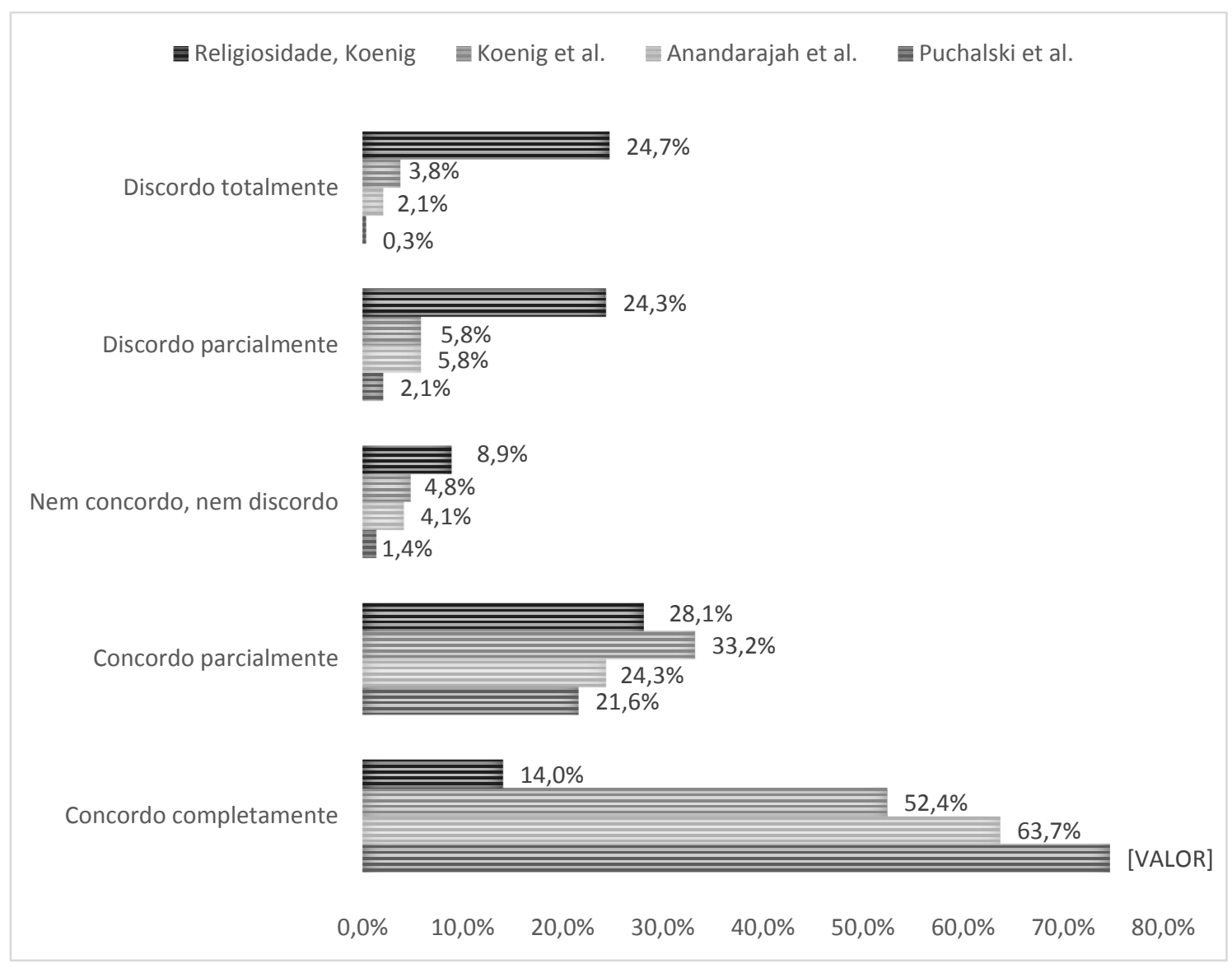

Quanto às formas de abordagem da espiritualidade e religiosidade na prática clínica, os MFC relataram a frequência com que costumavam realizar perguntas do compilado construído a partir das questões dos questionários FICA, HOPE e Spiritual History. Para análise, as questões foram agrupadas por eixos temáticos, conforme disposto na metodologia como QUADRO 2. A distribuição de frequência numérica e 
percentual de respostas dos MFC sobre a frequência de realização de cada pergunta em sua prática clínica pode ser encontrada na TABELA 7.

TABELA 7 - Caracterização da frequência de questões sobre $R / E$ realizados pelos MFC em suas consultas de rotina, por eixos temáticos - 2017

\begin{tabular}{|c|c|c|}
\hline Religião organizada $(\mathrm{N}=292)$ & $\mathbf{N}$ & $(\%)$ \\
\hline Nunca & 73 & 12,5 \\
\hline Raramente & 157 & 26,9 \\
\hline Às vezes & 163 & 27,9 \\
\hline Frequentemente & 150 & 25,7 \\
\hline Sempre & 41 & 7,0 \\
\hline Significado da $R / E$ para a pessoa $(N=292)$ & $\mathbf{N}$ & $(\%)$ \\
\hline Nunca & 72 & 12,3 \\
\hline Raramente & 143 & 24,5 \\
\hline Às vezes & 185 & 31,7 \\
\hline Frequentemente & 144 & 24,7 \\
\hline Sempre & 40 & 6,9 \\
\hline Coping religioso espiritual $(\mathrm{N}=292)$ & $\mathbf{N}$ & $(\%)$ \\
\hline Nunca & 61 & 10,5 \\
\hline Raramente & 134 & 23,0 \\
\hline Às vezes & 185 & 31,7 \\
\hline Frequentemente & 167 & 28,6 \\
\hline Sempre & 37 & 6,3 . \\
\hline Espiritualidade e resiliência $(\mathrm{N}=\mathbf{2 9 2})$ & $\mathbf{N}$ & $(\%)$ \\
\hline Nunca & 52 & 8,9 \\
\hline Raramente & 116 & 19,9 \\
\hline Às vezes & 181 & 31,0 \\
\hline Frequentemente & 187 & 32,0 \\
\hline Sempre & 48 & 8,2 \\
\hline Rede de suporte social $(\mathrm{N}=292)$ & $\mathbf{N}$ & $(\%)$ \\
\hline Nunca & 50 & 8,6 \\
\hline Raramente & 92 & 15,8 \\
\hline
\end{tabular}




\begin{tabular}{|c|c|c|}
\hline Às vezes & 192 & 32,9 \\
\hline Frequentemente & 197 & 33,7 \\
\hline Sempre & 53 & 9,1 \\
\hline Práticas e estilo de vida $(\mathrm{N}=292)$ & $\mathbf{N}$ & $(\%)$ \\
\hline Nunca & 120 & 20,6 \\
\hline Raramente & 188 & 32,2 \\
\hline Às vezes & 140 & 24,0 \\
\hline Frequentemente & 116 & 19,9 \\
\hline Sempre & 20 & 3,4 \\
\hline Relação da $R / E$ com o projeto terapêutico & $\mathbf{N}$ & $(\%)$ \\
\hline$(\mathrm{N}=\mathbf{2 9 2})$ & 166 & 28,4 \\
\hline Nunca & 212 & 36,3 \\
\hline Raramente & 117 & 20,0 \\
\hline Às vezes & 70 & 12,0 \\
\hline Frequentemente & 19 & 3,3 \\
\hline \multicolumn{3}{|l|}{ Sempre } \\
\hline Impacto da $R / E$ na relação médico-paciente & $\mathbf{N}$ & $(\%)$ \\
\hline$(\mathrm{N}=\mathbf{2 9 2})$ & 246 & 42,1 \\
\hline Nunca & 186 & 31,9 \\
\hline Raramente & 94 & 16,1 \\
\hline Às vezes & 46 & 7,9 \\
\hline Frequentemente & 12 & 2,1 \\
\hline Sempre & & \\
\hline
\end{tabular}

NOTA: Como cada MFC poderia optar por duas assertivas para cada eixo temático, os valores brutos e percentuais foram calculados com base no total de 584 respostas.

A distribuição desses dados segue disponível na FIGURA 10, para melhor compreensão visual. 
FIGURA 10. Frequência de perguntas sobre R/E realizadas pelos MFC, conforme eixo temático de abordagem, 2017

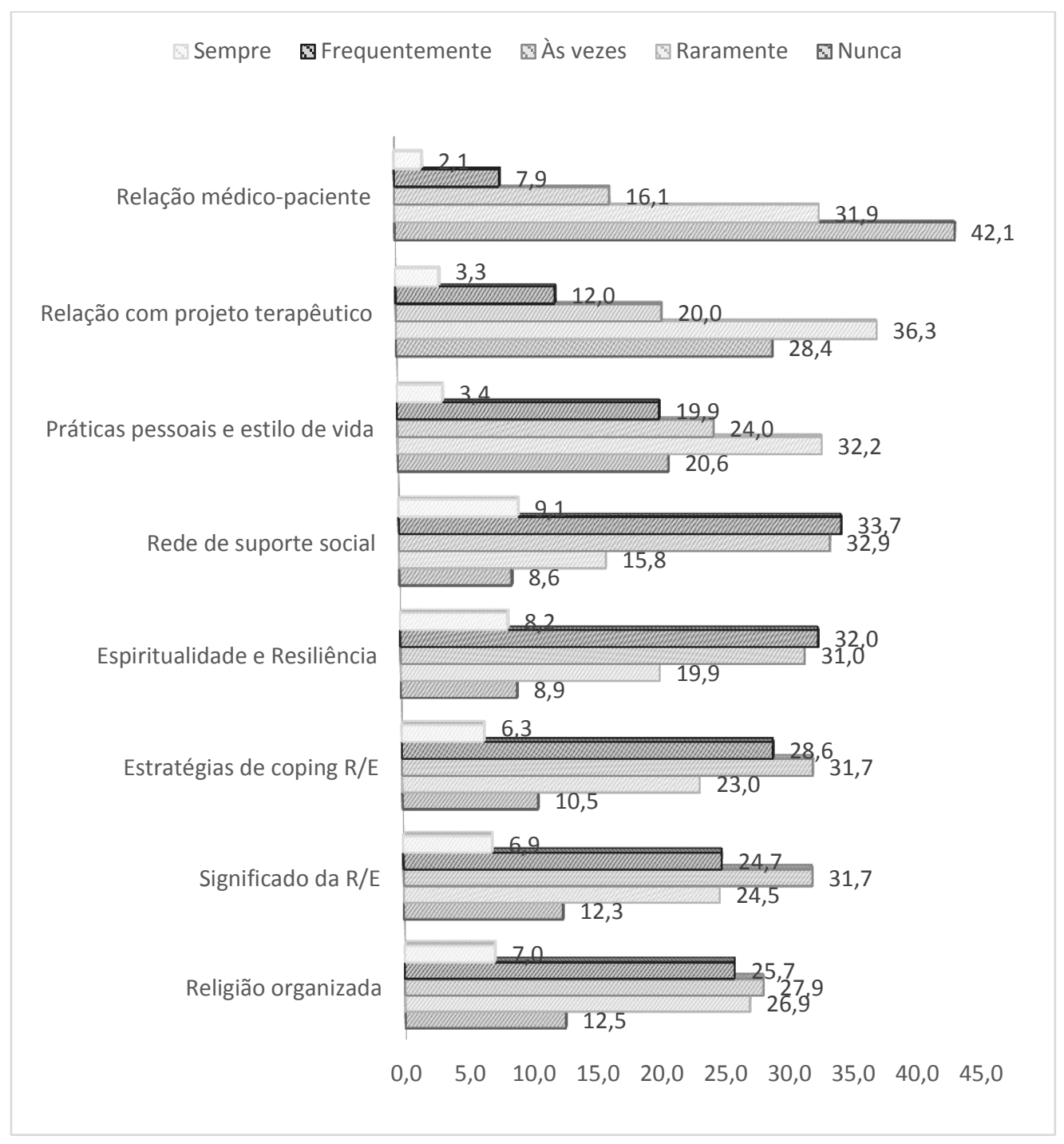

A área temática que os profissionais relataram abordar com maior frequência foi a relacionada à rede de suporte social, a partir da participação em grupos religiosos ou relações afetivas significativas para a pessoa. Essa temática foi apontada como assunto presente sempre ou frequentemente em suas consultas por $42,8 \%$ dos MFC respondedores. O segundo eixo temático discutido mais frequentemente com os pacientes foi relacionado à resiliência, ou seja, à capacidade de a dimensão espiritual atuar como suporte para crescimento pessoal diante das situações de dificuldade, abordado sempre ou frequentemente por $40,2 \%$ dos profissionais. 
Dentre as áreas temáticas enumeradas pela pesquisa, as menos abordadas pelos profissionais foram as que questionavam sobre a relação da dimensão religiosoespiritual com o plano terapêutico e a relação médico-paciente. $\mathrm{O}$ impacto sobre a relação médico-paciente só é abordado de modo frequente ou sempre por 9,9\% dos profissionais, sendo que a grande maioria $(74,0 \%)$ declara abordar essa relação raramente ou nunca. Os MFC declaram discutir sobre o impacto da temática no plano terapêutico frequentemente ou sempre por apenas $15,2 \%$ dos profissionais, enquanto $65,2 \%$ referem fazer perguntas relacionadas a esse quesito raramente ou nunca.

\subsection{Caracterização da amostra conforme a religiosidade e}

\section{espiritualidade do profissional}

Quando questionados sobre com que intensidade acreditam que sua religiosidade ou espiritualidade poderia interferir no entendimento do processo saúde-doença e na relação médico-paciente, a percepção subjetiva dos médicos de família e comunidade demonstra que a grande maioria $(217$ ou $74,3 \%)$ acredita haver um grau de interferência grande (123 MFC ou 42,1\%) ou moderado (94 ou 32,2\%). Apenas $9(3,1 \%)$ dos MFC acreditam que não haveria nenhum grau de interferência de sua dimensão R/E sobre sua prática clínica. Os dois extremos dos graus de interferência também foram menos referidos pelos médicos, sendo que 32 ou 11,0\% acreditam que a interferência seria enorme e 34 ou $11,6 \%$ acreditam que seria pequena.

De modo objetivo, a religiosidade e espiritualidade (avaliada por meio de escore de bem-estar espiritual) dos MFC foram respectivamente avaliadas por meio das escalas Duke Religion Index (DUREL) e Functional Assessment of Chronic Illness Therapy Spiritual Well-Being, na versão modificada para "non-illness" (FACIT-SP - Non Illness), conforme descrito na metodologia.

A distribuição geral das respostas dos médicos de família e comunidade $(\mathrm{N})$, seu percentual e medidas de centralização (média e desvio padrão) para a DUREL podem ser visualizados na TABELA 8, conforme distribuição quanto à religiosidade organizacional (RO), avaliada a partir da frequência de ida à igreja, culto ou grupo religioso; religiosidade extrínseca não organizacional (RNO), caracterizada palas práticas, como orações, preces, meditação ou leitura da bíblia ou texto sagrado; e à 
religiosidade intrínseca (RI), escore calculado a partir da soma do grau de concordância com três assertivas dessa categoria.

Os MFC apresentam pouca frequentação a instituições religiosas (religiosidade organizacional), sendo que $49,3 \%$ deles raramente ou nunca as frequentam. Por outro lado, apresentam forte prática de religiosidade não organizacional, sendo que 39,7\% declaram práticas como preces, rezas, meditações, leitura da bíblia ou textos religiosos no mínimo diárias e $25,7 \%$, no mínimo semanais. O escore de religiosidade intrínseca médio, calculado a partir da DUREL-P, para a amostra foi de 10,62 (+/-3,74).

TABELA 8 - Escores obtidos na DUREL, por domínio avaliado ( $\mathrm{N}=292)$ - 2017

\begin{tabular}{|c|c|c|c|c|c|}
\hline $\begin{array}{l}\text { Dimensão da } \\
\text { DUREL }\end{array}$ & Assertivas possíveis & $\mathbf{N}$ & $(\%)$ & Média & DP \\
\hline $\begin{array}{l}\text { RO) } \\
\text { Frequência de } \\
\text { visita a igreja, } \\
\text { grupo } \quad \text { ou } \\
\text { templo religioso }\end{array}$ & $\begin{array}{l}\text { Algumas vezes por ano } \\
\text { Duas a três vezes por mês } \\
\text { Mais do que uma vez por } \\
\text { semana } \\
\text { Nunca } \\
\text { Uma vez por ano ou menos } \\
\text { Uma vez por semana }\end{array}$ & $\begin{array}{l}98 \\
24 \\
28 \\
46 \\
50 \\
46\end{array}$ & $\begin{array}{r}33,56 \% \\
8,22 \% \\
9,59 \% \\
15,75 \% \\
17,12 \% \\
15,75 \%\end{array}$ & 3,2 & 1,5 \\
\hline $\begin{array}{l}\text { (RNO) } \\
\text { Frequência de } \\
\text { práticas } \\
\text { individuais } \\
\text { (preces, } \\
\text { meditações, } \\
\text { leituras, etc) }\end{array}$ & $\begin{array}{l}\text { Diariamente } \\
\text { Duas ou mais vezes por semana } \\
\text { Mais do que uma vez ao dia } \\
\text { Poucas vezes por mês } \\
\text { Raramente ou nunca } \\
\text { Uma vez por semana }\end{array}$ & $\begin{array}{l}89 \\
58 \\
27 \\
43 \\
58 \\
17\end{array}$ & $\begin{array}{l}30,48 \% \\
19,86 \% \\
9,25 \% \\
14,73 \% \\
19,86 \% \\
5,82 \%\end{array}$ & 3,4 & 1,7 \\
\hline $\begin{array}{l}\text { (RI 1) O quanto } \\
\text { acredita sentir a } \\
\text { presença de } \\
\begin{array}{l}\text { Deus em sua } \\
\text { vida }\end{array}\end{array}$ & $\begin{array}{l}\text { Em geral é verdade } \\
\text { Em geral não é verdade } \\
\text { Não é verdade } \\
\text { Não estou certo } \\
\text { Totalmente verdade para mim }\end{array}$ & $\begin{array}{r}72 \\
17 \\
29 \\
26 \\
148\end{array}$ & $\begin{array}{r}24,66 \% \\
5,82 \% \\
9,93 \% \\
8,90 \% \\
50,68 \%\end{array}$ & 4,0 & 1,3 \\
\hline
\end{tabular}




\begin{tabular}{|c|c|c|c|c|c|}
\hline (RI 2) O quanto & Em geral é verdade & 104 & $35,62 \%$ & \multirow{5}{*}{3,5} & \multirow{5}{*}{1,4} \\
\hline crenças & Em geral não é verdade & 34 & $11,64 \%$ & & \\
\hline religiosas estão & Não é verdade & 44 & $15,07 \%$ & & \\
\hline por trás da & Não estou certo & 32 & $10,96 \%$ & & \\
\hline $\begin{array}{l}\text { maneira de } \\
\text { viver }\end{array}$ & Totalmente verdade para mim & 78 & $26,71 \%$ & & \\
\hline \multirow{5}{*}{$\begin{array}{l}\text { (RI 3) O quanto } \\
\text { se esforça para } \\
\text { viver a religião } \\
\text { em todos os } \\
\text { aspectos da vida }\end{array}$} & Em geral é verdade & 94 & $32,19 \%$ & \multirow{5}{*}{3,2} & \multirow{5}{*}{1,4} \\
\hline & Em geral não é verdade & 33 & $11,30 \%$ & & \\
\hline & Não é verdade & 62 & $21,23 \%$ & & \\
\hline & Não estou certo & 50 & $17,12 \%$ & & \\
\hline & Totalmente verdade para mim & 53 & $18,15 \%$ & & \\
\hline \multicolumn{6}{|l|}{ RI Total } \\
\hline (3 a 15) & & & & 10,6 & 3,7 \\
\hline
\end{tabular}

Quanto à avaliação do bem-estar espiritual dos médicos de família e comunidade foi utilizada a escala a FACIT-Sp-Non illness. Os escores médios obtidos pelos participantes, bem como o desvio padrão, se encontram disponíveis na TABELA 9, também divididos conforme as dimensões de significado, paz, fé e escore total da escala.

TABELA 9 - Escores obtidos na FACIT-Sp-NI, por domínio (N=292) - 2017

\begin{tabular}{|l|r|r|r|r|r|}
\hline $\begin{array}{l}\text { Domínio da FACIT } \\
\text { Non Illness }\end{array}$ & $\begin{array}{c}\text { Escore } \\
\text { Máximo }\end{array}$ & $\begin{array}{c}\text { Escore } \\
\text { Mínimo }\end{array}$ & \multicolumn{1}{c|}{$\begin{array}{c}\text { Escore } \\
\text { Médio }\end{array}$} & Mediana & \multicolumn{1}{c|}{$\begin{array}{l}\text { Desvio } \\
\text { Padrão }\end{array}$} \\
\hline $\begin{array}{l}\text { Significado } \\
(\mathbf{0} \text { a 16) }\end{array}$ & 16 & 5 & 13,9 & 15 & $+/-2,3$ \\
\hline $\begin{array}{l}\text { Paz } \\
(\mathbf{0} \text { a 16) }\end{array}$ & 16 & 0 & 11,0 & 11 & $+/-3,1$ \\
\hline $\begin{array}{l}\text { Fé } \\
(\mathbf{0} \text { a 16) }\end{array}$ & 16 & 0 & 10,8 & 12 & $+/-4,4$ \\
\hline $\begin{array}{l}\text { Total FACIT } \\
(\mathbf{0} \text { a 48) }\end{array}$ & 48 & 18 & 35,7 & 36 & $+/-6,5$ \\
\hline
\end{tabular}




\section{DISCUSSÃo}

\section{$\underline{6.1 \text { Síntese }}$}

A presente dissertação de mestrado se propôs a descrever aspectos da dimensão espiritual e religiosa de médicos de família e comunidade brasileiros, com residência médica na área, bem como conhecer aspectos sobre a inserção do tema da espiritualidade na prática clínica rotineira desse grupo de profissionais, dado que várias pesquisas na área vem demonstrando o impacto dos valores pessoais, incluindo aspectos religioso-espirituais dos médicos em suas decisões clínicas (Curlin et al., 2006; Curlin et al., 2007a; Hvidt et al., 2017).

O inquérito transversal online obteve taxa de resposta de $15,8 \%$ e a amostra da pesquisa foi composta em sua maioria por sexo feminino $(65,1 \%)$, com idade média de 35,8 anos e média de tempo de trabalho na área de 7,9 anos. As principais modalidades de atuação profissional foram assistência clínica $(87,7 \%)$ e atuação no ensino $(67,1 \%)$. Em relação à religião, 78,4\% declaram identificação com pelo menos uma matriz religiosa. As religiões com maior identificação foram catolicismo (21,6\%), espiritismo $(13,7 \%)$ e evangélicos ou protestantes $(11,3 \%)$, destacando-se que grande parte da amostra $(35,8 \%)$ declarava se identificar com mais de uma matriz religiosa ou sistema de crenças. Os MFC apresentam baixa religiosidade organizacional (49,3\% raramente ou nunca frequentam instituições), porém, forte prática de religiosidade não organizacional, sendo que 39,7\% declaram práticas no mínimo diárias e 25,7\%, no mínimo semanais. O escore de religiosidade intrínseca médio para a amostra foi de 10,6 (padrão: 3 a 15). Já quanto ao bem-estar espiritual, a amostra apresenta média de 35,7 (padrão: 0 a 48).

No âmbito da aplicação clínica, houve tendência de maior concordância com um conceito de espiritualidade de amplitude moderada, modelado por Puchalski (2014a). O grau de concordância com os conceitos apresentados aponta no sentido de que os médicos diferenciam os conceitos de espiritualidade do de religiosidade para a aplicação na prática clínica.

Em relação à inserção da $\mathrm{E} / \mathrm{R}$ na prática clínica, embora a grande maioria acredite que a $\mathrm{E} / \mathrm{R}$ influencia muito ou extremamente a saúde das pessoas $(88,4 \%)$ e que essa abordagem é pertinente à prática clínica do $\operatorname{MFC}(81,16 \%)$, apenas 35,0\% da 
amostra se sentia preparada para abordar o tema em consultas e a maioria o faz com frequência moderada $(50,3 \%)$ em sua rotina. A principal barreira que dificultaria a inserção da temática da $\mathrm{E} / \mathrm{R}$ na prática rotineira dos MFC seria a falta de tempo, citada por $53,4 \%$ dos profissionais. Também se destacaram fatores relacionados a treinamento $(39,7 \%)$, conhecimento $(27,7 \%)$ e valores pessoais dos profissionais, tais como o medo de impor sua religião $(27,7 \%)$ e o medo de ofender o paciente $(23,6 \%)$. As áreas mais frequentemente discutidas pelos MFC com os pacientes tratam da rede de suporte social (tema abordado sempre ou frequentemente por 42,8\% dos médicos) e resiliência $(40,2 \%)$. Os temas menos discutidos seriam a relação médico-paciente $(74,0 \%$ referem realizar essa abordagem raramente ou nunca) e as implicações para o plano terapêutico $(64,7 \%)$.

\section{$\underline{6.2 \text { Interpretação e implicações dos resultados }}$}

\subsubsection{Dados demográficos: Quem somos nós e os “outros”?}

Em média, os MFC participantes do estudo são mais jovens quando comparados à média de idade nacional dos especialistas na área (35,8 vs 41,0 anos completos), sendo que a amostra também demonstra ter menos tempo de exercício na área de medicina e família e comunidade quando comparada ao tempo de graduação da média de especialistas nacionais. A média de tempo de trabalho como MFC é de 7,9 anos (DP: 5,8 anos, IC95\%), enquanto o tempo médio de graduado em Medicina dentre os especialistas descritos pela Demografia Médica é de 15,7 anos (DP: 8.5 anos, IC 95\%). Essa diferença pode se dever ao fato de a amostra de Scheffer et al. (2015) ser composta, em sua maior parte, por especialistas em Medicina de Família e Comunidade titulados, mas que não cursaram residência médica (3344 versus 648 médicos), enquanto a amostra do presente estudo foi analisada exclusivamente com MFC que já tivessem concluído residência na área, populações que podem ter perfis diferentes. Outra possibilidade é que os MFC cursem residência médica depois de alguns anos de graduados em Medicina.

Os resultados amostrais também apontam a tendência de feminização da especialidade, embora a proporção de sexo feminino na amostra seja significativamente superior à proporção esperada em cenário nacional. Essa diferença pode indicar maior 
sensibilização das mulheres a responderem questões sobre a temática da espiritualidade e religiosidade. Comparando com o estudo de Koenig et al. (2005) com médicos norteamericanos, observamos que o sexo feminino apresenta maior tendência a realizar perguntas sobre E/R em sua prática clínica $(35+/-5$ vs $31+/-4, p=0,007)$. Contudo, dentre a proporção de respostas em pesquisas com médicos sobre E/R, nem sempre a feminização se faz presente. Por exemplo, embora a amostra NERSH (Hvidt et al., 2017) apresente 56,8\% de sexo feminino e a de Koenig et al. (2005), 57,0\%, a amostra de Curlin et al. (2006), com médicos americanos, apresentou apenas 26,0\% de mulheres.

Outra característica da amostra que merece destaque são as modalidades de atuação profissional. Embora a maior parte dos MFC se declare atuante na assistência clínica direta $(87,7 \%)$, a maioria também refere ter alguma atuação na área do ensino $(67,1 \%)$. Essa atuação se dá nas modalidades de docência universitária e preceptoria em campos de prática com estudantes e médicos residentes. A característica do forte envolvimento de médicos de família e comunidade já é esperada frente às diretrizes curriculares nacionais (Brasil, 2014) e às competências esperadas dos egressos de residência médica na área (SBMFC, 2015), contudo, essa característica amostral deve ser destacada, uma vez que a opinião e prática referida pelos MFC tem impacto direto na formação médica sobre a temática $\mathrm{E} / \mathrm{R}$ no Brasil. Médicos que trabalham com ensino também podem ter tido maior tendência a responder a pesquisa.

Em relação à distribuição por região geográfica, comparada à Demografia Médica Nacional (Scheffer et al., 2015), a amostra da pesquisa alcançou representatividade regional, conforme pode ser visualizado no FIGURA 11. Embora esse aspecto não seja analisado no presente estudo, as diferenças culturais regionais podem interferir com o perfil da abordagem da $\mathrm{E} / \mathrm{R}$ do paciente na prática médica, conforme já é possível verificar pela diferença entre profissionais estudados em diferentes países (Lucchetti et al., 2016; Hvidt et al., 2017). 


\section{FIGURA 11. Distribuição percentual da amostra por região geográfica, comparada à Demografia Médica Brasileira para MFC}

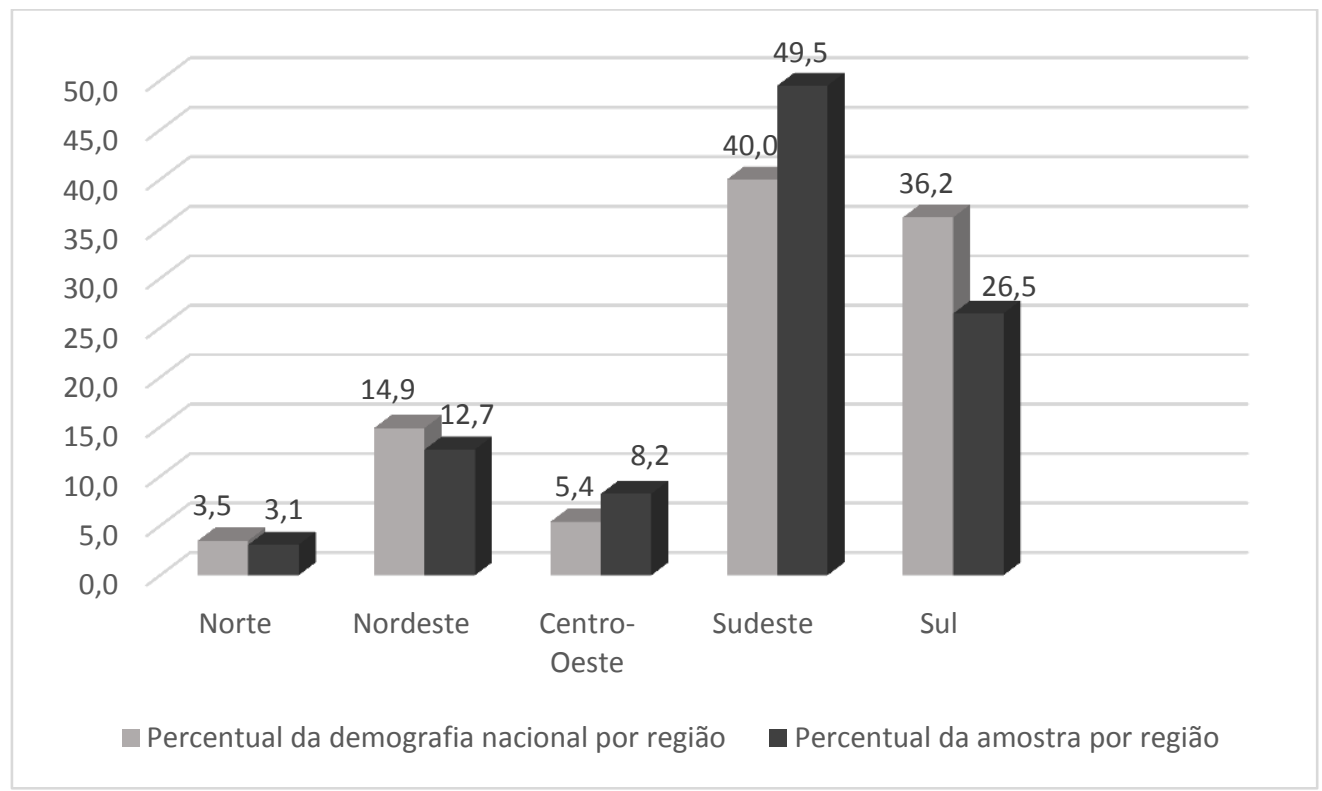

FONTE: Gráfico construído a partir dos dados brutos do número de médicos em cada estado no país disponíveis na Demografia Médica Brasileira (Scheffer, 2015). Valor percentual calculado em função do total de especialistas no país segundo a fonte.

Outro aspecto essencial de ser destacado do ponto de vista sócio-cultural é a diferença da amostra de MFC, quando comparada à população brasileira em geral, em relação à filiação religiosa. De acordo com o último Censo Demográfico (IBGE, 2010), 92,6\% da população brasileira declara professar uma religião, fato declarado por apenas 78,4\% dos respondedores da pesquisa. Embora distante da realidade brasileira, essa proporção se aproxima de uma amostra de MFC canadenses, na qual $81.8 \%$ dos participantes declaravam ser adeptos de crenças espirituais ou religiosas (Lee-Poy et al., 2016) e está baixo do achado dos EUA (Curlin et al., 2006), no qual 89\% dos médicos declaravam alguma filiação religiosa.

Além da menor religiosidade, o perfil de crença dos médicos brasileiros se diferenciou da população geral nacional (IBGE, 2010). Na amostra estudada, para os que declararam apenas uma filiação religiosa, a distribuição de crenças religiosas foi bastante diferente da amostra nacional: a proporção de católicos foi bem mais baixa (21,6\% vs $64,6 \%$ ), enquanto a de espíritas $(13,7 \%$ vs $2,0 \%)$ superou bastante. A proporção de católicos na amostra, embora ainda baixa, aumenta quando se considera o 
pluralismo religioso (21,6 vs 36,0\%). Outro aspecto interessante foi o destaque para religiões com pouco contingente no cenário nacional, como as de matriz africana $(3,1 \%$ vs $0,3 \%$ ) e budista ( $3,1 \%$ vs sem representatividade pelo IBGE). O percentual dos que não possuem religião também foi bastante superior ao da população geral brasileira $(7,8$ vs $18,8 \%$ ). Por outro lado, a distribuição de filiação religiosa se aproximou bastante do estudo realizado com 484 psiquiatras brasileiros por Menegatti-Chequini et al. (2016), que encontrou $31,2 \%$ católicos, 18,0\% espíritas, 7,4\% evangélicos, 10,8\% de outras religiões e $32,6 \%$ de outras religiões. A pesquisa, no entanto, trabalho com essas cinco assertivas de modo fechado, não havendo detalhamento de que religiões estariam incluídas no campo "outras religiões".

As diferenças em relação à filiação religiosa entre população geral e MFC, também refletida na amostra de psiquiatras de Menegatti-Chequini et al. (2016) encontram eco em questões socioeconômicas já conhecidas no país. Segundo o IBGE (2010), a população de católicos vem diminuindo e se observa aumento da diversidade religiosa. A população de espíritas, religião muito prevalente na amostra de MFC, no Brasil, é composta por maioria de brancos $(68,7 \%)$ e, dentre as religiões estudadas, é a que possui a maior proporção de praticantes com nível superior completo $(31,5 \%)$ e maior faixa de renda (19,7\% declaram rendimento acima de 5 salários mínimos). Esses achados podem refletir o perfil de acesso ao curso de medicina e a diferença da classe médica em relação ao perfil socioeconômico da população em geral.

Os dados sobre religiosidade obtidos no presente estudo também podem ser comparados ao estudo de Peres et al. (2017). Em uma amostra de 782 brasileiros recrutados por meio do cadastro Qualtrics ${ }^{\circledR}$, com características de escolaridade e socioeconômicas semelhantes às do presente estudo, o perfil de filiação religiosa também foi um pouco diferente dos dados do IBGE, sendo 45,3\% de católicos, 21,7\% evangélicos e 5,9\% espíritas. Esse achado reforça a possibilidade de que a distribuição diferenciada dos achados de nossa pesquisa seja decorrente do perfil socioeconômico da população estudada.

As diferenças entre MFC e a população geral, segundo o IBGE (2010), contudo, não se detêm ao campo da prática religiosa em si. Elas também se fazem presentes na forma como cada um dos grupos vivencia sua religiosidade e espiritualidade. $\mathrm{O}$ estudo de Moreira-Almeida (2010) traz dados de uma amostra probabilística de 3.007 
brasileiros. $\mathrm{Na}$ amostra do estudo, $37 \%$ deles frequentavam serviços religiosos no mínimo uma vez por semana. Já quase metade dos MFC raramente ou nunca frequentam essas instituições $(49,3 \%)$, sendo poucos $(9,6 \%)$ os que o fazem ao menos semanalmente, embora tenham prática não institucionalizada frequente $(65,4 \%$ realizam práticas independentes no mínimo semanais). Já a amostra de Peres et al. (2017), de características mais próximas a do presente estudo, observou que uma proporção maior $(26,7 \%)$ dos participantes frequentava serviços religiosos ao menos uma vez por semana e um percentual semelhante realizava práticas individuais ao menos diárias $(35,4 \%)$.

Para além da filiação religiosa, tem se observado que a vivência religiosa e o significado da experiência espiritual são fatores que parecem influenciar no comportamento e até mesmo nos desfechos em saúde das pessoas (Peres et al., 2017). Em relação ao significado da vivência religiosa em suas vidas, 83,0\% dos participantes da amostra nacional consideraram a religião como um aspecto muito importante de suas vidas. Esse aspecto, que se aproxima do conceito de religiosidade intrínseca, também foi mais baixo dentre os MFC, para os quais as crenças religiosas estariam por trás de seu modo de viver em apenas $26,7 \%$ e apenas $18,2 \%$ se esforçariam muito para viverem sua religião em todos os aspectos de suas vidas.

Ainda assim, avaliando-se o escore total para as três assertivas que avaliam religiosidade intrínseca, observa-se envolvimento mais expressivo dos MFC quando comparados aos aspectos de frequentação religiosa. O estudo de Peres et al. (2017) encontrou um escore médio de 11,4, que se aproxima do valor encontrado na amostra desse estudo $(10,62)$. Já em relação ao bem-estar espiritual, o escore geral médio na FACIT-SpNI foi de 35,7, com forte impacto da dimensão de significado (média de 13,9, DP: =/-2,3), tendo essa também sido a dimensão de maior expressão no estudo de Peres (2017), com média de 11,1. O domínio de significado na FACIT-Sp12 tem sido a dimensão da escala mais fortemente associada a desfechos em saúde. Não há dados utilizando a DUREL e FACIT-SpNI que alcancem a população brasileira de modo representativo.

O distanciamento entre os profissionais e população em geral pode se refletir na forma como a relação médico-paciente se dá em consultório, sendo permeada por relações de poder e tensões sociais implícitas. O estudo de Shafranske (2001), por exemplo, observou que apenas 24,0\% dos psicólogos americanos acreditavam em Deus, 
ao passo que, na população geral, essa crença se faz presente em 90,0\% das pessoas. Para o autor, a visão de mundo dos psicólogos, construída a partir de seus valores pessoais e filosófico-existenciais, poderiam levar os profissionais a subestimarem o significado da religião e da espiritualidade na vida das pessoas de que cuidavam. Nesse sentido, o distanciamento econômico, religioso, cultural e em termos de valores pessoais entre médicos e pacientes se faz presente nas consultas de modo oculto. Esses fatores, ao deixarem de ser explicitados no processo de preparação do médico para o atendimento, pode ser um limitador da empatia e do cuidado em saúde no encontro clínico (Pendleton, 2011).

A religiosidade e a espiritualidade têm se mostrado aspectos importantes da vida da maioria das sociedades. Nesse sentido, compreende-las como parte do cuidado em saúde passa a ser uma prática de competência cultural. A competência cultural é um atributo derivado da Atenção Primária à Saúde (Starfield, 2002) que, junto da abordagem familiar, busca agregar os valores da pessoas e grupos ao cuidado em saúde. Essa postura busca minimizar as barreiras de comunicação com as pessoas e potencializar a atuação da equipe de saúde no território de cuidado.

O exercício consciente da competência cultural pelo profissional de saúde pode auxiliar a explicitar as relações de poder que tencionam a relação médico-paciente no campo da religiosidade. Para Targa (2010), um termo de uso corriqueiro no ambiente da APS é o de considerar o pensamento leigo trazido pelas pessoas como "crendices". Para o autor, a adoção do termo "crendice" pressupõe a existência de diferentes valores, que caracterizam saberes diversos. De um lado estaria o saber baseado na crença mítica do leigo; do outro, o saber científico do profissional. Nesse sentido, o autor discute que as visões religiosa e mística, por seu caráter, seriam muitas vezes apontadas como nãocientíficas ou inapropriadas para os profissionais, sendo assim, desvalorizadas na cultura do próprio serviço de saúde. Essa postura poderia resultar em um processo de distanciamento e destruição dos valores relacionados à E/R pelos profissionais.

Nesse sentido, uma postura essencial é que o profissional se mantenha em situação de igualdade com a pessoa na construção da relação, de modo a garantir um ambiente seguro, livre de julgamento ou depreciação devido à fé ou conjunto de crenças da pessoa. Ter em mente valores humanos, como a compaixão, pode auxiliar o profissional a assumir uma postura de não julgar, mas sim, reconhecer a competência e 
o potencial que existe no outro e compreender que a função do profissional é acompanhar a pessoa em seu processo de busca, autoconhecimento e, por fim, nas suas possibilidades de auto transcendência ou autocuidado (Goetz et al., 2010; Stewart et al., 2014).

\subsubsection{Que espiritualidade é essa abordada pelos MFC?}

$\mathrm{Na}$ introdução do presente trabalho e no questionário aplicado aos MFC, foram utlizados os conceitos de Koenig et al. (2001) - que trata da busca pessoal para entender questões relacionadas ao fim da vida, ao seu sentido e sobre as relações com o sagrado ou transcendente; Puchalski (2014a) - que defende que a espiritualidade seria intrínseca à experiência humana, expressando o significado, propósito e transcendência da existência na vida pessoal e relações; e Anandarajah e Hight (2001) que afirma que a espiritualidade seria a dimensão em que se vivencia significado, conforto, conexão e paz na existência. Também discutimos a importância de usar o termo espiritualidade de modo a sermos mais inclusivos (Vasconcelos, 2009), porém, assumindo-se um risco de perda de acurácia no campo das pesquisas.

As diferenças encontradas entre profissionais e população em geral demonstram as várias nuances interpretativas acerca do tema e a dificuldade de situá-lo entre a subjetividade de cada indivíduo e a objetividade necessária à prática clínica e, ainda mais, à academia. Nesse sentido, descortina-se também a dificuldade de consenso entre os próprios profissionais nessa área. Naturalmente, o próprio conceito de espiritualidade é expresso de múltiplas maneiras a depender do contexto cultural, econômico, religioso e do próprio meio científico.

Diante desse cenário, torna-se essencial conhecer a visão dos médicos a respeito do conceito de espiritualidade, uma vez que essa premissa é norteadora do comportamento do profissional em sua prática clínica. A amostra de MFC estudada apresentou tendência de maior concordância com um conceito de espiritualidade de amplitude moderada, modelado por Puchalski (2014a) que alcançou 74,7\% de concordância total dentre os participantes e teve apenas uma discordância completa $(0,3 \%)$.

A proporção de concordância com os conceitos apresentados também aponta no sentido de que os médicos diferenciam os conceitos de espiritualidade do de 
religiosidade para a aplicação na prática clínica. Houve grande discordância $(49,0 \%)$ quando o conceito de religiosidade de Koenig et al. (2001) foi apresentado como sendo referente a um conceito de espiritualidade, embora $14,0 \%$ da amostra tenha concordado totalmente com essa definição.

As proporções de concordância entre os conceitos de Puchalski (2014a) e Koenig et al. (2001) encontradas na presente amostra foram bastante diferentes. Embora esse tema não tenha sido objeto de estudo direto de Menegatti-Chequini et al. (2016), observa-se que os psiquiatras brasileiros também apresentam tendência de diferenciação dos conceitos entre si, uma vez que $30,6 \%$ da amostra se considera muito “espiritualizada" e 38,1\% se percebem moderadamente "espiritualizados". No entanto, quando a mesma pergunta é feita perguntando-se sobre a auto percepção de religiosidade, os resultados já mudam bastante de distribuição, sendo que apenas 13,7\% se considera muito "religioso" e $29,6 \%$ se descrevem moderadamente.

Nas pesquisas de Curlin et al. $(2006 ; 2007)$ os conceitos de espiritualidade e religiosidade foram assumidos como sinônimos no questionário respondido pelos médicos. Koenig (2008) é favorável a essa proposta e critica o fato de o conceito de espiritualidade vir sendo ampliado ao passar de um modo de descrever a pessoa profundamente religiosa para ser expandido para incluir também as pessoas de religiosidade mais superficial, os buscadores religiosos e pessoas que estejam em busca de felicidade ou bem-estar, ainda que de modo completamente secular. Para o autor, cada vez mais a literatura vem apresentando a tendência de ampliar o conceito de espiritualidade, diferenciando-o do conceito de religiosidade, porém, passando a incluir aspectos relacionados a características mentais positivas (otimismo, perdão, gratidão, senso de propósito) e ao bem-estar geral e saúde mental, o que, em sua visão, não seria adequado, uma vez que esse não é o desfecho responsável pelas fortes associações encontradas entre E/R e desfechos em saúde e esses aspectos poderiam consistir em variáveis confundidoras.

Vários autores, no entanto, discordaram dessa posição de manter ambos os conceitos próximos e defendem a diferenciação entre espiritualidade ou bem-estar espiritual e religiosidade, incluindo os autores do Instrumento de Qualidade de Vida da Organização Mundial da Saúde - Módulo Espiritualidade, Religiosidade e Crenças Pessoais (WHOQOL-SRPB). Para esse grupo, a definição de espiritualidade não foi 
conectada à religião na pesquisa sobre qualidade de vida, devido ao fato de que as pessoas com pontos de vista agnósticos ou ateístas também podem ter uma vida espiritual rica (Fleck e Skevington, 2007). Outros autores advogam que os termos devem ser diferenciados, pois avançar no sentido de avaliação de bem-estar espiritual não deixa de ser uma dimensão importante e que tem se diferenciado dos parâmetros em saúde mental como variável independente (Tsuang e Simpson, 2008). O processo de validação da própria FACIT-Sp12 no Brasil demonstra a discriminação significativa entre as escalas de depressão, ansiedade e otimismo da dimensão de bem-estar espiritual, por exemplo (Lucchetti et al., 2015).

A nosso ver, a maior concordância dos MFC estudados com o conceito de espiritualidade de amplitude moderada proposto por Puchalski (2014a) nos parece ser interessante, do ponto de vista da aplicação na prática clínica. Embora o conceito da autora traga a presença do "sagrado" ou "transcendente", a definição proposta não fica restrita à dimensão religiosa, embora essa seja uma forma de vivência e expressão frequente da dimensão espiritual da pessoa. Desse modo, consideramos que esse conceito pode ter encontrado maior proporção de concordância ao dialogar bem tanto com a circunscrição necessária às pesquisas, como com a amplitude necessária para adequar a abordagem clínica às necessidades das pessoas.

Uma vez que já se sabe da interferência dos valores religiosos dos profissionais de saúde em sua decisão de abordar temas com pacientes (Curlin et al., 2007) e buscarem treinamento na área de E/R relacionada à saúde (Curlin et al., 2006), uma dúvida que também pode ser explorada em pesquisas futuras no Brasil é se a filiação a diferentes religiões ou perfis religiosos estaria ou não associada à discriminação desses conceitos. Essa discussão também foi trazida por Menegatti-Chequini et al. (2016) ao observar que os psiquiatras brasileiros apresentavam elevada auto percepção de serem espiritualizados e também de crerem em Deus (71,4\%), embora apenas 67,4\% deles declarassem uma filiação religiosa. Para os autores, os participantes da pesquisa poderiam ter envolvimento espiritual que iria além de convenções sociais ou instituições religiosas, delineando-se de modo mais individualizado, comportamento que também foi observado em nossa amostra de MFC. O próprio contexto de sincretismo religioso no Brasil poderia dificultar o processo de identificação desses profissionais com uma religião específica. 
Por outro lado, as definições até o momento discutidas representam o olhar da academia, que tem se mostrado bastante distante da vivência da população em geral (Shafranske, 2001), como discutido no item 6.6.1 da presente dissertação. No sentido de como a vivência religiosa se dá no cotidiano das pessoas, um aspecto histórico-cultural singular do Brasil deve ser destacado. Para Andrade (2009), o brasileiro é marcadamente religioso e isso se reflete no cotidiano e na expressão de múltiplas formas de fé religiosa. Com isso, as condutas e crenças religiosas constituiriam parte fundamental do ethos da cultura brasileira. A autora ainda diferencia o conceito de sincretismo (interpenetração de crenças e ritos) do de pluralismo religioso (introdução a diferentes sistemas religiosos). Desse modo, apesar das dificuldades conceituais no campo da religiosidade e espiritualidade, uma necessidade que deve ser buscada nas pesquisas nacionais é o olhar para o pluralismo religioso.

No inquérito de Moreira-Almeida et al. (2010), única pesquisa de âmbito demográfico nacional que conhecemos que abordou o denominado "sincretismo religioso", foi observado que $10,0 \%$ da população geral brasileira frequentaria de modo organizacional (ida a templos, igrejas ou instituições religiosas) mais de uma religião. Embora não haja dados a respeito na literatura para comparação, os autores acreditam que esse índice de $10,0 \%$ poderia estar subestimado, uma vez que o pluralismo religioso também poderia se dar de modo não organizacional (por exemplo, por meio de leituras, programas de televisão e práticas pessoais, como orações e meditações).

Nesse sentido, os achados com os médicos de família e comunidade brasileiros foram bastante surpreendentes. Ao buscarmos ampliar o espectro do sincretismo religioso e nos aproximarmos mais da vivência religiosa-espiritual cotidiana dos participantes, utilizamos uma pergunta ampla, questionando sobre a identificação com diferentes denominações ou matrizes religiosas. A prevalência de MFC que declarou identificação com mais de uma modalidade religiosa foi de 21,6\% quando considerados todos os que responderam mais de uma religião. Esse percentual sobre para $35,8 \%$ quando se agrega à religião apontada a possibilidade de assinalar, além da denominação religiosa assinalada, a frase "Acredito em Deus e não tenho religião".

Faz-se necessário, portanto, que a academia vá até a população brasileira e busque conhece-la melhor nos aspectos quantitativo e qualitativo da vivência religiosa. O trabalho de Couto (2001) estudou qualitativamente a multiplicidade de sistemas 
religiosos do universo cultural de 15 famílias urbanas pobres em Pernambuco. Para a autora, a vivência religiosa é buscada pela população para explicar fenômenos do processo saúde-doença devido ao fato de oferecer não apenas o alívio ou cura momentâneos do campo da saúde, mas também proporcionar a construção de novos valores e padrões comportamentais. Assim, a adesão religiosa promoveria transformações duradouras na vida dos sujeitos e relações familiares. A importância da dimensão do significado do bem-estar espiritual e sua associação com desfechos importantes em saúde, como redução da depressão e melhora da qualidade de vida global, também já começam a ser evidenciados nos estudos quantitativos que avaliam os mecanismos de relação entre espiritualidade e saúde (Canada et al., 2016; Peres et al., 2017).

À medida que o aspecto de significado da vivência ganha força para os desfechos em saúde, cabe destacar que as áreas mais frequentemente discutidas pelos MFC com os pacientes vão ao encontro do modelo de cuidado integral (Anderson e Rodrigues, 2012; Ayres, 2004), abordando a temática da espiritualidade de modo conectado com a rede social e vínculos afetivos da pessoa (abordagem rotineira para $42,8 \%$ dos profissionais), bem como aspectos direcionados para a resiliência da pessoa frente às adversidades do seu contexto pessoal e social (40,2\%).

Já o perfil de perguntas feito com menor frequência pelos MFC nas consultas foi a respeito do impacto para a própria relação médico-paciente (abordada raramente ou nunca por $74,0 \%$ da amostra) e das implicações para o plano terapêutico $(64,7 \%)$. Esse achado pode estar relacionado ao dissenso entre médicos e pacientes sobre o conteúdo e momento adequados para a inserção da abordagem da E/R no cuidado clínico, podendo trazer inseguranças para a abordagem clínica (Best et al., 2015). Por outro lado, também pode estar relacionado à interferência dos valores pessoais do profissional no momento da abordagem.

Um estudo bastante interessante sobre essa temática foi desenvolvido por Ledford et al. (2015), no qual grupos de médicos foram avaliados durante simulações de consultas. Em um grupo, pacientes-atores davam brechas e demonstravam abertura para o diálogo sobre sua dimensão espiritual, enquanto que, no outro grupo, o médico já era incisivamente abordado pelo paciente-ator com o desejo de falar sobre sua espiritualidade/religiosidade. Nesse contexto, observou-se que, quando os pacientes 
eram mais incisivos, forçando o médico a discutir a dimensão espiritual, os médicos reagiam utilizando frases que demonstravam busca por maior controle da situação, em vez da construção comum. Além disso, nesses casos, os médicos também demonstraram menor frequência de uso de frases de suporte ao paciente. Dado o impacto da discussão na relação médico-paciente e vinculo terapêutico, a conclusão do estudo foi justamente a necessidade de treinamento antecipado para manejar essas situações.

Por outro lado, a literatura aponta que a tomada de decisão clínica para construção do plano terapêutico tem sido bastante associada aos valores pessoais do profissional, incluindo os valores morais e religiosos. O estudo de Curlin et al. (2007b) estudou a percepção de médicos americanos a respeito de situações em que os médicos fossem solicitados a realizar procedimentos legais dos quais pudessem ter alguma discordância por valores religiosos ou morais, por exemplo, administração de sedação ao final da vida, realização de aborto casos de falha de método contraceptivo e também a prescrição de métodos de controle de natalidade para adolescente sem o conhecimento ou aprovação dos pais. Frente a essas situações, a maioria $(86,0 \%)$ dos médicos concorda que, a despeito dos valores ou crenças, o profissional deve apresentar todas as opções possíveis ao paciente e encaminha-lo para outro serviço para a realização do procedimento $(71,0 \%)$, caso o médico responsável não deseje realiza-lo, por questões pessoais. Contudo, essa postura não foi consenso entre os profissionais e se observou que os médicos do sexo masculino, os que se declararam mais religiosos e os que declararam objeções morais pessoais para a realização da prática demonstraram-se menos dispostos a apresentar as opções das quais discordavam ou encaminhar o paciente para realiza-la (OR: 0,3-0,5 na análise multivariada). O mesmo grupo de pesquisadores (Curlin et al., 2008) também estudou a percepção dos médicos diante de situações eticamente controversas, encontrando que os médicos que se declaravam mais religiosos eram mais propensos a se posicionarem de modo contrário ao suicídio assistido ( $84 \%$ vs $55 \%, \mathrm{P}<.001)$ e sedação terminal $(25 \%$ vs $12 \%, \mathrm{P}<.001)$, por exemplo.

No Brasil, um prolongamento do estudo SBRAME (Lucchetti et al., 2014b) também demonstrou que os valores religiosos (afiliação religiosa, frequentação à instituição religiosa, religiosidade não organizacional e religiosidade intrínseca) dos estudantes de medicina estiveram fortemente correlacionados à opinião que os 
estudantes referiam sobre sua percepção a respeito de temas considerados controversos em termos de ética médica, tais como controle de natalidade, uso de células tronco, aborto, eutanásia e clonagem humana.

\subsubsection{Valores pessoais do profissional: desdobramentos no cuidado integral}

Apesar do distanciamento sociocultural entre a classe médica e a população geral, a opinião dos MFC brasileiros acerca da relação entre E/R e saúde, no entanto, fala a favor da valorização da inserção desse campo no cuidado em saúde. Destoando de estudos com médicos anglo-saxões, ou seja, de maioria protestante, 88,3\% dos MFC brasileiros julgaram que o domínio da E/R teria grande influência sobre a saúde das pessoas e, nesse sentido, $81,2 \%$ consideram a abordagem da temática como pertinente a sua prática clínica. Dados semelhantes foram encontrados com psiquiatras Brasileiros (Menegatti-Chequini et al., 2016), dos quais 76,8\% julgam importante integral E/R na prática clínica. Contudo, ficou claro que aqueles que traziam essa opinião tinham quatro vezes mais chance de declararem uma filiação religiosa ( $\mathrm{OR}=4.33,95 \%$ CI 2.75-6.81). Já dentre médicos de família e comunidade canadenses (Lee-Poy et al., 2016), a opinião foi bastante diferente. Pouco mais da metade da amostra considerava que as crenças religiosas ou espirituais não seriam relevantes para o cuidado em saúde, contudo, 65,0\% afirmavam que seria importante perguntar a respeito dessa temática em alguns momentos. Esse achado reforça a importância da compreensão do contexto cultural em que o médico está inserido.

Embora a opinião dos MFC brasileiros denote importância à inserção da temática da espiritualidade e da religiosidade como parte do cuidado em saúde, os participantes da pesquisa expressam a dificuldade de inserção dessa temática no cotidiano clínico, uma vez que, embora 50,3\% afirmem abordar a temática de modo frequente em consultório, apenas 35,0\% da amostra se considera tecnicamente preparada para abordar essa questão. Dado semelhante foi referido pelos psiquiatras do estudo de MenegattiChequini et al. (2016), sendo que 45,5\% relatam abordar o tema de modo frequente.

Comparado à literatura internacional, os MFC e psiquiatras brasileiros também perguntam mais frequentemente sobre E/R em suas consultas. Estudos americanos com diferentes especialidades apontavam que os médicos discutiam alguma temática 
relacionada à E/R em menos de $20,0 \%$ das consultas para o estudo de Koenig et al. (2005) e de modo frequente para apenas 10,0\% dos médicos da amostra de Curlin et al. (2006). O aumento das pesquisas e discussão sobre a temática nos últimos dez anos pode ter influenciado a maior abertura dos médicos para realizarem essa abordagem (Lucchetti et al., 2014a). Contudo, o estudo canadense com MFC, realizado em 2016, mantém uma frequência de inserção desse tema nas consultas bastante baixa $(4,4 \%$ abordariam frequentemente e 51,8\% abordariam às vezes). Como apontado no item 6.2.1 da presente dissertação, fatores sociais e culturais também podem contribuir para as diferenças entre os países, questão que precisa ser mais estudada (Hvidt et al., 2017).

A tendência de que os valores religiosos e espirituais dos profissionais de saúde interfiram em suas decisões clínicas quanto à abordagem da $\mathrm{E} / \mathrm{R}$ dos pacientes também se reproduziu com psiquiatras brasileiros (Menegatti-Chequini et al.,2016). Embora poucos psiquiatras se considerassem muito religiosos $(13,7 \%)$, o grupo que tinha essa percepção demonstrou chance cinco vezes maior de perguntarem aos pacientes sobre $\mathrm{E} / \mathrm{R}(\mathrm{OR}=4.58,95 \%$ CI 2.39-8.80). Um aspecto comportamental bastante interessante foi que, embora a tendência de abordagem da $\mathrm{E} / \mathrm{R}$ do paciente tenha se mantido mais frequente no grupo com maior auto percepção de serem espiritualizados, a associação teve impacto bem menor $(\mathrm{OR}=1.87,95 \%$ CI $1.05-3.35)$.

A tendência de os médicos abordarem a questão da E/R pode, portanto, sofrer influência de diversos fatores pessoais, muitos já explorados pela literatura. Contudo, uma pergunta bastante cabível nesse campo é se os médicos conseguem perceber essas interferências no cotidiano de sua prática clínica. Nesse sentido, o campo do autoconhecimento do profissional e a autoconsciência ou auto percepção sobre sua prática podem ser estudados a partir dos fatores que os médicos julgam dificultar a inserção da temática E/R em sua atuação profissional.

Dentre os fatores apontados pelos MFC como limitantes para a inserção da temática sobre E/R em sua prática clínica, a falta de tempo se destacou para a maioria dos profissionais $(53,4 \%)$. De longe, a falta de tempo tem sido apontada como o maior impeditivo para a abordagem da $\mathrm{E} / \mathrm{R}$ em diversas pesquisas com médicos. Essa barreira foi enumerada por 95,0\% dos participantes da clássica pesquisa de Koenig et al. (2005), uma das pioneiras nesse campo. Essa barreira continua a ser um fator limitante, embora em estudo mais recente (Lee-Poy et al., 2016), com amostra de MFC canadenses, a 
proporção de profissionais que enumeraram o fato tempo como impeditivo se aproximou mais da amostra da presente pesquisa, sendo enumerada por $58,2 \%$ dos MFC canadenses. O único grupo que destoou desse achado foi o de psiquiatras brasileiros, para os quais a limitação de tempo é apenas a terceira barreira apontada, sendo relatada por apenas 16,3\% dos profissionais (Menegatti-Chequini et al.,2016).

A falta de treinamento para a abordagem do tema também merece destaque, uma vez que é declarada por 39,7\% dos MFC como fator limitante, mesmo se tratando de uma amostra de profissionais em que $67,1 \%$ trabalham na área do ensino. Dada a relevância do perfil da amostra para a prática clínica e formação de recursos humanos na área da saúde (Brasil, 2014), o dado de que apenas 34,9\% dos participantes se sentia muitíssimo ou muito preparados para abordar a espiritualidade dos pacientes traz preocupação.

A literatura também apresenta a falta de treinamento como um limitador frequentemente citado pelos profissionais entrevistados nas amostras de Koenig et al. (2005) (69,0\%), Curlin et al. (2006) (26\%), Lee-Poy et al. (2016) (17,2\%) e MenegattiChequini et al. (2016) (22,3\%). Contudo, na amostra de Curlin et al. (2006), o aspecto da falta de treinamento foi confrontado com a percepção de desconforto do médico quanto a abordar a $\mathrm{E} / \mathrm{R}$ dos pacientes, trazendo resultados interessantes. $\mathrm{Na}$ análise univariada, os médicos que relataram desconforto com a discussão de assuntos religiosos ou insuficiente conhecimento e treinamento eram menos propensos a questionarem sobre $\mathrm{E} / \mathrm{R} \quad(\mathrm{p}<0.01)$, mas esse grupo de profissionais também apresentavam baixa espiritualidade/religiosidade (termos adotados como sinônimos para o autor). No entanto, após o ajuste para religiosidade, o aspecto da falta de treinamento não mais permaneceu associado ao nenhum comportamento (abordar ou não abordar $\mathrm{E} / \mathrm{R}$ ), enquanto o relato de desconforto com o tema permaneceu associado à menor chance de o profissional perguntar sobre a religião do paciente (OR 0.6, 95\% CI 0.4 0.9) e de continuar o assunto caso o paciente comece a falar sobre suas crenças religiosas (OR $0.4,95 \%$ CI $0.3-0.7)$.

A própria decisão em adquirir treinamento para a abordagem da espiritualidade na prática clínica pode, no entanto, estar subordinada aos valores pessoais, religiosos ou espirituais do médico. Menegatti-Chequini et al. (2016) encontrou que 71,1\% dos psiquiatras brasileiros entrevistados consideravam muito ou razoavelmente importante 
incluir treinamento em abordagem da E/R para médicos. Contudo, esses participantes eram quatro vezes mais propensos a possuírem uma filiação religiosa $(\mathrm{OR}=4.14,95 \%$ CI 2.69-6.36).

Esses achados corroboram para a importância de ser explorado o grupo de barreiras relacionadas aos valores pessoais do médico. Na amostra de MFC brasileiros, as barreiras dependentes apenas dos valores pessoais dos profissionais foram apontadas por somente $10,6 \%$ da amostra. Já quando se consideram profissionais que percebam, simultaneamente, barreiras pessoais e externas (como falta de tempo e treinamento), o percentual de médicos que percebem ambos os limitantes aumenta para 35,6\%. Nesse sentido, os MFC parecem julgar que seus valores pessoais teriam menor interferência que o que vem sendo descrito pela literatura (Curlin et al. 2006; 2007). Há uma limitação para avaliarmos se essa menor percepção seria decorrente da dificuldade dos médicos de perceberem o impacto de suas crenças sobre sua tomada de decisão ou se os MFC se sentiriam menos encorajados a falar de seus valores pessoais em vez de apontarem fatores externos como barreiras.

Os psiquiatras brasileiros já apontam uma barreira pessoal como a principal limitadora de sua abordagem (Menegatti-Chequini et al.,2016), uma vez que 30,2\% deles relatam não abordar o tema de modo frequente devido ao medo de "excederem o que seria o papel do médico”. Dentre os MFC canadenses (Lee-Poy et al., 2016), por sua vez, o desconforto com o tema ou experiências prévias com a abordagem foram enumerados como barreiras para $10 \%$ dos respondedores. O grau de conforto do profissional se mostrou significativamente associado à maior frequência de discussão do tema nas consultas $(\mathrm{p}<0,001)$.

Vale ainda destacar que $27,4 \%$ dos MFC afirmaram não se sentirem desencorajados para abordarem a $\mathrm{E} / \mathrm{R}$ em suas consultas. Na amostra de MenegattiChequini et al. (2016), 40,3\% dos médicos que fizeram essa declaração se mostraram mais propensos a discutir o E/R com pacientes. Esse mesmo grupo referiu possuir uma filiação religiosa com menor frequência.

Embora estejamos discutindo as barreiras para a abordagem da espiritualidade do paciente, não se trata de considerar que essa dimensão seja sempre benéfica à saúde. Pelo contrário, essa temática se torna importante nas consultas também por seu potencial de danos à saúde e do impacto negativo de crenças ou comportamentos sobre 
o próprio bem-estar espiritual da pessoa (Pargament et al., 2001). Proceder com essa avaliação é adequado à abordagem da espiritualidade do paciente no contexto da atenção primária à saúde (APS), campo em que a atenção centrada na pessoa, de modo individualizado e subjetivo, ganha importância (Oliveira et al., 2018). Sob a ótica do método clínico centrado na pessoa, as crenças e valores espirituais podem interferir diretamente na experiência com a doença, afetando a evolução, o desfecho clínico e a relação médico-paciente. Sob o ponto de vista integral, essa dimensão deve ser rotineiramente avaliada, por seu impacto nas estratégias de coping ou enfrentamento da pessoa perante o adoecimento ou situações de crise. Esse impacto pode se dar reforçando estratégias de coping positivo (por exemplo, "adoecimento pode levar a aprofundamento da vida espiritual") ou ressignificado nas situações de coping negativo (por exemplo, "perda de fé com base no sentimento de abandono por Deus" (Panzini et al., 2006).

A questão do coping negativo ganha importância para discussão sobre a prática clínica dos MFC e futuros treinamentos voltados para esses profissionais, uma vez que a temática do coping religioso-espiritual (CRE) é a terceira mais abordada na rotina desses profissionais. Embora 34,9\% abordem as estratégias de enfrentamento de situações estressoras sempre ou frequentemente, a grande maioria dos MFC percebe a influência da E/R na saúde como positiva $(78,4 \%)$, o que pode mascarar situações de sofrimento ou angústia espiritual. Assim, a habilidade de comunicação, a postura empática e livre de julgamento se tornam essenciais para que, na comunicação clínica, o MFC consiga perceber as necessidades de saúde e angústias do paciente. Compreender a experiência de adoecimento e o significado da vivência para a pessoa vai além de perguntar sobre espiritualidade ou religiosidade e podem configurar intervenções breves importantes no manejo de situações estressoras e seu impacto sobre a saúde (Oliveira et al., 2018; Van Tongeren et al., 2017).

Retomamos, assim, o conceito de cuidado como a continuidade do projeto de Ser do humano proposto por Ayres (2004). A consulta constitui processo dialógico em que a pessoa do médico e a pessoa do paciente interagem entre si. Nesse intercâmbio, para o autor, se percebe que é justamente no encontro e no cotidiano das interações humanas que cada pessoa "Vai se "re-apropriando" do seu próprio ser [...]. Nos encontros que vai estabelecendo, ao longo da vida, essas referências identitárias vão se transformando, 
reconstruindo continuamente a percepção do si mesmo e do outro". Ou seja, no momento da consulta, o sistema profissional de saúde interage com o sistema paciente, cada um trazendo sua experiência prévia e produzindo novas reações um ao outro. A partir do encontro terapêutico, como já discutido sobre o processo de cuidado, o médico é solicitado a auxiliar o paciente na elaboração de situações de crise enfrentadas. Contudo, para Vasconcelos (2009), a participação do profissional de saúde neste processo elaborativo seria dificultada pelo fato de sua formação não valorizar e não o preparar para lidar com dimensões subjetivas não expressas de forma racional e clara.

Dadas as necessidades de saúde trazidas por esse conceito de cuidado voltado para a integralidade do ser, também proposto por Stewart et al. (2014), a existência de tantos valores pessoais do profissional que interferem com a decisão clínica ganha especial destaque. É preciso questionar sobre o porquê de médicos apontarem mais barreiras externas e menos internas, quando, nos estudos, as internas é que parecem ser os fatores mais limitantes para abordagem clínica da espiritualidade da pessoa. Com isso, urge discutir o autoconhecimento e a auto percepção ou autoconsciência (melhor descritas pelo termo em inglês self-awareness) do profissional como campos que necessitam de atenção, treinamento e autocuidado para o pleno exercício do cuidado integral (Smith et al., 1999).

\subsubsection{Inserção na prática clínica: cuidado centrado na pessoa, família e comunidade}

Para além da cultura dos serviços de saúde, os profissionais MFC também buscam compreender aspectos que sejam significativos para a pessoa em seu contexto familiar e comunitário ao longo do seu processo de cuidado em saúde (Saguil e Phelps, 2012). Uma das tecnologias leves utilizadas por esse grupo de profissionais, nesse sentido, consiste no método clínico centrado na pessoa (MCCP), utilizado de modo rotineiro por 86,6\% da amostra. O MCCP é recomendado como competência esperada dos egressos dos programas de residência médica na área pela Sociedade Brasileira de Medicina e Família e Comunidade (SBMFC, 2015) e se encontra detalhado no item 1.4 da Introdução do presente trabalho. 
Esse método de comunicação clínica tem se mostrado efetivo para melhorar a relação médico-paciente e a efetividade do cuidado no âmbito da APS (Stewart, 1995; Lewin et al., 2005). Além disso, já há evidências demonstrando que a abordagem centrada na pessoa é capaz de ampliar o espectro de cuidado, integrando necessidades emocionais e sociais em saúde. A coorte de acompanhamento clínico de Pratt et al. (2015), por exemplo, observou que a aplicação do MCCP por enfermeiras e médicos da APS escocesa aumentava a percepção dos profissionais sobre necessidades de saúde relacionadas à dimensão psicológica, social e estilo de vida, bem como o encaminhamento de necessidades em saúde relacionadas a esses aspectos.

Não há estudos relacionando o aumento da percepção sobre necessidades espirituais do paciente com o uso do método clínico centrado na pessoa, contudo, há recomendação de vários autores para que a abordagem dessa temática seja realizada de modo centrado na pessoa (Puchalski, 2014a). Um dos desdobramentos do presente trabalho de pesquisa foi a publicação de um artigo original trazendo a proposta metodológica de abordagem da espiritualidade em consultas ambulatoriais utilizando-se os quatro passos do método clínico centrado na pessoa (Oliveira et al, 2018). Essa metodologia tem sido usada em treinamentos realizados pelo Grupo de Trabalho em Saúde e Espiritualidade da SBMFC e foi analisada por estudo qualitativo que entrevistou oito residentes de MFC que passaram pelo treinamento. A análise dos discursos a partir da metodologia do sujeito coletivo apontou maior inserção da abordagem da $\mathrm{E} / \mathrm{R}$ pelos residentes dois meses após a intervenção realizada. Os residentes também se sentiam mais seguros e satisfeitos com os resultados da abordagem, embora não tenham deixado de vivenciar situações desconfortáveis (Stange, 2018).

Essa proposta de abordagem ganha forças uma vez que não há consenso entre os médicos a respeito da frequência ou melhor momento para realizar essa abordagem (Curlin et al., 2007). Dentre os médicos norte-americanos de diferentes especialidades (Curlin et al., 2006), por exemplo, embora 91,0\% dos médicos considerasse adequado conversar sobre E/R quando o paciente trazia essas questões, os profissionais se dividiam quanto a perguntar sobre a temática espontaneamente, sendo que 45,0\% deles consideravam que isso seria inapropriado. Já 65,0\% dos MFC canadenses julgam que seria apropriado abordar a questão de modo ocasional (Lee-Poy et al., 2016). 
Na presente dissertação, não foi analisada a associação entre o maior preparo para a prática do MCCP e a frequência de inserção da abordagem da E/R na prática clínica. Contudo, pela análise das barreiras declaradas, no campo "Outros", 4,1\% dos médicos declararam abordar o tema conforme a necessidade da pessoa. Esse é um campo de estudo ainda pouco explorado para a prática do MFC, mas que parece se relacionar à prática centrada na pessoa. Os profissionais desse grupo declararam realizar a abordagem da espiritualidade conforme a necessidade de saúde apresentado pelo paciente na consulta, por exemplo, abordando-se questões existenciais, saúde mental, rede social e questões familiares. Desse modo, um fator que pode ser explorado em relação ao $\mathrm{MCCP}$ em futuros estudos seria o perfil do paciente e não apenas a frequência de abordagem. Outro campo a ser explorado é se o tipo de barreira relatada pelos profissionais de saúde para inserção da $\mathrm{E} / \mathrm{R}$ em sua prática clínica seria diferente conforme o tipo de método de comunicação rotineiramente adotado pelo profissional.

Embora o presente estudo não tenha perguntado diretamente sobre a interferência do tipo de atendimento na realização ou não da abordagem da $E / R$, essa vertente se fez presente na categorização temática do discurso livre sobre limitações para a abordagem para $12(4,1 \%)$ dos respondedores. Uma vez que esse fator ainda não foi relatado na literatura em trabalhos prévios (Vermandere e Lepeleire, 2011), é interessante que futuros trabalhos questionem diretamente sobre essa questão.

Embora o MCCP, por si, tenha potencial de impactar sobre a qualidade da comunicação (Lewin et al., 2005), a capacitação exclusiva no método não parece dispensar a necessidade de treinamento específico na temática da E/R. Na amostra de residentes de MFC de Stange, 2018, por exemplo, embora o MCCP fizesse parte do conteúdo programático do programa, os residentes não se sentiam preparados para abordar a $\mathrm{E} / \mathrm{R}$ dos pacientes antes da capacitação específica. A partir do banco de dados da presente dissertação, ainda devem ser realizadas análises em futuras pesquisas a respeito da associação entre o preparo específico em MCCP e sua relação com a frequência de inserção da abordagem da $E / R$ na prática clínica. A percepção de que somente o preparo em MCCP não seria suficiente para promover a abordagem da E/R, no entanto, vai ao encontro do estudo realizado com MFC canadenses (Lee-Poy et al., 2016). O grupo de autores da pesquisa contem autores do próprio MCCP, metodologia de comunicação bastante difundida no Canadá. No entanto, na amostra estudada, a falta 
de treinamento específico em $\mathrm{E} / \mathrm{R}$ foi significativamente associada à decisão do profissional de não perguntar sobre essa temática $(\mathrm{p}=0,007)$.

Como já discutido no item 6.2.2, valores pessoais dos profissionais podem contribuir para a maior dificuldade em discutir a temática da $\mathrm{E} / \mathrm{R}$ com pacientes, mesmo em se tratando de profissionais com capacitação adequada em habilidades de comunicação, como na presente amostra $(74,7 \%$ dos MFC se consideram bem preparados para aplicarem o MCCP). Desse modo, o processo de autoconsciência do profissional pode passar a ser necessário para auxiliar na aquisição dessa competência global (conhecimentos, habilidades e atitudes para a abordagem clínica da E/R).

O autoconhecimento sobre as emoções advindas da prática clínica (Kozishek et al., 2008), a necessidade de tomada de consciência do médico (awareness) (Smith et al., 1999), sua postura de atenção plena (mindfulness) (Atanes et al., 2015) e sua vivência espiritual intrínseca (Curlin et al., 2006) tem impacto sobre a forma como o profissional maneja demandas clínicas, éticas e espirituais trazidas pelo paciente, bem como sobre sua disponibilidade para fomenta-las e abordá-las.

A maioria dos MFC brasileiros declara estar atenta a essa questão, uma vez que $53,1 \%$ deles acreditam que a $\mathrm{E} / \mathrm{R}$ dos médicos interfere com intensidade grande ou enorme no processo saúde-doença e na relação médico-paciente e 32,2\% acham que essa interferência seria moderada. Dada a forte associação dos valores religiosos com determinantes da prática clínica de médicos estadunidenses de diferentes especialidades, Curlin (2007) conclui que os médicos deveriam seguir a recomendação da Association of American Medical Colleges (1999) para buscarem reconhecer sua própria espiritualidade pois essa postura poderia afetar a forma como eles se relacionam e provém cuidado em saúde para seus pacientes. A importância do autoconhecimento do médico, incluindo sua dimensão espiritual, também foi recomendada como uma das áreas de competência esperadas segundo as diretrizes de ensino em E/R dos Estados Unidos da América (Puchalski, 2014 b).

Nesse sentido, já existem evidências apontando que o MCCP poderia ser uma porta de entrada para o autoconhecimento, tomada de consciência do médico sobre sua prática e abordagem do paciente como um todo, incluindo sua dimensão espiritual (Smith et al., 1999). O estudo de Smith (1999) avalia a tomada de consciência do médico residente como um dos fatores que determinam o desempenho teórico-prático 
do MCCP. Foram avaliados 53 residentes que, juntamente ao treinamento em habilidades de comunicação dirigidas para o MCCP, receberam treinamento específico para auto identificação de atitudes pessoais negativas (medo, insegurança, vieses) que pudessem interferir com o andamento da consulta, em termo de habilidades centradas no paciente. Desse total, 44 residentes demonstraram bom ganho de tomada de consciência sobre atitudes avaliadas como negativas e conseguiram melhorar seu desempenho com o MCCP. Já 6 residentes não tiveram tão bom desempenho e isso impactou em sua habilidade de comunicação. Interessante resultado observacional também foi que 3 residentes considerados pelos avaliadores como não expressando atitudes negativas em consultas, também tiveram um desempenho acima da média no desenvolvimento da prática centrada na pessoa.

Ainda para os autores desse estudo, os resultados demonstram que, a partir do processo de crescimento pessoal e desenvolvimento de tomada de consciência sobre suas emoções e atitudes, os profissionais são capazes de melhor desenvolver seu potencial de intervenções curativas integrais. Quando sentimentos como medo, insegurança, estresse e problemas familiares são trazidos à consciência para reflexão, os médicos podem passar a melhor utilizar sua própria resposta emocional como fator de benefício da saúde do paciente. Essa postura poderia contribuir para a construção de paz interior, autoestima e segurança do médico e, portanto, deveria ser abordada na formação médica.

Em relação à abordagem da espiritualidade, já se sabe que a frequência com que médicos perguntam sobre esse tema está fortemente associada à opinião do profissional de que seria importante perguntar aos pacientes sobre a temática da $E / R(p=.001)$ e $o$ nível de conforto percebido pelo próprio médico para falar sobre isso $(\mathrm{p}<.001)$ (LeePoy et al., 2016). Por outro lado, esses dois fatores também se mostraram associados a menor índice de religiosidade e espiritualidade dos profissionais. Um fato interessante é que esse mesmo estudo observou que, na análise multivariada, o impacto da religiosidade do profissional sobre a decisão de abordar E/R em consultas era reduzido, contudo, a percepção de desconforto do profissional permanecia associada a comportamentos como perguntar sobre o tema com menor frequência (OR: 0.6, IC 95\% 0.4-0.9), serem menos propensos a discutirem suas crenças e experiências pessoais com os pacientes (OR: 0.2, IC 95\% 0.1-0.4), não mudarem de assunto quando o paciente 
começa a falar sobre suas crenças (OR: 0.4, IC 95\% 0.3-0.7) e terem maior chance de rezarem com seus pacientes (OR 0.5, IC 95\% 0.3-0.8).

Em relação ao desempenho clínico específico para abordagem da espiritualidade do paciente no Brasil, um estudo avaliou a percepção de estudantes de medicina (Gonçalves et al., 2015). Cinquenta estudantes foram treinados para realização da anamnese espiritual e, então, realizavam entrevistas com pacientes internados $(\mathrm{N}=362)$. Após a realização da anamnese, os estudantes respondiam a um questionário sobre suas percepções. O estudo observou que houve significância estatística entre situações em que os estudantes se sentiam mais confortáveis para realizar a anamnese espiritual com sua tendência a acreditar que o paciente havia gostado da abordagem $(\mathrm{p}<0,01)$, havia se sentido melhor $(\mathrm{p}<0,01)$ e mais motivado $(\mathrm{p}<0,01)$. Além de demonstrar que estratégias educacionais sobre a abordagem da espiritualidade podem ser válidas para preparar futuros profissionais de saúde, a pesquisa traz à tona a interrogação sobre o quanto a percepção de autoconfiança ou conforto do estudante treinado impacta sobre suas percepções acerca da abordagem da espiritualidade.

\subsubsection{Se treinamento é uma necessidade, como está o ensino?}

Dada a importância da abordagem da dimensão espiritual da pessoa no cuidado em saúde, devido aos efeitos promotores e deletérios à saúde relacionados à vivência pessoal dessa temática, a questão sobre a formação nessa área ganha forte importância. $\mathrm{Na}$ amostra do presente estudo, $67,1 \%$ dos MFC declararam realizar atividade relacionada ao ensino, contudo, a maioria da amostra se sente moderadamente $(50,3 \%)$ ou pouco $(13,7 \%)$ preparada para abordar a temática na prática clínica. Além disso, as barreiras relacionadas à formação (treinamento e conhecimento) são limitantes importantes da inserção dessa temática no cotidiano das consultas, sendo apontadas por $67,4 \%$ dos profissionais. A própria falta de tempo, apontada como limitador por $53,4 \%$ dos profissionais, pode estar relacionada à falta de treinamento, uma vez que o treinamento em habilidades e atitudes tende a reduzir o tempo de execução de uma atividade.

Segundo levantamento nacional nos EUA, 75,0\% das escolas médicas americanas fornecem ensino sobre questões religiosas e espirituais com aplicação à medicina (Puchalski, 2006). Além disso, houve um desenvolvimento significativo em 
programas de residência médica dos EUA, com a implementação de cursos de espiritualidade e saúde em programas de residência em medicina interna, psiquiatria e medicina de família (Puchalski, 2006). Outras pesquisas apontam que 90,0\% das escolas de medicina dos EUA (Koenig et al., 2010) e 59,0\% das escolas de medicina britânica (Neely e Mindford, 2008), possuem cursos ou conteúdo em espiritualidade e saúde.

Em um estudo mais recente de Lucchetti et al. (2012a), sobre o ensino de espiritualidade e saúde nas escolas médicas no Brasil, observou-se que poucas escolas têm cursos que abordam especificamente a espiritualidade e a saúde, e menos da metade fornecem alguma forma de ensino sobre o assunto. Entretanto, a maioria dos diretores médicos $(54,0 \%)$ acreditam que esta questão é um assunto importante que deve ser ensinado.

Observa-se, portanto, avanços importantes na graduação médica, sobretudo nos EUA, para a abordagem da espiritualidade do paciente. Já a literatura sobre a incorporação da temática de espiritualidade e saúde durante a residência médica é ainda escassa e evidencia um cenário que requer muitos avanços. Em um estudo realizado nos EUA com a avaliação do treinamento em espiritualidade e cuidado em saúde nos programas de residência médica de medicina de família, aproximadamente 92,0\% dos diretores dos programas disseram ser o ensino da espiritualidade importante. No entanto, apenas 31,0\% dos programas têm um currículo específico (com média de 6 horas) para ensinar espiritualidade e cuidado em saúde para seus residentes (King et al., 2005).

Comparado ao progresso do tema em outros países, o reconhecimento da importância da religiosidade e espiritualidade para a saúde, bem como de sua abordagem na prática médica não parece estar sendo suficiente para promover mudanças nos documentos regulamentadores dos programas de residência médica no Brasil. Em levantamento realizado por nosso grupo de pesquisa e que aguarda publicação, foram analisadas as ementas em vigor relacionadas aos requisitos mínimos dos programas de residência médica no Brasil. Foi encontrada menção direta à temática da religiosidade apenas na ementa da residência médica em psiquiatria. Em nenhuma outra especialidade há menção direta ou indireta à abordagem espiritual. 
No entanto, para além da discussão sobre a inserção da temática da $\mathrm{E} / \mathrm{R}$ no ensino de graduação e residência médica, a presente dissertação de mestrado apresenta outro desafio para essa área: como se deve atuar no ensino, considerando que os valores pessoais do profissional possuem forte influência na atuação clínica nesse campo?

Nesse sentido, vem à tona a necessidade de desenvolvimento de um projeto de ensino-aprendizagem que vá ao encontro da proposta trazida pela modificação da pirâmide de Miller, que passa a incluir a dimensão de Ser (Cruess et al., 2016). A pirâmide de Miller é um clássico modelo teórico que norteia a formação médica ao dividir a aquisição de competências em etapas que passam por conhecimentos (saber e saber como), habilidades (demonstrar) e atitudes (fazer). De acordo com a nova proposta, no entanto, além dessas etapas, a formação deve contemplar a construção de uma identidade profissional, descrita como "ser". Para os autores, a dimensão de "ser" corresponde à capacidade de o estudante ou residente médico apresentar, de modo consistente, atitudes, valores e comportamentos que demonstrem que é capaz de "pensar, agir e sentir como um médico".

A partir dessa proposta, a formação passa a exigir educação emocional e atitudinal. A incorporação de valores como ética, empatia e autoconhecimento passam a ser necessidades para a formação do profissional qualificado. Nesse sentido, métodos de ensino que tenham a capacidade de estimular o autoconhecimento sobre as emoções advindas da prática clínica (Kozishek et al., 2008) e sobre tomada de consciência do médico (self-awareness) (Smith et al., 1999) passam a ser essenciais para a formação.

A partir da presente dissertação de mestrado, essa possibilidade de ensino no campo da espiritualidade/religiosidade em saúde foi organizada em um treinamento teórico-prático em modelo de oficina, com duração de 2 a 4 horas, que já foi reproduzida em mais de dez eventos ou cidades brasileiras, além de já ter sido realizado no Peru e Equador. O impacto dessa oficina foi avaliado pelo trabalho de Stange (2018) e aguarda publicação de dois artigos, um contendo a descrição da metodologia de ensino e outro com a análise qualitativa do processo de aprendizagem e desdobramento para a prática dos residentes.

O aprendizado do método clínico centrado na pessoa, como discutido no item 6.2.4 dessa dissertação, tem potencial de contribuir para a formação da dimensão de autoconhecimento do profissional (Stewart et al., 2014). A postura centrada no paciente 
pode favorecer a comunicação, o cuidado biopsicossocial e melhorar a adesão ao tratamento (Dwamena et al., 2012). Além disso, o treinamento em habilidades centradas no paciente contribui para a empatia, o que promove uma melhor relação médicopaciente e melhores resultados nos cuidados emocionais e físicos (Howick et al., 2018).

Além do MCCP, outras metodologias são descritas por Wenceslau et al. (2016) como estratégias para subsidiarem o trabalho de autoconsciência (self-awareness) e aprimoramento pessoal do profissional na prática clínica. Os autores propõem o desenvolvimento pessoal do profissional de modo a exercer uma prática clínica compassiva apresentando como estratégias de formação a participação em grupos Balint; os grupos de família de origem; os grupos de consciência pessoal propostos por Carl Rogers; a leitura de clássicos da literatura sobre trajetórias de adoecimento; e a reflexão sobre a experiência pessoal despertada pelo contato com os pacientes.

Contudo, deve-se ter clareza de que o aprendizado da prática centrada na pessoa deve ser contínuo e realizado mediante suporte do preceptor ou docente. O educador deve estar atento ao processo de aprendizagem centrada no educando (Stewart et al., 2014), procurando compreender a experiência de aprendizagem e considerando o contexto pessoal e emocional do educando. Avaliação, feedback e suporte emocional são parte do processo de ensino, sobretudo com o intuito de auxiliar o educando a perceber dificuldades específicas, como trabalhar com pacientes em terminalidade ou comprometimento da saúde mental, por exemplo. Nesse sentido, realizar a prática médica tendo-se consciência do processo de transferência e contratransferência torna-se essencial (Balint, 1988; Stewart et al., 2014).

A necessidade de o médico estar autoconsciente (self-awareness) de fatores pessoais tem papel fundamental para que o processo de comunicação e a empatia não sejam prejudicados na prática clínica. Domínios como manter comportamentos de bemestar, demonstrar "abertura espiritual" (spiritual disclosure), religiosidade e grau de burnout são descritos como importantes preditores independentes de empatia em estudantes de medicina pelo trabalho de Damiano et al. (2017). De acordo com esta pesquisa, a saúde mental dos médicos também poderia corroborar para a abordagem da E/R na prática clínica, pois a empatia de estudantes com níveis mais altos de depressão se mostrou menor, mesmo para os estudantes que demonstravam maior "abertura espiritual". 
No campo do ensino da $\mathrm{E} / \mathrm{R}$, a prática do autoconhecimento relacionada ao crescimento pessoal também já vem sendo descrita, por exemplo, na proposta do exercício da compaixão. Em pesquisa qualitativa, Anandarajah et al. (2014) entrevistou individualmente 13 MFC egressos de residência médica. Apesar da diversidade de crenças espirituais pessoais, todos os médicos do estudo descreveram que a compaixão seria "essencial para um médico". A maioria vinculava o conceito de compaixão a valores espirituais (religiosos ou seculares). Muitos médicos consideraram que a prática da medicina proporciona oportunidades para aprendizado de disciplina e vivência da compaixão. O grupo apontou como barreiras significativas para o cuidado compassivo as pressões de tempo e valores da cultura da medicina moderna. Um fator facilitador dessa prática seria dispor de tempo para o autocuidado.

Nesse sentido, a tendência da amostra da presente dissertação em diferenciar o conceito de religiosidade do de espiritualidade pode ser um facilitador da comunicação, uma vez que a utilização do termo espiritualidade poderia fomentar práticas pessoais, religiosas ou seculares de bem-estar e autoconhecimento individuais ou em grupo. A introdução dessa temática na graduação e residência médica pode ter tanto o potencial de melhorar a comunicação e empatia, bem como atuar como fator promotor da saúde dos profissionais em formação, impactando os índices de burnout e transtornos de saúde mental. Nesse sentido, a reflexão sobre a dimensão espiritual do médico nos ambientes de ensino pode ter um potente papel na humanização da prática e do próprio profissional.

Retomamos assim, a proposição de Ian McWhinney (1997) no artigo "The importance of being different", um dos textos em que o autor, considerado "pai da MFC", detalha os princípios da medicina de família e comunidade, enquanto especialidade médica moderna:

A essência da prática clínica centrada na pessoa é que o médico atende não só pessoas, como também seus sentimentos, emoções e estados de espírito, além de categorizar a doença do paciente. Compreender emoções é algo que se dá pessoa a pessoa, e não podemos atender às emoções da outra pessoa sem atender às nossas próprias. Para isso, a habilidade essencial é a escuta ativa. Ouvir uma pessoa com atenção total é um dos maiores 
presentes que podemos dar. Significa ouvir não só com nossos ouvidos, mas com todas as nossas faculdades, especialmente com um coração aberto. Não podemos fazer isso se nossos olhos estão voltados para nós; se estamos pensando o que dizer depois; ou se estamos consumidos com nossas próprias emoções negativas. Esse estado de abertura é descrito como um estado atencioso "não-egoísta, dotado de amor impessoal", um amor chamado pelos gregos de ágape [charity; compaixão]. Não podemos atender os sentimentos e emoções de um paciente sem conhecermos os nossos próprios. Há muitos caminhos para esse conhecimento e a educação médica poderia ser um deles. Pode a medicina se tornar uma disciplina auto reflexiva?

\subsubsection{Limitacões}

A partir das reflexões sobre o distanciamento cultural entre o saber científico e o popular, bem como sobre a necessidade do autoconhecimento como mediador do processo de reflexão sobre a própria prática, é preciso que a própria academia observe e assuma as limitações de seu ponto de vista. Retomando o pensamento de Kuhn (2013), sabemos que nosso olhar nunca é livre de julgamento. Estamos imersos no paradigma científico vigente e, desse modo, embora nossa visão para o novo seja limitada pela ciência "normal", é preciso observar como nos portamos quando nos deparamos com "anomalias". O campo de estudo da espiritualidade e religiosidade é permeado por questões subjetivas, metafísicas, culturais, ancestrais e existenciais, além do impacto dos fatores socioeconômicos e comunitários já bem descritos. Com isso, constitui-se em prerrogativa das reflexões sobre esse tema que nos questionemos sobre nossas motivações e barreiras extrínsecas e intrínsecas ao nos debruçarmos sobre esse campo.

Apesar das muitas limitações conceituais e metodológicas de estudo desse campo, na presente dissertação, procuramos estudá-lo buscando referências e constructos validados na literatura.

A amostra do presente estudo foi coletada com o objetivo de analisar a prática clínica de MFC em relação à abordagem da espiritualidade do paciente. Como isso foi posto de modo claro na divulgação da pesquisa, pode ter havido viés de seleção, uma 
vez que médicos mais interessados no tema podem ter se sensibilizado mais para responder ao questionário. Um aspecto que reforça essa perspectiva é a feminização da amostra, uma vez que, embora o sexo feminino seja mais comum dentre MFC, as mulheres tendem a abordar mais o tema em sua prática clínica, como já foi discutido no item 6.2.1., a partir de Koenig et al. (2005). Por outro lado, embora em primeiro momento tenhamos pensado que a diferença de distribuição de filiação religiosa entre os sujeitos da pesquisa e população brasileira em geral fosse um dado enviesado, ao buscarmos na literatura, percebemos outras causas muito relevantes para essa questão. Os percentuais encontrados são compatíveis com outros estudos realizados com médicos, inclusive em amostra nacional (Menegatti-Chequini et al., 2016) e podem ser decorrentes de diferenças socioeconômicas sabidamente existentes entre a população de médicos e a população geral (IBGE, 2010). Além disso, o fenômeno da cultura religiosa singular ao Brasil, sobretudo o pluralismo e sincretismo religiosos, tornaram-se saudáveis "anomalias" da pesquisa, nos levando a olhar para a dimensão cultural de modo ampliado.

Outro fator que deve ser trazido à reflexão são os fatores psicológicos e motivacionais que podem estar envolvidos com o processo de decisão de responder ou não à pesquisa, como discutido por Hornsey et al. (2018). Nesse sentido, os próprios dados da literatura que mostram que a $\mathrm{E} / \mathrm{R}$ do profissional determina a decisão clínica também indicam que pode haver interferência na atitude de responder ou não a uma pesquisa sobre esse tema.

Diante disso, a reflexão sobre os cuidados metodológicos da pesquisa em relação a viés de seleção se faz necessária. Embora a explicitação de que a pesquisa estudava a relação entre espiritualidade e cuidado em saúde possa ter atraído como respondedores pessoas mais sensíveis ao tema, essa questão não pode ser evitada, uma vez que é uma prerrogativa que o sujeito respondedor conheça as premissas e objetivos da pesquisa, a partir do termo de consentimento livre e esclarecido, quando é convidado a responde-la. Além disso, o e-mail de convite foi enviado em dois momentos, por e-mail, a todos os contatos disponíveis do banco de dados. Desse modo, fica claro que é possível que a pesquisa seja limitada pelo viés dos não-respondedores, contudo, não há viés de amostragem que possa ser conferido a erro probabilístico na seleção amostral. 
Outro fator metodológico que deve ser discutido pela preocupação com o viés de seleção é a baixa taxa de resposta (15,8\%). Para a revisão de Basílio et al. (2018), a taxa de respostas esperada em pesquisas com médicos portugueses que trabalham na atenção primária à saúde é de 56\% (IC95\%, 47-64\%). Os autores, contudo, apontam que é esperado que pesquisas consideradas maiores $(\mathrm{N}>500)$ tenham taxas de resposta mais baixas, comparadas às com $\mathrm{N}<500(\mathrm{p}<0.0001)$. Para os autores, as pesquisas realizadas por telefone ainda teriam uma taxa de resposta melhor que as realizadas por e-mail. A dificuldade de acessarmos e conhecermos os sujeitos de fato elegíveis para a pesquisa também foi importante delimitador para a estimativa de cálculo amostral e do processo de coleta de dados. Como, na época da coleta, o dado oficial disponível era da Demografia Médica de 2015 (Scheffer et al., 2015), que descrevia 658 MFC com residência médica na área concluída. Embora se estimasse a existência de mais médicos nessa categoria ficou difícil prever qual o número de respostas esperado, tendo sido o cálculo estimado a partir de estudos internacionais e se considerando um universo desconhecido. A falta de dados sobre os médicos de família egressos de programas de residência médica no Brasil também dificultou bastante o processo de busca de respondedores. A amostra estimada na fase de planejamento do estudo, no entanto, foi alcançada.

Uma limitação que não pode deixar de ser avaliada é decorrente da própria natureza de estudos transversais à distância, uma vez que as informações coletadas são autor referidas pelos profissionais. Desse modo, podem estar sujeitas a vieses de aferição condicionados à memória, percepção e opinião sobre o tema. Fatores psicológicos, como oferecer respostas socialmente aceita ou esperadas também podem prejudicar a qualidade das informações dessa modalidade. A aplicação de constructos validados e de diferentes questões que tangenciassem os mesmos temas constituíram em estratégia para lidar com esse tipo de limitação.

Uma limitação específica deve ser feita aos dados demográficos descritos a respeito da filiação religiosa, comportamento em relação à religiosidade e pluralismo religioso, área ainda pouco estudada em inquéritos nacionais. Embora os achados nesse campo tenham sido muito interessantes, a amostra reflete uma camada populacional com perfil socioeconômico específico, não permitindo extrapolações para a população brasileira geral. No entanto, dada a carência de estudos nacionais na área, tanto com 
médicos, quanto com a população brasileira, os achados desse estudo ganham muita relevância ao apontarem as diferenças religiosas e culturais entre esses grupos, bem como ressaltar a importância da melhor compreensão dos processos de pluralismo e sincretismo religiosos no cotidiano da comunidade. 


\section{CONCLUSÕES}

Este estudo mostrou que, no Brasil, os MFC auto referem prática pessoal em diferentes matrizes religiosas, com distribuição particular quando comparada a população geral, merecendo destaque o pluralismo religioso. Os MFC frequentam pouco os serviços religiosos, mas tem prática espiritual frequente. As medias encontradas nos instrumentos DUREL-P e FACIT-SpNI mostram que um pouco o componente intrínseco da religiosidade e sobretudo a dimensão de significado da espiritualidade são aspectos presentes na vida cotidiana destes profissionais da saúde. A pesquisa reforça a complexidade do tema $E / R$, sobretudo quanto ao sincretismo e pluralismo. Além disso, a caracterização da E/R entre os MFC no Brasil descortina desafios ainda de difícil consolidação para a comunicação clínica nesse campo, como a postura empática, livre de julgamento, e a competência cultural.

Em relação à aplicação clínica, os MFC parecem diferenciar os conceitos de religiosidade e espiritualidade entre si, além de preferirem o conceito de espiritualidade de Puchalski (2014a), que nos parece ser um conceito de amplitude moderada quando comparado aos conceitos de Koenig et al. (2001) e Anadarajah e Hight (2001). Os temas em E/R mais abordados em consultas dialogam com a proposta de cuidado integral da especialidade, contudo, deve-se observar a possibilidade de limitação do processo de decisão compartilhada e vínculo médico-paciente pelas áreas que são menos discutidas. Embora a maioria da amostra fosse capacitada em habilidades de comunicação, com enfoque no método clínico centrado na pessoa, essa competência não se mostrou suficiente para, de modo isolado, promover a abordagem da $\mathrm{E} / \mathrm{R}$ na prática clínica. Desse modo, fica clara a necessidade de treinamento específica na área, sobretudo em se tratando de uma amostra com potencial de atuar na formação de profissionais de saúde.

Embora as barreiras mais apontadas pelos MFC como limitadoras da abordagem clínica do tema sejam falta de tempo, treinamento e conhecimento específicos em $\mathrm{E} / \mathrm{R}$, a literatura já deixa claro o forte impacto dos valores religioso-espirituais do médico. A tendência de crescimento da percepção sobre o impacto das barreiras limitadoras determinadas por valores pessoais sinaliza a necessidade de olhar para a dimensão de autoconhecimento e auto percepção (ou autoconsciência) do médico como um agente 
determinante em termos de prática clínica e formação, que deve ser ativamente desenvolvido para a consolidação do cuidado integral em saúde, incluindo o cuidado da dimensão espiritual da pessoa. Nesse sentido, a reflexão sobre a dimensão espiritual do médico nos ambientes de ensino pode ter um potente papel na humanização da prática e do próprio profissional.

\section{CUSTOS DO TRABALHO DE PESQUISA}

O presente projeto foi realizado com recursos próprios da instituição. Os autores declaram não ter incentivo financeiro ou conflito de interesse para a publicação deste artigo. O presente trabalho configura tese de mestrado da autora. A mesma não recebeu bolsa ou fomento para a realização da pesquisa. 


\section{ANEXOS}

\subsection{ANEXO 1: Livre traducão da ferramenta FICA para abordagem da}

\section{espiritualidade:}

F - Fé / crença

- Você se considera religioso ou espiritualizado?

- Você tem crenças espirituais ou religiosas que te ajudam a lidar com problemas?

- Se não: o que te dá significado na vida?

I - Importância ou influência

- Que importância você dá para a fé ou crenças religiosas em sua vida?

- A fé ou crenças já influenciaram você a lidar com estresse ou problemas de saúde?

- Você tem alguma crença específica que pode afetar decisões médicas ou o seu tratamento?

C - Comunidade

- Você faz parte de alguma comunidade religiosa ou espiritual?

- Ela te dá suporte, como?

- Existe algum grupo de pessoas que você "realmente" ama ou que seja importante para você?

- Comunidades como igrejas, templos, centros, grupos de apoio são fontes de suporte importante?

A - Ação no tratamento

- Como você gostaria que o seu médico ou profissional da área da saúde considerasse a questão religiosidade / espiritualidade no seu tratamento?

- Indique, remeta a algum líder espiritual / religioso.

Fonte: LucchettiG, Granero AL, Bassi RM, Latorraca R, Nacif SAP. Spirituality in clinical practice: what should the general practitioner know? Rev Bras Clin Med 2010;8(2):154-8 


\subsection{ANEXO 2: Livre tradução da ferramenta HOPE para abordagem da espiritualidade:}

H - Fontes de Esperança (Hope), significância, conforto, força, paz, amor e relacionamento social.

- Quais são as suas fontes de esperança, força, conforto e paz?

- Ao que você se apega em tempos difíceis?

- $\mathrm{O}$ que o sustenta e o faz seguir adiante?

O - Religião Organizada

- Você faz parte de uma comunidade religiosa ou espiritual? Ela o ajuda? Como?

- Em que aspectos a religião o ajuda e em quais não o ajuda muito?

$\mathrm{P}$ - Espiritualidade pessoal e prática

- Você tem alguma crença espiritual que é independente da sua religião organizada?

- Quais aspectos de sua espiritualidade ou prática espiritual você acha que são mais úteis à sua personalidade?

E - Efeitos no tratamento médico e assuntos terminais

- Ficar doente afetou sua habilidade de fazer coisas que o ajudam espiritualmente?

- Como médico, há algo que eu possa fazer para ajudar você a acessar os recursos que geralmente o apóiam?

- Há alguma prática ou restrição que eu deveria saber sobre seu tratamento médico?

Fonte: LucchettiG, Granero AL, Bassi RM, Latorraca R, Nacif SAP. Spirituality in clinical practice: what should the general practitioner know? Rev Bras Clin Med 2010;8(2):154-8 


\subsection{ANEXO 3: Livre traducão da ferramenta SPIRITualHistory para abordagem da espiritualidade:}

$\mathrm{S}$ - Sistema de crença espiritual

- Você tem alguma afiliação religiosa?

- Como você nomeia ou descreve seu sistema de crença espiritual?

$\mathrm{P}$ - Espiritualidade pessoal

- O que a sua espiritualidade / religião significa para você?

- Quão importante é a sua espiritualidade / religião na vida diária?

I - Integração com uma comunidade espiritual

- Você pertence a algum grupo ou comunidade religiosa ou espiritual?

- Como você participa neste grupo / comunidade? Qual é o seu papel?

- Qual é a importância deste grupo para você?

- Esse grupo é uma fonte de apoio para você? Em que sentido?

- Esse grupo lhe dá ou daria algum apoio em assuntos ligados à sua saúde?

$\mathrm{R}$ - Rituais de práticas e restrições

- Você tem práticas específicas realizadas como parte de sua vida religiosa ou espiritual (por exemplo, oração, meditação, serviço)?

- Há práticas ou atividades que o estilo de vida de sua religião encoraja ou proíbe? Como você aceita isso?

- Qual o significado dessas práticas ou restrições para você?

- Há outros elementos específicos de cuidados médicos que você recusa por motivos religiosos / espirituais?

I - Implicações para cuidados médicos

- Que aspectos da sua religião / espiritualidade você gostaria que eu considerasse em seu cuidado?

- Você gostaria de discorrer sobre implicações religiosas ou espirituais no cuidado de sua saúde?

- Que conhecimento ou entendimento sobre isso você acha que fortaleceria nossa relação médico-paciente?

- Você gostaria de discutir as implicações religiosas ou espirituais dos cuidados de saúde?

$\mathrm{T}$ - Planejamento de eventos terminais

- Quais são as práticas religiosas ou espirituais gostaria de ter disponível no hospital ou em casa?

- Que práticas planejaria no momento da morte, ou após a morte?

- De onde você tira a força para lidar com esta doença?

- Quando você tem dor ou medo, como você encontrar conforto?

- Ao planejar seu cuidado perto do fim da vida, como a religião ea espiritualidade influenciar as suas decisões?

- Há aspectos particulares do seu tratamento que você gostaria de dispensar ou suspender por causa da sua fé?

FONTE: Adaptado de Koenig HG, (editor). Espiritualidade no cuidado com o paciente. Por quê, como, quando e o quê. São Paulo: Editora FE; 2005. 


\subsection{ANEXO 4: Os quatro componentes do Método Clínico Centrado}

\section{na Pessoa:}

Passo 1. Explorando saúde, doença e a experiência de doença: como a pessoa vivencia o processo de adoecimento?

a. História clínica, exame físico e exames complementares

b. Dimensões da doença e adoecimento (sentimentos, ideias, impacto funcional e expectativas)

c. Percepções singulares e experiência de saúde (significado e expectativas)

Passo 2. Entendendo a pessoa como um todo: como abordar a pessoa em suas dimensões biopsicossocias em suas relações?

a. A pessoa (História de vida, questões pessoais e de desenvolvimento)

b. O contexto próximo (família, trabalho, rede social)

c. O contexto remoto (cultura, comunidade, ecossistema)

Passo 3. Elaborando um plano conjunto de manejo dos problemas: como centrar a conduta nas necessidades integrais da pessoa?
a. Problemas e prioridades
b. Objetivos do tratamento e/ou manejo da doença
c. Papéis da pessoa e do médico

Passo 4. Intensificando o relacionamento entre pessoa e médico: como construir vínculo e uma relação terapêutica?
a. Compaixão e empatia
b. Relação de poder entre médico e pessoa
c. Cura e esperança
d. Consciência de si mesmo e prática reflexiva
e. Transferência e contra-transferência (autoconhecimento do médico)

Fonte: Stewart M, Brown JB, McWhinney IR et al. (2014). Patient-centered medicine transforming the clinical method (3rd Edn.). London, UK: Radcliffe Publishing. ISBN13: 9781846195662. 


\subsection{ANEXO 5: Versão preliminar do questionário de participacão na pesquisa:}

EIXO I: Aspectos demográficos:

PERGUNTAS OBRIGATÓRIAS:

1- Qual o estado (unidade federativa) em que você atua profissionalmente no momento? (Selecionar opções por sigla)

2- Qual o número do seu registro no Conselho Regional de Medicina (CRM) em seu estado de atuação? (Esse dado será utilizado apenas para evitar duplicidade de respostas. Os participantes da pesquisa não serão identificados por meio desse dado).

3- Você é especialista em medicina de família e comunidade?

- Sim, já CONCLUÍ residência médica em medicina de família e comunidade

- Sim, POSSUO título de especialista pela SBMFC

- Sim, concluí residência médica e possuo título de especialista pela SBMFC

- Não possuo nenhuma das titulações dispostas anteriormente

4- (IBGE) Idade em anos completos: (Aceitar numeral de 18 a 99)

5- (IBGE) Sexo:

- Masculino

- Feminino

6- Há quantosanos COMPLETOS você atua na área de medicina de família e comunidade? (Aceitar numeral de 0 a 99)

7- Atualmente, qual(is) seu(s) campo(s) de atuação profissional? É possível assinalar mais de uma opção:

- Assistência clínica no sistema público ou privado

- Gestão no setor público ou privado

- Ensino

- Outra atividade

8- (SBRAME) Você se enquadra em alguma dessas filiações religiosas ou sistemas de crenças?

- Católica Apostólica Romana

- Evangélica

- Espírita

- Outras religiões:

- Não tenho religião e não acredito em Deus

- Não tenho religião mas acredito em Deus

- Não me enquadro

EIXO II: Espiritualidade e prática clínica: 
1. De 0 (zero) a 10 (dez), o quanto você considera que conhece o método clínico centrado na pessoa, metodologia de consulta proposta por Moira Stewart et al? (Assinale 0 para não conheço nada e 10 para tenho domínio do conteúdo)

$\begin{array}{llllllllllll}0 & 1 & 2 & 3 & 4 & 5 & 6 & 7 & 8 & 9 & 10\end{array}$

2. De 0 (zero) a 10 (dez), o quanto você costuma utilizar o método clínico centrado na pessoa em sua prática médica?(Assinale 0 para não utilizo em momento algum e 10 para utilizo todo o tempo)

$\begin{array}{lllllllllll}0 & 1 & 2 & 3 & 4 & 5 & 6 & 7 & 8 & 9 & 10\end{array}$

3. DURANTE AS CONSULTAS MÉDICAS QUE VOCÊ REALIZA, assinale com que frequência você costuma FAZERAS SEGUINTES PERGUNTAS aos pacientes:

Você tem alguma afiliação religiosa?

Nunca Raramente Às vezesFrequentemente Sempre

Você tem alguma crença espiritual que é independente da sua religião organizada?

Nunca Raramente Às vezesFrequentemente Sempre

O que a sua espiritualidade / religião significa para você?

Nunca Raramente Às vezesFrequentemente Sempre

O que te dá significado na vida?

Nunca Raramente Às vezesFrequentemente Sempre

Você tem crenças espirituais ou religiosas que te ajudam a lidar com problemas?

Nunca Raramente Às vezesFrequentemente Sempre

Em que aspectos a religião o ajuda e em quais não o ajuda muito?

Nunca Raramente Às vezesFrequentemente Sempre

Quais são as suas fontes de esperança, força, conforto e paz?

Nunca Raramente Às vezesFrequentemente Sempre

$\mathrm{O}$ que o sustenta e o faz seguir adiante?

Nunca Raramente Às vezesFrequentemente Sempre

Comunidades como igrejas, templos, centros, grupos de apoio são fontes de suporte importante?

Nunca Raramente Às vezesFrequentemente Sempre

Existe algum grupo de pessoas que você "realmente" ama ou que seja importante para você?

Nunca Raramente Às vezesFrequentemente Sempre

Você tem práticas específicas realizadas como parte de sua vida religiosa ou espiritual (por exemplo, oração, meditação, serviço)?

Nunca Raramente Às vezesFrequentemente Sempre

Há alguma prática ou restrição que eu deveria saber sobre seu tratamento médico?

Nunca Raramente Às vezesFrequentemente Sempre

Você tem alguma crença específica que pode afetar decisões médicas ou o seu tratamento?

Nunca Raramente Às vezesFrequentemente Sempre

Que aspectos da sua religião / espiritualidade você gostaria que eu considerasse em seu cuidado?

Nunca Raramente Às vezesFrequentemente Sempre

Que conhecimento ou entendimento sobre suas crenças e seu cuidado você acha que fortaleceria nossa relação médico-paciente? 
Nunca Raramente Às vezesFrequentemente Sempre

Como médico, há algo que eu possa fazer para ajudar você a acessar os recursos que geralmente o apoiam?

Nunca Raramente Às vezesFrequentemente Sempre

4. Em geral, o quanto você acha que a religião/espiritualidade influencia na saúde de seus pacientes?

Extremamente

Muito

Mais ou menos

Pouco

$\square$ Muito pouco ou nada

5. A influência da religião/espiritualidade na saúde geralmente é positiva ou negativa?

Geralmente positiva

Geralmente negativa

$\square$ Igualmente positiva e negativa

$\square$ Não tem influência

6. Em sua opinião, com que intensidade a espiritualidade/religiosidade dos médicos interfere no entendimento do processo saúde-doença e na relação médico-paciente?

$\square$ Enorme intensidade

$\square$ Grande intensidade

$\checkmark$ Moderada intensidade

$\square$ Pequena intensidade

Não interfere

7. O quanto você se considera preparado para abordar aspectos religiosos/espirituais com seus pacientes?

$\square$ Muitíssimo preparado

$\square$ Muito preparado

$\square$ Moderadamente preparado

$\square$ Pouco preparado

Nada preparado

$\square$ Não se aplica

8. O quanto você acha pertinente tal abordagem?

$\square$ Muitíssimo pertinente

$\square$ Muito pertinente

Moderadamente pertinente

$\checkmark$ Pouco pertinente

$\square$ Nada pertinente

9. Alguma das afirmações seguintes desencorajam você a discutir religião/espiritualidade com seus pacientes? (MARQUE TODAS QUE ACHAR CABIVEIS) 
$\square$ Falta de conhecimento

$\square$ Falta de treinamento

$\neg$ Falta de tempo

$\square$ Desconforto com o tema

$\square$ Medo de impor pontos de vista religiosos aos pacientes

$\square$ Conhecimento sobre religião não é relevante no tratamento médico

$\square$ Não faz parte do meu trabalho

$\square$ Medo de ofender os pacientes

$\checkmark$ Medo de que meus colegas não aprovem

$\square$ Outros

10. Qual dos seguintes questionários de abordagem da espiritualidade ou religiosidade do paciente você conhece? (MARQUE TODAS QUE ACHAR CABÍVEIS):
FICA
HOPE
SPIRITualHistory
Outro(s):

EIXO III: Espiritualidade e Religiosidade do profissional de saúde:

Avaliação da auto percepção de espiritualidade a partir do instrumento BEM -ESTAR ESPITITUAL (FACIT_Sp - Non illness). Por favor, escolha a opção que melhor corresponda ao seu estado durante os ÚLTIMOS 7 DIAS:

Sinto -me em paz

Nem um pouco Um pouco Mais ou menos Muito Muitíssimo

Tenho uma razão para viver

Nem um pouco Um pouco Mais ou menos Muito Muitíssimo

A minha vida tem sido produtiva

Nem um pouco Um pouco Mais ou menos Muito Muitíssimo

Custa -me sentir paz de espírito

Nem um pouco Um pouco Mais ou menos Muito Muitíssimo

Sinto que a minha vida tem um propósito

Nem um pouco Um pouco Mais ou menos Muito Muitíssimo

Sou capaz de encontrar conforto dentro de mim mesmo(a)

Nem um pouco Um pouco Mais ou menos Muito Muitíssimo

Sinto -me em harmonia comigo mesmo(a)

Nem um pouco Um pouco Mais ou menos Muito Muitíssimo

Falta sentido e propósito em minha vida

Nem um pouco Um pouco Mais ou menos Muito Muitíssimo

Encontro conforto na minha fé ou crenças espirituais

Nem um pouco Um pouco Mais ou menos Muito Muitíssimo

A minha fé ou crenças espirituais dão-me força

Nem um pouco Um pouco Mais ou menos Muito Muitíssimo

Tempos difíceis tem fortalecido a minha fé ou crenças espirituais

Nem um pouco Um pouco Mais ou menos Muito Muitíssimo

Mesmo em tempos difíceis, acredito que tudo acabaria bem

Nem um pouco Um pouco Mais ou menos Muito Muitíssimo 
Avaliação da auto percepção de religiosidade a partir do instrumento Índice de Religiosidade da Universidade Duke (DUREL):

(1) Com que frequência você vai a uma igreja, templo ou outro encontro religioso?

1. Mais do que uma vez por semana

2. Uma vez por semana

3. Duas a três vezes por mês

4. Algumas vezes por ano

5. Uma vez por ano ou menos

6. Nunca

(2) Com que frequência você dedica o seu tempo a atividades religiosas individuais, como preces, rezas, meditações, leitura da bíblia ou de outros textos religiosos?

1. Mais do que uma vez ao dia

2. Diariamente

3. Duas ou mais vezes por semana

4. Uma vez por semana

5. Poucas vezes por mês

6. Raramente ou nunca

A seção seguinte contém três frases a respeito de crenças ou experiências religiosas. Por favor, anote o quanto cada frase se aplica a você:

(3) Em minha vida, eu sinto a presença de Deus (ou do Espírito Santo).

1. Totalmente verdade para mim

2. Em geral é verdade

3. Não estou certo

4. Em geral não é verdade

5. Não é verdade

(4) As minhas crenças religiosas estão realmente por trás de toda a minha maneira de viver.

1. Totalmente verdade para mim

2. Em geral é verdade

3. Não estou certo

4. Em geral não é verdade

5. Não é verdade

(5) Eu me esforço muito para viver a minha religião em todos os aspectos da vida.

1. Totalmente verdade para mim

2. Em geral é verdade

3. Não estou certo

4. Em geral não é verdade

5. Não é verdade 


\subsection{ANEXO 6: QUADRO 2}

QUADRO 2 - Sistematização dos instrumentos de abordagem da espiritualidade e religiosidade na prática clínica. Em negrito, seguem as perguntas selecionadas em cada área temática para serem utilizadas no questionário da pesquisa:

\begin{tabular}{|c|c|c|c|}
\hline Área temática & Pergunta & $\begin{array}{l}\text { Instrume } \\
\text { nto de } \\
\text { origem }\end{array}$ & $\begin{array}{c}\text { Subgrupo } \\
\text { da } \\
\text { questão } \\
\text { no } \\
\text { Acróstico } \\
\text { dos } \\
\text { instrume } \\
\text { ntos }\end{array}$ \\
\hline \multirow{3}{*}{$\begin{array}{l}\text { Religião } \\
\text { organizada } \\
\text { (3 perguntas) }\end{array}$} & Você tem alguma afiliação religiosa? & $\begin{array}{l}\text { SPIRITual } \\
\text { History }\end{array}$ & $\begin{array}{l}\text { S (Sistema } \\
\text { de crença) }\end{array}$ \\
\hline & $\begin{array}{l}\text { Como você nomeia ou descreve seu } \\
\text { sistema de crença espiritual? }\end{array}$ & $\begin{array}{l}\text { SPIRITual } \\
\text { History }\end{array}$ & $\begin{array}{l}\text { S (Sistema } \\
\text { de crença) }\end{array}$ \\
\hline & $\begin{array}{l}\text { Você tem alguma crença espiritual } \\
\text { além da sua religião? }\end{array}$ & HOPE & $\begin{array}{l}\text { P } \\
\text { (Espiritpes } \\
\text { soal e } \\
\text { prática) }\end{array}$ \\
\hline \multirow{4}{*}{$\begin{array}{l}\text { Significado da } \\
\text { religiosidade } \\
\text { e/ou } \\
\text { espiritualidade } \\
\text { para a pessoa } \\
\text { (4 perguntas) }\end{array}$} & $\begin{array}{l}\text { Você se considera religioso ou } \\
\text { espiritualizado? Se não, o que te dá } \\
\text { significado na vida? }\end{array}$ & FICA & $\begin{array}{l}\text { F (Fé / } \\
\text { Crença) }\end{array}$ \\
\hline & $\begin{array}{l}\text { O que a sua espiritualidade / religião } \\
\text { significa para você? }\end{array}$ & $\begin{array}{l}\text { SPIRITual } \\
\text { History }\end{array}$ & $\begin{array}{l}\mathrm{P} \text { (Espirit } \\
\text { pessoal) }\end{array}$ \\
\hline & $\begin{array}{l}\text { Quão importante é a sua espiritualidade / } \\
\text { religião na vida diária? }\end{array}$ & $\begin{array}{l}\text { SPIRITual } \\
\text { History }\end{array}$ & $\begin{array}{l}\mathrm{P}(\text { Espirit } \\
\text { pessoal })\end{array}$ \\
\hline & $\begin{array}{l}\text { Que importância você dá para a fé ou } \\
\text { crenças religiosas em sua vida? }\end{array}$ & FICA & $\begin{array}{l}\text { I } \\
\text { (Importân } \\
\text { cia) }\end{array}$ \\
\hline \multirow{4}{*}{$\begin{array}{l}\text { Coping } \\
\text { religioso } \\
\text { espiritual } \\
\text { (4 perguntas) }\end{array}$} & $\begin{array}{l}\text { Você tem crenças espirituais ou } \\
\text { religiosas que te ajudam a lidar com } \\
\text { problemas? }\end{array}$ & FICA & $\begin{array}{l}\text { F (Fé / } \\
\text { Crença) }\end{array}$ \\
\hline & $\begin{array}{l}\text { A fé ou crenças já influenciaram você a } \\
\text { lidar com estresse ou problemas de } \\
\text { saúde? }\end{array}$ & FICA & $\begin{array}{l}\text { I } \\
\text { (Importân } \\
\text { cia) }\end{array}$ \\
\hline & $\begin{array}{l}\text { Quais aspectos de sua espiritualidade ou } \\
\text { prática espiritual você acha que são mais } \\
\text { úteis à sua personalidade? }\end{array}$ & HOPE & $\begin{array}{l}\mathrm{P}(\text { Espirit } \\
\text { pessoal) }\end{array}$ \\
\hline & $\begin{array}{l}\text { Em que aspectos a religião o ajuda e } \\
\text { em quais não o ajuda muito? }\end{array}$ & HOPE & $\begin{array}{l}\text { O } \\
\text { (Religião }\end{array}$ \\
\hline
\end{tabular}




\begin{tabular}{|c|c|c|c|}
\hline & & & organizada \\
\hline \multirow[t]{5}{*}{$\begin{array}{l}\text { Espiritualidade } \\
\text { e resiliência } \\
\text { (5 perguntas) }\end{array}$} & $\begin{array}{l}\text { Quais são as suas fontes de esperança, } \\
\text { força, conforto e paz? }\end{array}$ & HOPE & $\begin{array}{l}\mathrm{H} \\
\text { Esperança, } \\
\text { conforto }\end{array}$ \\
\hline & $\begin{array}{l}\text { Ao que você se apega em tempos } \\
\text { difíceis? }\end{array}$ & HOPE & $\begin{array}{l}\mathrm{H} \\
\text { Esperança, } \\
\text { conforto }\end{array}$ \\
\hline & $\begin{array}{l}O \text { que o sustenta e o faz seguir } \\
\text { adiante? }\end{array}$ & HOPE & $\begin{array}{l}\mathrm{H} \\
\text { Esperança, } \\
\text { conforto }\end{array}$ \\
\hline & $\begin{array}{l}\text { De onde você tira a força para lidar com } \\
\text { esta doença? }\end{array}$ & $\begin{array}{l}\text { SPIRITual } \\
\text { History }\end{array}$ & $\begin{array}{l}\mathrm{T} \\
\text { (Eventos } \\
\text { terminais) }\end{array}$ \\
\hline & $\begin{array}{l}\text { Quando você tem dor ou medo, como } \\
\text { você encontra conforto? }\end{array}$ & $\begin{array}{l}\text { SPIRITual } \\
\text { History }\end{array}$ & $\begin{array}{l}\mathrm{T} \\
\text { (Eventos } \\
\text { terminais) }\end{array}$ \\
\hline \multirow[t]{11}{*}{$\begin{array}{l}\text { Rede de } \\
\text { suporte social } \\
\text { (11 perguntas) }\end{array}$} & $\begin{array}{l}\text { Você faz parte de alguma comunidade } \\
\text { religiosa ou espiritual? }\end{array}$ & FICA & $\begin{array}{l}\text { C } \\
\text { (Comunid } \\
\text { ade) }\end{array}$ \\
\hline & $\begin{array}{l}\text { Sua comunidade religiosa ou espiritual te } \\
\text { dá suporte? Como? }\end{array}$ & FICA & $\begin{array}{l}\text { C } \\
\text { (Comunid } \\
\text { ade) }\end{array}$ \\
\hline & $\begin{array}{l}\text { Comunidades como igrejas, templos, } \\
\text { centros, grupos de apoio são fontes de } \\
\text { suporte importante? }\end{array}$ & FICA & $\begin{array}{l}\text { C } \\
\text { (Comunid } \\
\text { ade) }\end{array}$ \\
\hline & $\begin{array}{l}\text { Você pertence a algum grupo ou } \\
\text { comunidade religiosa ou espiritual? }\end{array}$ & $\begin{array}{l}\text { SPIRITual } \\
\text { History }\end{array}$ & $\begin{array}{l}\text { I (Integrar } \\
\text { comunida } \\
\text { de) }\end{array}$ \\
\hline & $\begin{array}{l}\text { Como você participa neste grupo / } \\
\text { comunidade? Qual é o seu papel? }\end{array}$ & $\begin{array}{l}\text { SPIRITual } \\
\text { History }\end{array}$ & $\begin{array}{l}\text { I (Integrar } \\
\text { comunida } \\
\text { de) }\end{array}$ \\
\hline & $\begin{array}{l}\text { Você faz parte de uma comunidade } \\
\text { religiosa ou espiritual? Ela o ajuda? } \\
\text { Como? }\end{array}$ & HOPE & $\begin{array}{l}\text { O } \\
\text { (Religião } \\
\text { organizada }\end{array}$ \\
\hline & $\begin{array}{l}\text { Qual é a importância deste grupo para } \\
\text { você? }\end{array}$ & $\begin{array}{l}\text { SPIRITual } \\
\text { History }\end{array}$ & $\begin{array}{l}\text { I (Integrar } \\
\text { comunida } \\
\text { de) }\end{array}$ \\
\hline & $\begin{array}{l}\text { Esse grupo é uma fonte de apoio para } \\
\text { você? Em que sentido? }\end{array}$ & $\begin{array}{l}\text { SPIRITual } \\
\text { History }\end{array}$ & $\begin{array}{l}\text { I (Integrar } \\
\text { comunida } \\
\text { de) }\end{array}$ \\
\hline & $\begin{array}{l}\text { Esse grupo lhe dá ou daria algum apoio } \\
\text { em assuntos ligados à sua saúde? }\end{array}$ & $\begin{array}{l}\text { SPIRITual } \\
\text { History }\end{array}$ & $\begin{array}{l}\text { I (Integrar } \\
\text { comunida } \\
\text { de) }\end{array}$ \\
\hline & $\begin{array}{l}\text { Existe algum grupo de pessoas que } \\
\text { você "realmente" ama ou que seja } \\
\text { importante para você? }\end{array}$ & FICA & $\begin{array}{l}\text { C } \\
\text { (Comunid } \\
\text { ade) }\end{array}$ \\
\hline & Indique, remeta a algum líder espiritual / & FICA & A (Ação \\
\hline
\end{tabular}




\begin{tabular}{|c|c|c|c|}
\hline & religioso. & & no tto) \\
\hline \multirow[t]{6}{*}{$\begin{array}{l}\text { Práticas e } \\
\text { estilo de vida } \\
\text { ( } 6 \text { perguntas) }\end{array}$} & $\begin{array}{l}\text { Você tem práticas específicas } \\
\text { realizadas como parte de sua vida } \\
\text { religiosa ou espiritual (por exemplo, } \\
\text { oração, meditação, serviço)? }\end{array}$ & $\begin{array}{l}\text { SPIRITual } \\
\text { History }\end{array}$ & $\begin{array}{l}\mathrm{R} \text { (Rituais, } \\
\text { práticas e } \\
\text { restrições) }\end{array}$ \\
\hline & $\begin{array}{l}\text { Há práticas ou atividades que o estilo de } \\
\text { vida de sua religião encoraja ou proíbe? } \\
\text { Como você aceita isso? }\end{array}$ & $\begin{array}{l}\text { SPIRITual } \\
\text { History }\end{array}$ & $\begin{array}{l}\mathrm{R} \text { (Rituais, } \\
\text { práticas e } \\
\text { restrições) }\end{array}$ \\
\hline & $\begin{array}{l}\text { Qual o significado dessas práticas ou } \\
\text { restrições para você? }\end{array}$ & $\begin{array}{l}\text { SPIRITual } \\
\text { History }\end{array}$ & $\begin{array}{l}\mathrm{R} \text { (Rituais, } \\
\text { práticas e } \\
\text { restrições) }\end{array}$ \\
\hline & $\begin{array}{l}\text { Quais são as práticas religiosas ou } \\
\text { espirituais gostaria de ter disponível no } \\
\text { hospital ou em casa? }\end{array}$ & $\begin{array}{l}\text { SPIRITual } \\
\text { History }\end{array}$ & $\begin{array}{l}\mathrm{T} \\
\text { (Eventos } \\
\text { terminais) }\end{array}$ \\
\hline & $\begin{array}{l}\text { Que práticas planejaria no momento da } \\
\text { morte, ou após a morte? }\end{array}$ & $\begin{array}{l}\text { SPIRITual } \\
\text { History }\end{array}$ & $\begin{array}{l}\mathrm{T} \\
\text { (Eventos } \\
\text { terminais) }\end{array}$ \\
\hline & $\begin{array}{l}\text { Em suas crenças, há alguma prática ou } \\
\text { restrição sobre seu tratamento médico } \\
\text { que eu deveria saber? }\end{array}$ & HOPE & $\begin{array}{l}\text { E (Efeitos } \\
\text { notto) }\end{array}$ \\
\hline \multirow{7}{*}{$\begin{array}{l}\text { Relação da } \\
\text { religiosidade/ } \\
\text { espiritualidade } \\
\text { com o projeto } \\
\text { terapêutico } \\
\text { (7 perguntas) }\end{array}$} & $\begin{array}{l}\text { Você tem alguma crença específica que } \\
\text { pode afetar decisões médicas ou o seu } \\
\text { tratamento? }\end{array}$ & FICA & $\begin{array}{l}\text { I } \\
\text { (Importân } \\
\text { cia ou } \\
\text { Influência) }\end{array}$ \\
\hline & $\begin{array}{l}\text { Ao planejar seu cuidado perto do fim da } \\
\text { vida, como a religião ea espiritualidade } \\
\text { influenciar as suas decisões? }\end{array}$ & $\begin{array}{l}\text { SPIRITual } \\
\text { History }\end{array}$ & $\begin{array}{l}\mathrm{T} \\
\text { (Eventos } \\
\text { terminais) }\end{array}$ \\
\hline & $\begin{array}{l}\text { Há aspectos particulares do seu } \\
\text { tratamento que você gostaria de dispensar } \\
\text { ou suspender por causa da sua fé? }\end{array}$ & $\begin{array}{l}\text { SPIRITual } \\
\text { History }\end{array}$ & $\begin{array}{l}\mathrm{T} \\
\text { (Eventos } \\
\text { terminais) }\end{array}$ \\
\hline & $\begin{array}{l}\text { Ficar doente afetou sua habilidade de } \\
\text { fazer coisas que o ajudam } \\
\text { espiritualmente? }\end{array}$ & HOPE & $\begin{array}{l}\text { E (Efeitos } \\
\text { no tto) }\end{array}$ \\
\hline & $\begin{array}{l}\text { Você gostaria de discorrer sobre } \\
\text { implicações religiosas ou espirituais no } \\
\text { cuidado de sua saúde? }\end{array}$ & $\begin{array}{l}\text { SPIRITual } \\
\text { History }\end{array}$ & $\begin{array}{l}\text { I } \\
\text { Implicaçõ } \\
\text { es médicas }\end{array}$ \\
\hline & $\begin{array}{l}\text { Você gostaria de discutir as implicações } \\
\text { religiosas ou espirituais dos cuidados de } \\
\text { saúde? }\end{array}$ & $\begin{array}{l}\text { SPIRITual } \\
\text { History }\end{array}$ & $\begin{array}{l}\text { I } \\
\text { Implicaçõ } \\
\text { es médicas }\end{array}$ \\
\hline & $\begin{array}{l}\text { Há outros elementos específicos de } \\
\text { cuidados médicos que você recusa por } \\
\text { motivos religiosos / espirituais? }\end{array}$ & $\begin{array}{l}\text { SPIRITual } \\
\text { History }\end{array}$ & $\begin{array}{l}\mathrm{R} \text { (Rituais, } \\
\text { práticas e } \\
\text { restrições) }\end{array}$ \\
\hline
\end{tabular}




\begin{tabular}{|l|l|l|l|}
\hline $\begin{array}{l}\text { Impacto da } \\
\text { religiosidade/ } \\
\text { espiritualidade } \\
\text { na relação } \\
\text { médico- } \\
\text { paciente } \\
\text { (4 perguntas) }\end{array}$ & $\begin{array}{l}\text { Que conhecimento ou entendimento } \\
\text { sobre isso você acha que fortaleceria } \\
\text { nossa relação médico-paciente? }\end{array}$ & $\begin{array}{l}\text { SPIRITual } \\
\text { History }\end{array}$ & $\begin{array}{l}\text { Romo você gostaria que o seu médico ou } \\
\text { profissional da áticas e } \\
\text { ponsiderasse a questão religiosidade / } \\
\text { restrições) }\end{array}$ \\
\hline $\begin{array}{l}\text { espiritualidade no seu tratamento? } \\
\text { Que aspectos da sua religião / }\end{array}$ & $\begin{array}{l}\text { A (Ação } \\
\text { espiritualidade você gostaria que eu } \\
\text { considerasse em seu cuidado? }\end{array}$ & Ho tto) \\
\hline $\begin{array}{l}\text { Como médico, há algo que eu possa fazer } \\
\text { para ajudar você a acessar os recursos } \\
\text { que geralmente o apoiam? }\end{array}$ & HOPE & $\begin{array}{l}\text { Implicaçõ } \\
\text { es médicas }\end{array}$ \\
\hline $\begin{array}{l}\text { Total: } \\
8 \text { áreas } \\
44 \text { perguntas }\end{array}$ & $\begin{array}{l}\text { Perguntas selecionadas FICA: } 5 \\
\text { Perguntas selecionadas HOPE: } 6\end{array}$ & no tto) \\
\hline Perguntas selecionadas SPIRITual: 5 & & \\
\hline
\end{tabular}


9.7. ANEXO 7: Functional Assessment of Chronic Illness Therapy Spiritual Well-Being, na versão modificada para "non-illness" (FACIT-SP - Non Illness):

\section{FACT-Sp (Versào 4)}

Abaixo encontrará uma lista de afirmações que outras pessoas disseram ser importantes. Faça um círculo ou marque um número por linha para indicar a sua resposta no que se refere aos últimos 7 dias.

\section{PREOCUPACÕES ADICIONAIS}

Sinto-me em paz..

\begin{tabular}{|c|c|c|c|}
\hline $\begin{array}{c}\text { Nem } \\
\text { un } \\
\text { pouco }\end{array}$ & $\begin{array}{c}\text { Un } \\
\text { pouco }\end{array}$ & $\begin{array}{l}\text { Mais } \\
\text { ou } \\
\text { menos }\end{array}$ & Muito \\
\hline
\end{tabular}

Tenho uma razão para viver

0

A minha vida tem sido produtiva

Custa-me sentir paz de espirito.

Sinto que a minha vida tem um propósito

1

23

4

Sou capaz de encontrar conforto dentro de mim mesmo/a.

Sinto-me em harmonia comigo mesmo/a

Falta sentido e propósito em minha vida

0

1

2

Encontro conforto na minha fé ou crenças espirituais.

0

1

$$
2
$$

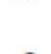

4

4

A minha fé ou crenças espirituais dão-me força.

Tempos dificeis tem fortalecido minha fé ou crenças espirituais.

Mesmo em tempos dificeis, acredito que tudo acabaria bem 
Metodologia para cálculo dos domínios e análise da escala FACIT-SP - Non Illness: 
Table 2. FACIT-Sp-12 Scoring Guidelines (Version 4).

Subscals

Item Cads Reverseitem? Item resonoss

Item Sorres

Meaning

$\mathrm{S} p 2$

$\mathrm{Sp} 3$

Score range: 0.16

$\mathrm{Sp} 5$

$\mathrm{Sp} 8$

$\begin{array}{lll}0 & + & \\ 0 & + & - \\ 0 & + & - \\ 4 & + & \end{array}$

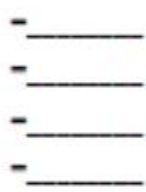

Sum individual iten scores:

Multiply by 4:

Divide by number of items answered: -Meaning subscale score

$\begin{array}{llllll}\text { Pcace } & \text { Spl } & 0 & + & - \\ \text { Scare range: } 0.16 & \text { Sp4 } & 4 & + & - \\ & \text { Sp6 } & 0 & + & - \\ & \text { Sp7 } & 0 & + & -\end{array}$

Sum individual item scores:

Multiply by 4:

Divide by number of items answered: -Pcace subscale scerc

Subscale

$\underline{\text { Item Code Reverse item? }} \underline{\text { Item response }}$

$\underline{\text { Item Score }}$

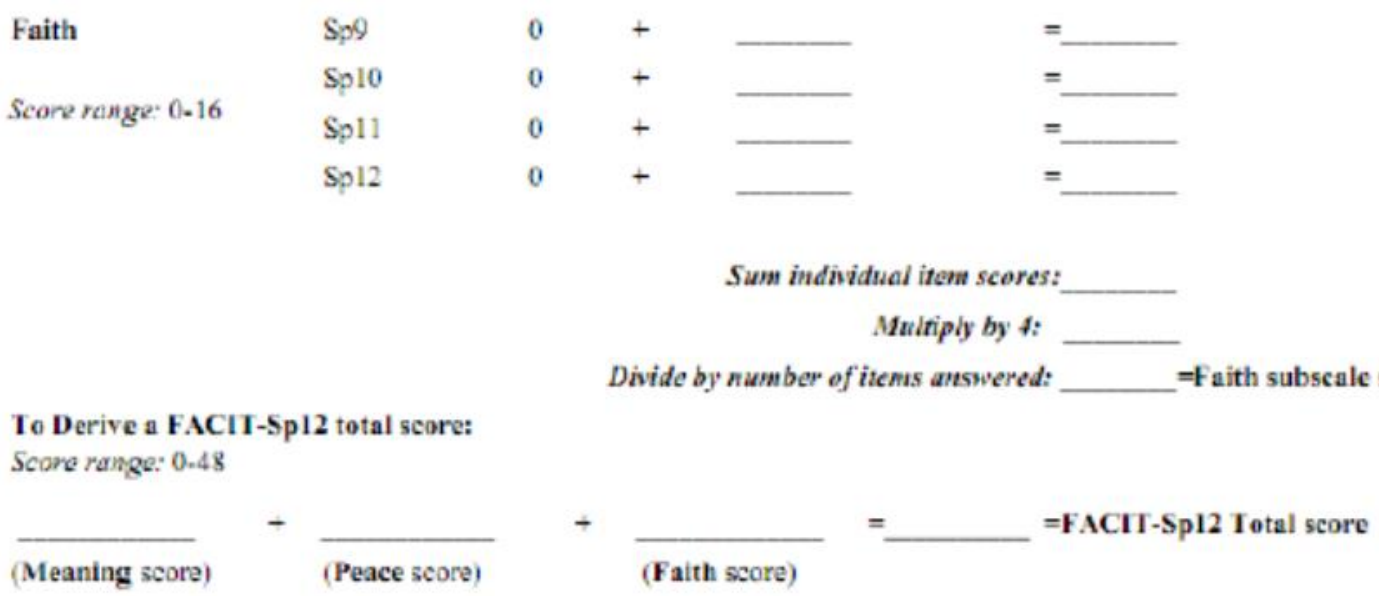

Instructions: 1. Record answers in "item response" column. If missing, mark with an X; 2. Perform reversals as indicated, and sum individual items to obtain a score; 3 . Multiply the sum of the item scores by the number of items in the subscale, then divide by the number of items answered. This produces the subscale score; 4 . The higher the score, the better the QOL/spiritual well-being. 


\subsection{ANEXO 8: Versão final do questionário de participacão na pesquisa, incluindo o termo de consentimento livre e esclarecido}

Olá!

Você já ser perguntou se a dimensão espiritual da pessoa, seja de caráter religioso ou não, pode interferir com desfechos em sua saúde? As evidências têm demonstrado forte associação entre saúde e espiritualidade. Para compreendermos melhor essa relação em meio à prática clínica do médico de família e comunidade, convidamos você a colaborar conosco, participando de nossa pesquisa.

Para isso, conheça mais sobre nossa pesquisa por meio do termo de consentimento abaixo. Ao final, declare seu aceite ou recusa em participar desse projeto.

Termo de consentimento livre e esclarecido online:

Convidamos o(a) senhor(a) para participar da Pesquisa DESAFIOS DO CUIDADO INTEGRAL EM SAÚDE: A DIMENSÃO ESPIRITUAL DO MÉDICO PODE INTERFERIR COM SUAS HABILIDADES DE ABORDAR A DIMENSÃO ESPIRITUAL DO PACIENTE?, realizada como pesquisa de Mestrado de Janaine Aline Camargo de Oliveira, sob a responsabilidade da pesquisadora Prof. ${ }^{a}$ Dr. ${ }^{a}$ Ana Cláudia Camargo Germani, do Departamento de Medicina Preventiva da Universidade de São Paulo.

A pesquisa pretende compreender a percepção de médicos de família e comunidade com residência médica na área sobre o impacto da vivência de sua dimensão espiritual e religiosa em sua desenvoltura para a abordagem da dimensão espiritual do paciente.

Sua participação é voluntária e se dará por meio do preenchimento de questionário online. Sua participação nessa pesquisa não lhe trará risco biológico, embora traga necessidade de investimento de tempo de cerca de 20 minutos para resposta completa do questionário. Fica sob responsabilidade dos pesquisadores a preservação da identidade dos participantes e o sigilo dos dados da pesquisa. É garantida a você a liberdade da retirada de consentimento a qualquer momento e deixar de participar do estudo, sem qualquer prejuízo.

Em qualquer etapa do estudo, você pode acessar os profissionais responsáveis pela pesquisa para esclarecimentos e dúvidas. O contato com os pesquisadores, Dr. José Eluf Neto e Dra. Janaine Aline Camargo de Oliveira, pode ser feito por meio do Departamento de Medicina Preventiva (Av. Dr. Arnaldo, 455, São Paulo - Tel: 30617091) ou pelo e-mail: jancamargo@hotmail.com. Se você tiver alguma 
consideração ou dúvida sobre a ética da pesquisa, entre em contato com o Comitê de Ética em Pesquisa da Faculdade de Medicina da Universidade de São Paulo (CEPFMUSP): Av. Dr. Arnaldo, 251 - Cerqueira César - São Paulo - SP -210 andar sala 36- CEP: 01246-000 Tel: 3893-4401/4407 E-mail: cep.fm@usp.br.

\section{Consentimento Pós-Informação}

- Aceito os termos da pesquisa e confirmo minha participação

- Não aceito os termos da pesquisa e recuso minha participação

Os dados que você fornecer nesse questionário são sigilosos e você não será identificado. Contudo, para evitarmos duplicidade de respostas, nos forneça algumas informações antes de seguir em frente:

\section{PERGUNTA OBRIGATÓRIA:}

9- Qual o estado (unidade federativa) em que você atua profissionalmente no momento?

(Selecionar opções por sigla em barra de rolagem)

PERGUNTA OBRIGATÓRIA:

10- Qual o número do seu registro no Conselho Regional de Medicina (CRM) em seu estado de atuação? PERGUNTA OBRIGATÓRIA:

11- Você é especialista em medicina de família e comunidade?

- Sim, já CONCLUÍ residência médica em medicina de família e comunidade

- Sim, POSSUO título de especialista pela SBMFC

- Sim, concluí residência médica e possuo título de especialista pela SBMFC

- Não possuo nenhuma das titulações dispostas anteriormente

EIXO I: Espiritualidade e prática clínica:

Vamos começar sabendo um pouco de sua atuação profissional:

5. O quanto você se considera preparado para aplicar o método clínico centrado na pessoa, metodologia de consulta proposta por Moira Stewart et al?

1- Não conheço

2- Conheço pouco 
3- Conheço razoavelmente

4- Conheço muito

5- Tenho pleno domínio do conteúdo

6. O quanto você costuma utilizar o método clínico centrado na pessoa em sua prática médica?

1- Não utilizo

2- Utilizo pouco

3- Utilizo razoavelmente

4- Utilizo frequentemente

5- Utilizo todo o tempo

7. DURANTE AS CONSULTAS MÉDICAS QUE VOCÊ REALIZA, assinale com que frequência você costuma FAZER AS SEGUINTES PERGUNTAS aos seus pacientes:

Você tem alguma afiliação religiosa?

Nunca Raramente Ầs vezes Frequentemente Sempre

Você tem alguma crença espiritual além da sua religião?

Nunca Raramente Às vezes Frequentemente Sempre

O que a sua espiritualidade / religião significa para você?

Nunca Raramente Às vezes Frequentemente Sempre

O que te dá significado na vida?

Nunca Raramente Às vezes Frequentemente Sempre

Você tem crenças espirituais ou religiosas que te ajudam a lidar com problemas?

Nunca Raramente Às vezes Frequentemente Sempre

Em que aspectos a religião o ajuda e em quais não o ajuda muito?

Nunca Raramente Às vezes Frequentemente Sempre

Quais são as suas fontes de esperança, força, conforto e paz?

Nunca Raramente Às vezes Frequentemente Sempre

O que o sustenta e o faz seguir adiante?

Nunca Raramente Às vezes Frequentemente Sempre 
Comunidades como igrejas, templos, centros, grupos de apoio são fontes de suporte importante?

Nunca Raramente Às vezes Frequentemente Sempre

Existe algum grupo de pessoas que você "realmente" ama ou que seja importante para você?

Nunca Raramente Às vezes Frequentemente Sempre

Você tem práticas específicas realizadas como parte de sua vida religiosa ou espiritual (por exemplo, oração, meditação, serviço)?

Nunca Raramente Âs vezes Frequentemente Sempre

Há alguma prática ou restrição que eu deveria saber sobre seu tratamento médico?

Nunca Raramente Às vezes Frequentemente Sempre

Ficar doente afetou sua habilidade de fazer coisas que o ajudam espiritualmente?

Nunca Raramente Às vezes Frequentemente Sempre

Você tem alguma crença específica que pode afetar decisões médicas ou o seu tratamento?

Nunca Raramente Às vezes Frequentemente Sempre

Que aspectos da sua religião / espiritualidade você gostaria que eu considerasse em seu cuidado?

Nunca Raramente Às vezes Frequentemente Sempre

Que conhecimento ou entendimento sobre suas crenças e seu cuidado você acha que fortaleceria nossa relação médico-paciente?

Nunca Raramente Âs vezes Frequentemente Sempre

8. Em geral, o quanto você acha que a religião/espiritualidade influencia na saúde de seus pacientes?

1. Extremamente

2. Muito

3. Mais ou menos

4. Pouco

5. Muito pouco ou nada 
5. A influência da religião/espiritualidade na saúde geralmente é positiva ou negativa?

1. Geralmente positiva

2. Geralmente negativa

3. Igualmente positiva e negativa

4. Não tem influência

6. Em sua opinião, com que intensidade a espiritualidade/religiosidade dos médicos interfere no entendimento do processo saúde-doença e na relação médico-paciente?

1. Enorme intensidade

2. Grande intensidade

3. Moderada intensidade

4. Pequena intensidade

5. Não interfere

7. O quanto você se considera preparado para abordar aspectos religiosos/espirituais com seus pacientes?

1. Muitíssimo preparado

2. Muito preparado

3. Moderadamente preparado

4. Pouco preparado

5. Nada preparado

6. Não se aplica

8. O quanto você acha pertinente tal abordagem?

1. Muitíssimo pertinente

2. Muito pertinente

3. Moderadamente pertinente

4. Pouco pertinente

5. Nada pertinente

9. Abaixo você encontra afirmativas sobre o CONCEITO DE ESPIRITUALIDADE, conforme disponível na literatura científica. Assinale o grau de concordância entre cada assertiva e a visão que VOCÊ costuma adotar em sua prática clínica:

a. Espiritualidade é o quanto um indivíduo acredita, segue e pratica uma religião, seja de modo organizacional (ida a igreja ou templo) ou não (prece, meditação, hinos). 
Discordo totalmente Discordo parcialmente Indiferente Concordo parcialmente Concordo totalmente

b. Espiritualidade é uma busca pessoal para entender questões relacionadas ao fim da vida, seu sentido e as relações com o sagrado ou transcendente. Pode levar ao desenvolvimento de práticas religiosas ou não. Discordo totalmente Discordo parcialmente Indiferente Concordo parcialmente Concordo totalmente

c. Espiritualidade é um aspecto da humanidade que lida com a maneira como os indivíduos buscam significado e propósito, assim como com o modo como eles expressam sua conexão com o momento, consigo próprios, com os outros, com a natureza e com o sagrado.

Discordo totalmente Discordo parcialmente Indiferente Concordo parcialmente Concordo totalmente

d. Espiritualidade é a dimensão da experiência humana que inclui a busca por significado, propósito e conexão. Pode se desenvolver por meio da religião ou da relação com o divino, a arte, natureza e valores pessoais ou científicos.

Discordo totalmente Discordo parcialmente Indiferente Concordo parcialmente Concordo totalmente

9. Quais fatores desencorajam você a discutir religião ou espiritualidade com seus pacientes? (MARQUE TODAS QUE ACHAR CABÍVEIS, INDICANDO A ORDEM DE PRIORIDADE POR MEIO DE NUMERAIS)

- $\square$ Medo de ofender os pacientes

- $\square$ Medo de que meus colegas não aprovem

- $\square$ Medo de impor meus pontos de vista religiosos aos pacientes

- $\square$ Falta de conhecimento

- $\square$ Falta de treinamento

- $\square$ Falta de tempo

- $\square$ Desconforto com o tema

- $\square$ Considero que o conhecimento sobre o tema não é relevante no tratamento médico

- $\square$ Não faz parte do meu trabalho

- $\square$ Outros 
EIXO II: Espiritualidade e Religiosidade do profissional de saúde:

Agora, gostaríamos de saber mais sobre seus valores espirituais e/ou religiosos:

1- Em relação a sua percepção sobre sua própria espiritualidade, escolha a opção que MELHOR corresponda ao seu estado durante os ÚLTIMOS 7 DIAS:

Sinto -me em paz

Nem um pouco Um pouco Mais ou menos Muito Muitíssimo

Tenho uma razão para viver

Nem um pouco Um pouco Mais ou menos Muito Muitíssimo

A minha vida tem sido produtiva

Nem um pouco Um pouco Mais ou menos Muito Muitíssimo

Custa -me sentir paz de espírito

Nem um pouco Um pouco Mais ou menos Muito Muitíssimo

Sinto que a minha vida tem um propósito

Nem um pouco Um pouco Mais ou menos Muito Muitíssimo

Sou capaz de encontrar conforto dentro de mim mesmo(a)

Nem um pouco Um pouco Mais ou menos Muito Muitíssimo

Sinto -me em harmonia comigo mesmo(a)

Nem um pouco Um pouco Mais ou menos Muito Muitíssimo

Falta sentido e propósito em minha vida

Nem um pouco Um pouco Mais ou menos Muito Muitíssimo

Encontro conforto na minha fé ou crenças espirituais

Nem um pouco Um pouco Mais ou menos Muito Muitíssimo

A minha fé ou crenças espirituais dão-me força

Nem um pouco Um pouco Mais ou menos Muito Muitíssimo

Tempos difíceis têm fortalecido a minha fé ou crenças espirituais

Nem um pouco Um pouco Mais ou menos Muito Muitíssimo 
Mesmo em tempos difíceis, acredito que tudo acabaria bem Nem um pouco Um pouco Mais ou menos Muito Muitíssimo

2- Com que frequência você vai a uma igreja, templo ou outro encontro religioso?

1. Mais do que uma vez por semana

2. Uma vez por semana

3. Duas a três vezes por mês

4. Algumas vezes por ano

5. Uma vez por ano ou menos

6. Nunca

3- Com que frequência você dedica o seu tempo a atividades religiosas individuais, como preces, rezas, meditações, leitura da bíblia ou de outros textos religiosos?

1. Mais do que uma vez ao dia

2. Diariamente

3. Duas ou mais vezes por semana

4. Uma vez por semana

5. Poucas vezes por mês

6. Raramente ou nunca

4- Assinale o quanto essa frase se aplica a você: "Em minha vida, eu sinto a presença de Deus (ou do Espírito Santo)":

1. Totalmente verdade para mim

2. Em geral é verdade

3. Não estou certo

4. Em geral não é verdade

5. Não é verdade

5- Assinale o quanto essa frase se aplica a você: "As minhas crenças religiosas estão realmente por trás de toda a minha maneira de viver"

1. Totalmente verdade para mim

2. Em geral é verdade

3. Não estou certo

4. Em geral não é verdade

5. Não é verdade 
6- Assinale o quanto essa frase se aplica a você: "Eu me esforço muito para viver a minha religião em todos os aspectos da vida":

1. Totalmente verdade para mim

2. Em geral é verdade

3. Não estou certo

4. Em geral não é verdade

5. Não é verdade

EIXO III: Aspectos sociodemográficos:

Agradecemos muito pela sua contribuição até aqui! Para finalizarmos, gostaríamos de saber um pouco mais sobre você:

12- $\quad$ Idade em anos completos:

(Aceitar numeral de 18 a 99)

13- Sexo:

- Masculino

- Feminino

14- Há quantos anos COMPLETOS você atua na área de medicina de família e comunidade?

(Aceitar numeral de 0 a 99)

15- Atualmente, qual(is) seu(s) campo(s) de atuação profissional? (É possível assinalar mais de uma opção)

- Assistência clínica no sistema público ou privado

- Gestão no setor público ou privado

- Ensino

- Outra atividade

16- Quantas horas por semana você dedica a sua atuação profissional como médico de família e comunidade?

- Menos de 40 horas semanais

- 40 horas semanais

- Mais de 40 horas semanais 
17- Escolha abaixo uma ou mais afiliação(ões) religiosa(s) ou sistema(s) de crenças no(s) qual(is) você julgue se enquadrar:

- Católico

- Evangélico

- Espírita

- Outra crença de matriz cristã

- Religiões de matriz africana (como umbanda e candomblé)

- Religiões de matriz budista

- Religiões de matriz hindu

- Religiões de matriz judaíca

- Religiões de matriz muçulmana

- Acredito em Deus e não tenho religião

- Não acredito em Deus e não tenho religião

- Não me enquadro em nenhum dos descritos

- Outros (campo de resposta aberta)

Muito obrigada por contribuir com nossa pesquisa!

Caso tenha interesse em receber os resultados dessa pesquisa quando concluída ou se interesse em participar de futuros projetos de pesquisa relacionados ao questionário que você preencheu, por favor, deixe-nos seu e-mail para contato: 


\title{
9.9. ANEXO 9: Parecer do Comitê de Ética em Pesquisa
}

\author{
USP - FACULDADE DE \\ MEDICINA DA UNIVERSIDADE \\ DE SÃO PAULO - FMUSP
}

\section{PARECER CONSUBSTANCIADO DO CEP}

\section{DADOS DO PROJETO DE PESQUISA}

Título da Pesquisa: Desafios do cuidado integral em saúde: A dimensão espiritual do médico pode interferir com suas habilidades na abordagem do paciente?

Pesquisador: José Eluf Neto

Área Temática:

Versão: 2

CAAE: 68789117.9 .0000 .0085

Instituição Proponente: Faculdade de Medicina da Universidade de São Paulo

Patrocinador Principal: Financiamento Próprio

\section{DADOS DO PARECER}

Número do Parecer: 2.178.587

\section{Apresentaçäo do Projeto:}

Estudo voltado a obtençäo do título de mestre. A literatura demonstra que a abordagem espiritual tem impacto em termos de saúde biológica, emocional e social, uma vez que há associação entre crenças religiosas com preservação da saúde mental, qualidade de vida e controle de sintomas, além de redução da mortalidade global e cardiovascular. A literatura enumera várias barreiras para a abordagem da espiritualidade do paciente, tais como a falta de treinamento, tempo ou conheci-mento sobre o assunto. contudo, já se estuda que essas barreiras seriam quebradas à medida que o médico se aprofundasse no tema e se desvencilhasse de seus próprios medos e preconceitos. Desse modo, aventa-se a hipótese de que os valores pessoais do médico podem ter impacto sobre sua decisão de realizar ou não a anamnese espiritual em sua prática clínica. Estudo

observacional transversal, a ser realizado por meio de questionário online, com análise quantitativa de dados demográficos e quali-quantitativa (escala de likert) da percepção do médico de família e comunidade (MFC) brasileiro sobre espiritualidade e religiosidade na prática clínica.

\section{Objetivo da Pesquisa:}

Compreender a relação da espiritualidadee religiosidade de médicos de família e comunidade com residência médica na área, com a habilidade desses profissionais para realizarem a abordagem da

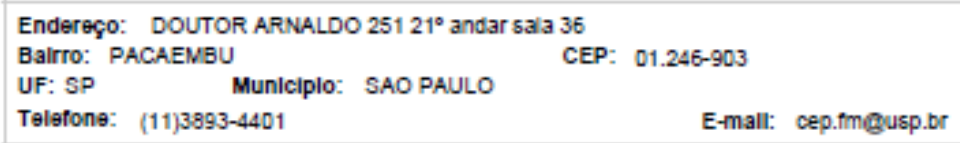




\section{USP - FACULDADE DE MEDICINA DA UNIVERSIDADE DE SÃO PAULO - FMUSP}

Continuaçlo do Parecer. 2.178 .587

dimensão espiritual do paciente.

O projeto será desenvolvido visando alguns objetivos específicos:

-Descrever aspectos demográficos de médicos de família e comunidade, com residência médica na área, em diferentes regiöes do Brasil;

-Descrever aspectos da dimensão espiritual e religiosa desse mesmo grupo de profissionais médicos; - Conhecer aspectos sobre a inserção do tema da espiritualidade na prática clínica rotineira desse grupo de profissionais:

- Verificar a presença de associaçäo entre a espiritualidade e a religiosidade do profissional e suaprática de abordagem da dimensão espiritual do paciente na prática clínica.

\section{Avaliaçäo dos Riscos e Benefícios:}

Riscos mínimos. Questionário online.

Comentários e Considerações sobre a Pesquisa:

Pesquisa bem desenhada. Apresenta temática original e de relevância para o campo de estudos em referência.

Consideraçōes sobre os Termos de apresentação obrigatória:

Adequado

Recomendaçöes:

Aprovado

Conclusões ou Pendências e Lista de Inadequações:

Aprovado

Considerações Finais a critério do CEP:

Este parecer foi elaborado baseado nos documentos abaixo relacionados:

\begin{tabular}{|l|l|c|l|c|}
\hline \multicolumn{1}{|c|}{ Tipo Documento } & \multicolumn{1}{|c|}{ Arquivo } & Postagem & Autor & Situação \\
\hline Informaçöes Básicas & PB_INFORMAÇŌES_BÁSICAS_DO_P & $23 / 06 / 2017$ & & Aceito \\
do Projeto & ROJETO 915091.pdf & $23 / 06 / 2017$ & José Eluf Neto & Aceito \\
\hline TCLE / Termos de & TCLE.docx & $14: 35: 17$ & & \\
Assentimento / & & & \\
\hline
\end{tabular}

Endereço: DOUTOR ARNALDO $25121^{\circ}$ andar sala 36

Balrro: PACAEMBU

UF: SP MunICIPlO: SAO PAULO

CEP: $01.246-903$

Telefone: (11)3893-4401

E-mall: cep.fmgusp.br 


\section{USP - FACULDADE DE MEDICINA DA UNIVERSIDADE DE SÃO PAULO - FMUSP}

Contnuaçlo do Parecer. 2.178.587

\begin{tabular}{|l|l|c|l|c|}
\hline $\begin{array}{l}\text { Justificativa de } \\
\text { Ausência }\end{array}$ & TCLE.docx & $\begin{array}{c}23 / 06 / 2017 \\
14: 35: 17\end{array}$ & José Eluf Neto & Aceito \\
\hline Outros & Cadastro_HCNet.pdf & $24 / 05 / 2017$ & José Eluf Neto & Aceito \\
& & $23: 46: 43$ & \\
\hline Outros & Licenca_FACIT.docx & $23: 41: 56$ & Aceito \\
\hline $\begin{array}{l}\text { Declaraçäo de } \\
\text { Instituiçăo e } \\
\text { Infraestrutura }\end{array}$ & Parecer_departamento_preventiva.JPG & $24 / 05 / 2017$ & José Eluf Neto & Aceito \\
\hline $\begin{array}{l}\text { Projeto Detalhado / } \\
\text { Brochura }\end{array}$ & Projeto_mestrado_Janaine.docx & $23: 40: 19$ & & Aceito \\
Investigador & & $23: 38: 34$ & & \\
\hline Folha de Rosto & Folha_de_rosto_plataforma_brasil.pdf & $24 / 05 / 2017$ & José Eluf Neto & Aceito \\
\hline
\end{tabular}

Situação do Parecer:

Aprovado

Necessita Apreciação da CONEP:

Não

SAO PAULO, 19 de Julho de 2017

Assinado por:

Maria Aparecida Azevedo Koike Folgueira

(Coordenador)

Endereço: DOUTOR ARNALDO $25121^{\circ}$ andar sala 36

Bairro: PACAENBU

UF: SP

CEP: $01.246-903$

Telefone: (11)3893-4401 


\title{
9.10. ANEXO 10: Carta de apoio da SBMFC, disponibilizando banco
}

\section{de contatos de e-mails}

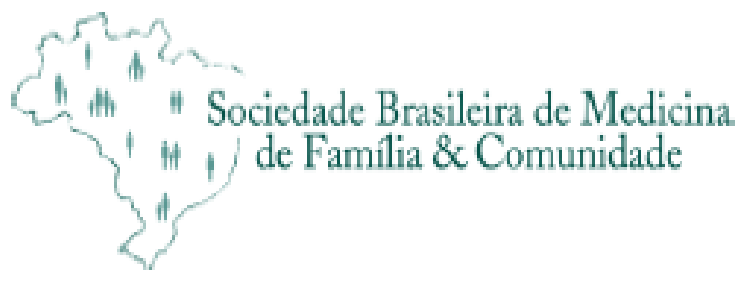

Rio de Janeiro, 14 de março de 2017

\author{
CARTA DE APOIO
}

A Sociedade Brasileira de Medicina de Família e Comunidade por meio desta manifesta apoio ao projeto de pesquisa da Dra. Janaine Aline Camargo de Oliveira, para o qual a entidade disponibilizará os contatos de e-mail dos sócios ativos.

Atenciosamente,

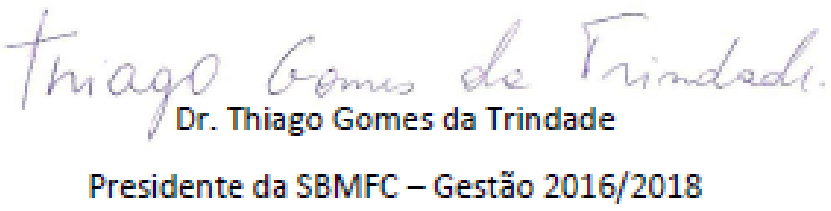




\subsection{ANEXO 11: Licença para utilizacão da FACIT Non Illness}

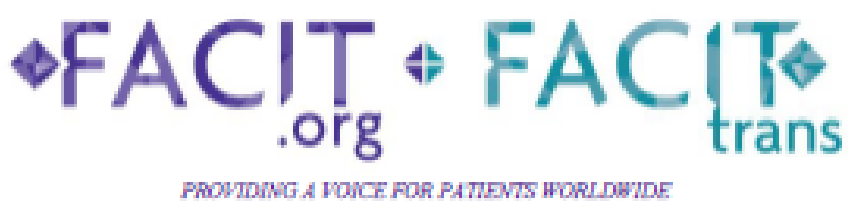

\section{FUNCTIONAL ASSESSMENT OF CHRONIC ILLNESS THERAPY (FACIT) LICENSING AGREEMENT}

The Functional Assessment of Chronic Illness Therapy system of Quality of Life questionnaires and all related subscales, translations, and adaptations ("FACIT System") are owned and copyrighted by David Cella, Ph.D. The ownership and copyright of the FACIT System - resides strictly with Dr. Cella. Dr. Cella has granted FACIT.org (Licensor) the right to license usage of the FACIT System to other parties. Licensor represents and warrants that it has the right to grant the License contemplated by this agreement. The terms of this license will grant permission Licensor provides to JANAINE ALINE CAMARGO DE OLIVEIRA ("Investigator") the licensing agreement outlined below.

This letter serves notice that JANAINE ALINE CAMARGO DE OLIVEIRA is granted license to use the Portuguese version of the FACIT-Sp-NI in one not for profit study:

This current license is only extended to JANAINE ALINE CAMARGO DE OLIVEIRA's research project subject to the following terms:

1) (JANAINE ALINE CAMARGO DE OLIVEIRA) agrees to provide Licensor with copies of any publications which come about as the result of collecting data with any FACIT questionnaire.

2) Due to the ongoing nature of cross-cultural linguistic research, Licensor reserves the right to make adaptations or revisions to wording in the FACT, and/or related translations as necessary. If such changes occur, JANAINE ALINE CAMARGO DE OLIVEIRA will have the option of using either previous or updated versions according to its own research objectives.

3) (JANAINE ALINE CAMARGO DE OLIVEIRA) and associated vendors may not change the wording or phrasing of any FACIT document without previous permission from Licensor. If any changes are made to the wording or phrasing of any FACIT item without permission, the document cannot be considered the FACIT, and subsequent analyses and/or comparisons to other FACIT data will not be considered appropriate. Permission to use the name "FACIT" will not be granted for any unauthorized translations of the FACIT items. Any analyses or publications of unauthorized changes or translated versions may not use the FACIT name. Any unauthorized translation will be considered a violation of copyright protection.

4) In all publications and on every page of the FACIT used in data collection, Licensor requires the copyright information be listed precisely as it is listed on the questionnaire itself.

5) This license is for paper administration only and is not extended to electronic data capture. 


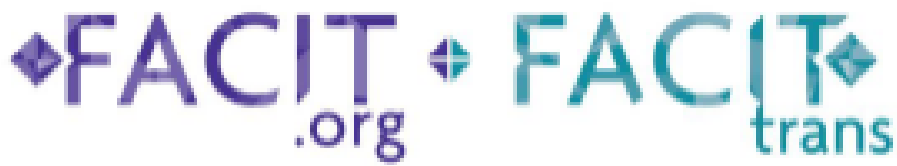

PROYIDNG A WONCE FOR PATHNTS WORL DWIDE

Electronic versions of the FACIT questionnaires are considered derivative works and are not covered under this license. Permission for use of an electronic version of the FACIT must be covered under separate agreement between the electronic data capture vendor and FACT.org

6) In no cases may any FACIT questionnaire be placed on the internet without password protection. To do so is considered a violation of copyright.

7) Licensor reserves the right to withdraw this license if JANAINE ALINE CAMARGO DE OLIVEIRA engages in scientific or copyright misuse of the FACIT system of questionnaires.

8) There are no fees associated with this license.

9) This license is effective upon date issued by FACIT.org and expires at the completion of JANAINE ALINE CAMARGO DE OLIVEIRA's project.

10) JANAINE ALINE CAMARGO DE OLIVEIRA agrees to provide FACIT.org with a copy of any publication which results from this study.

Issued on: February 9, 2017

Shannon C Romo

Assistant Business Manager

FACIT org

381 S. Cottage Hill Avenue

Elmhurst, IL 60126 USA

www.FACIT.org 


\section{REFERÊNCIAS:}

Abu-Raiya H, Pargament KI, Krause N et al. Robust links between religious/spiritual struggles, psychological distress, and well-being in a national sample of American adults. Am J Orthopsychiatry. 2015; 85(6):565-75.

Abu-Raiya H, Pargament KI, Krause N. Religion as problem, religion as solution: religious buffers of the links between religious/spiritual struggles and well-being/mental health. Qual Life Res. 2016; 25(5):1265-74.

Akrawi DA, Bartrop R, Potter U et al. Religiosity, spirituality in relation to disordered eating and body image concerns: A systematic review. J Eat Disord. 2015;15(3):29.

Anandarajah G, Hight E. Spirituality and medical practice: Using the HOPE questions as a practical tool for spiritual assessment. Am Fam Physician. 2001;63(1):81-8.

Anandarajah G, Craigie FJr, Hatch R. Toward competency-based curricula in patientcentered spiritual care: recommended competencies for family medicine resident education. Acad Med. 2010; 85(12):1897-904.

Anandarajah G and Roseman JL. A Qualitative Study of Physicians' Views on Compassionate Patient Care and Spirituality: Medicine as a Spiritual Practice? Rhode Island Medical Journal. 2014; Mar: 17-22.

Anderson, MIP e Rodrigues, RD. Integralidade na pratica do MFC e na APS. In: Gusso, GDF, Lopes, JMC. Tratado de Medicina de Família e Comunidade - Princípios, Formação e Pratica. Porto Alegre, Brasil: Editora Artmed: 2012.

Andrade MO. A Religiosidade Brasileira: o pluralismo religioso, a diversidade de crenças e o processo sincrético. CAOS - Revista Eletrônica de Ciências Sociais. 2009 (14): 106-18.

Association of American Medical Colleges. Report III: Contemporary Issues in Medicine: Communication in Medicine.1999.

Atanes AC, Andreoni S, Demarzo MM. Mindfulness, perceived stress, and subjective well-being: a correlational study in primary care health professionals. BMC ComplementAltern Med. 2015;2(15):303.

Ayres, JRCM. O cuidado, os modos de ser (do) humano e as práticas de saúde. Saúde e Sociedade. 2004: 13(3): 16-29.

Ayres JRCM. Organização das Ações de Atenção à Saúde: modelos e práticas (Organization of Health Care Actions: models and practices). Saúde e Sociedade. 2009: 18(2): 11-23.

Balint M. O médico, seu paciente e a doença. $1^{\mathrm{a}}$ ed. Rio de Janeiro, Brasil: Atheneu; 1988. 
Basílio N, Cardoso S, Nunes JM et al. Portuguese Primary Care physicians response rate in surveys: A systematic review. Rev Assoc Med Bras. 2018; 64(3):272-80.

Best M, Butow P, Olver I. Do patients want doctors to talk about spirituality? A systematic literature review. Patient Educ Couns. 2015;98(11):1320-8.

Brasil. Ministério da Educação. Conselho Nacional de Educação. Câmara de Educação Superior. Resolução No 3, de 20 de junho de 2014. Institui Diretrizes Curriculares Nacionais do Curso de Graduação em Medicina e dá outras providências. Diário Oficial da União, Brasília (DF). 2014; 23 jun.; Seção 1: 8-11.

Brasil. Ministério da Saúde. Secretaria-Executiva. Núcleo Técnico da Política Nacional de Humanização. HumanizaSUS: a clínica ampliada. Ministério da Saúde, SecretariaExecutiva, Núcleo Técnico da Política Nacional de Humanização. Brasília: Ministério da Saúde, 2004.

Boff, L. A opção pela terra - A Solução Para a Terra Não Cai do Céu. Petrópolis, Brasil: Record: 2009.

Boff, L. O cuidado necessário. 2ª ed. Petrópolis, Brasil: Vozes: 2013.

Borneman T.; Ferrell B.; Puchalski C.M. Evaluation of FICA tool for spiritual assessment. J Fam Symptom Manage. 2010; 40: 163-73.

Canada AL, Murphy PE, Fitchett G et al. Re-examining the Contributions of Faith, Meaning, and Peace to Quality of Life: a Report from the American Cancer Society's Studies of Cancer Survivors-II (SCS-II). Ann Behav Med. 2016 Feb;50(1):79-86.

Campbell, J.D.; Ellis, M.R., Breidenbach, A.D. et al. What do family physicians think about spirituality in clinical practice? J FamPract. 2002:51:249-54.

Chida Y, Steptoe A, Powell LH. Religiosity/spirituality and mortality. A systematic quantitative review. PsychotherPsychosom. 2009;78(2):81-90.

Clark L, Leedy S, McDonald L et al. Spirituality and job satisfaction among hospice interdisciplinary team members. J Palliat Med. 2007;10:1321-1328. apudSeccareccia D, Brown JB. Impact of spirituality on palliative care physicians: personally and professionally. J Palliat Med. 2009;12(9):805-9.

CNRM - Comissão Nacional de Residência Médica. Sistema CNRM - Consulta a Certificados de Residência Médica. Disponível em: http://mecsrv04.mec.gov.br/sesu/sist_cnrm/apps/cons_res.asp, acessado em 10/11/2017.

Couto MT. Religiosity, reproduction and health among underprivileged urban families. Interface_Comunic, Saúde, Educ. 2001; 5(8): 27-44. 
Craigie FC Jr, Hobbs RF III: Spiritual perspectives and practices of family physicians with an expressed interest in spirituality. Fam Med. 1999;31:578-585 apudSeccareccia D, Brown JB. Impact of spirituality on palliative care physicians: personally and professionally. J Palliat Med. 2009;12(9):805-9.

Cruess RL, Cruess SR and Steinert Y. Amending Miller's Pyramid to Include Professional Identity Formation. Academic Medicine. 2016; 91(2): 180-185.

Curlin FA, Chin MH, Sellergren SA et al. The association of physicians' religious characteristics with their attitudes and self-reported behaviors regarding religion and spirituality in the clinical encounter. Med Care.2006;44(5):446-53.

Curlin FA (2007a), Sellergren SA, Lantos JD and Chin MH. Physicians' observations and interpretations of the influence of religion and spirituality on health. Arch Inter Med. 2007; 167(7):649-54.

Curlin FA (2007b), Lawrence RE, Chin MH and Lantos JD. Religion, conscience, and controversial clinical practices. N Engl J Med. 2007; 356:593-600.

Curlin FA, Nwodim C, Vance JL et al. To Die, to Sleep: US Physicians' Religious and Other Objections to Physician-Assisted Suicide, Terminal Sedation, and Withdrawal of Life Support. Am J Hosp Palliat Care. 2008; 25(2):112-20.

Damiano RF, DiLalla LF, Lucchetti G et al. Empathy in Medical Students Is Moderated by Openness to Spirituality, Teaching and Learning in Medicine. 2017; 29(2):188-195.

Dearmond IM. The psychological experience of hospice workers during encounters with death. Omega. 2012-2013;66(4):281-99.

Dwamena F, Holmes-Rovner M, Gaulden CM et al. Interventions for providers to promote a patient-centered approach in clinical consultations. Cochrane Database Syst Rev. 2012; 12:CD003267.

Elwyn G, Gwyn R. Narrative based medicine: stories we hear and stories we tell: analysing talk in clinical practice. BMJ. 1999;318(7177):186-8.

Farias ER, Stein AT, Hoffmann JE. Os egressos da residência de Medicina de Família e Comunidade do Centro de Saúde Escola Murialdo, 1976-2000. Boletim da Saúde, Porto Alegre. 2004;18(1):99-111.

Fleck MP e Skevington S. Explicando o significado do WHOQOL-SRPB. Rev. Psiquiatr. Clín. [online]. 2007; 34 (1): 146-9.

Gillum RF, Ingram DD. Frequency of attendance at religious services, hypertension, and blood pressure: the Third National Health and Nutrition Examination Survey. Psychosom Med. 2006;68(3):382-5. 
Goetz J, Keltner D, Simon-Thomas E. Compassion: an evolutionary analysis and empirical review. Psychol Bull [Internet]. 2010;136(3):351-74. Available from: http://psycnet.apa.org/psycinfo/2010-07936-005.

Gonçalves JP, Lucchetti G, Menezes PRet al. Religious and spiritual interventions in mental health care: a systematic review and meta-analysis of randomized controlled clinical trials. Psychol Med. 2015; 45(14):2937-49.

Gonçalves LM, Osório IH, Lucchetti G. Learning from Listening: Helping Healthcare Students to Understand Spiritual Assessment in Clinical Practice.JRelig Health. 2015; Oct 29. [Epub ahead of print]

Gunther E, Jeremy W,McKenzieB. Using the Internet for Surveys and Health Research. J Med Internet Res. 2002; 4(2): e13.

Heidegger, M. Ser e tempo. Petrópolis, Brasil: Vozes: 1995.

Holland JM, Neimeyer RA. Reducing the risk of burnout in end-of-life care settings: The role of daily spiritual experiences and training. Palliat Support Care. 2005;3:17381 apudSeccareccia D, Brown JB. Impact of spirituality on palliative care physicians: personally and professionally. J Palliat Med. 2009;12(9):805-9.

Hornsey MJ, Harris EA and Fielding KS. The Psychological Roots of Anti-Vaccination Attitudes: A 24-Nation Investigation. Health Psychology. 2018; 37(4), 307-315.

Howick J, Moscrop A, Mebius A. et al. Effects of empathic and positive communication in healthcare consultations: a systematic review and meta-analysis. Jour Royal Society Medicine. 2018; 0(0):1-13.

Hummer RA, Rogers RG, Nam CB et al. Religious involvement and U.S. adult mortality. Demography. 1999;36(2):273-85.

Hvidt NL, Korup AK, Curlin FA et al. The NERSH International Collaboration on Values, Spirituality and Religion in Medicine: Development of Questionnaire, Description of Data Pool, and Overview of Pool Publications. Religions. 2017, 8(24): 115.

IBGE - Instituto Brasileiro de Geografia e Estatística. Censo demográfico 2010: características gerais da população, religião e pessoas com deficiência. Rio de Janeiro. 2010. ISSN: 01043145.

Kent M, Rivers CT, Wrenn G. Goal-Directed Resilience in Training (GRIT): A Biopsychosocial Model of Self-Regulation, Executive Functions, and Personal Growth (Eudaimonia) in Evocative Contexts of PTSD, Obesity, and Chronic Pain. Behavioral sciences. 2015;264-304.

King DE and Crisp, J. Spirituality and Health Care Education in Family Medicine Residency Programs. Fam Med. 2005; 37(6):399-403. 
Koenig HG, Mccullough ME, Larson DB. The handbook of religion and health. Oxford, England: University Press: 2001.

Koenig HG. Taking a spiritual history. JAMA. 2004; 16;291(23):2881.

Koenig HG, McCauley J, Jenckes MW et al. Spiritual beliefs and barriers among managed care practitioners. Jour Rel Health. 2005; 44(2):137-46.

Koenig HG. Concerns about measuring "spirituality" in research. J Nerv Ment Dis. 2008; 196(5):349-55.

Koenig HG, Hooten EG, Lindsay-Calkins E et al. Spirituality in Medical School Curricula: Findings from a National Survey. Int J Psychiatry Med. 2010, 40: 391-398.

Koenig HG. Religion, spirituality, and health: a review and update. Adv Mind Body Med. 2015;29(3):19-26.

Kozishek D, Bogdan-LovisE.Beliefs, boundaries, and self-knowledge in professional practice. J Clin Ethics. 2008; 19(1):26-30.

Kübler-Ross, E. Sobre a morte e o morrer. São Paulo, Brasil: Martins Fontes: 1987. (Original publicado em 1969).

Kuhn, T. A estrutura das revoluções científicas. 7. a ed. São Paulo, Brasil: Editora Perspectiva: 2003.

Lassiter JM, Parsons JT. Religion and Spirituality's Influences on HIV SyndemicsAmong MSM: A Systematic Review and Conceptual Model. AIDS Behav. 2016;20(2):461-472.

Lawrence RE, Oquendo MA, Stanley B.Religion and Suicide Risk: A Systematic Review. Arch Suicide Res. 2016; 20(1):1-21.

Ledford CJ, Canzona MR. SeehusenDA et al. Differences in physician communication when patients ask versus tell about religion/spirituality: a pilot study. Fam Med. 2015; 47(2): 138-42.

Lee-Poy M, Stewart M, Ryan BL. Asking patients about their religious and spiritual beliefs: Cross-sectional study of family physicians. Can Fam Physician. 2016 ;62(9):e555-61.

Lewin SA, Skea ZC, Entwistle V et al. Interventions for providers to promote a patientcentred approach in clinical consultations. Cochrane Database Syst Rev. 2001; (4):CD003267. 
Lucchetti G, Granero AL, Bassi RM et al. Spirituality in clinical practice: what should the general practitioner know? Rev Bras Clin Med. 2010;8(2):154-8.

Lucchetti G, Moreira-Almeida A, Koenig HG et al. Religiousness affects mental health, pain and quality of life in older people in an outpatient rehabilitation setting. $J$ Rehabil Med. 2011;43(4):316-22.

Lucchetti G (2012a), Lucchetti G, Moreira-Almeida A. Validation of the Duke Religion Index: DUREL (Portuguese Version). Rev PsiquiatrClin. 2012;51(2):579-86.

Lucchetti G (2012b), Lucchetti AL, Puchalski CM. Spirituality in medical education: global reality? J Relig Health. 2012; 51: 3-19.

Lucchetti G (2013a), Bassi RM, Lucchetti ALG. Taking spiritual history in clinical practice: a systematic review of instruments. Explore. 2013;9(3):159-70.

Lucchetti G (2013b), Lucchetti AG, Vallada H. Aferindo espiritualidade e religiosidade na pesquisa clínica: Uma revisão sistemática dos instrumentos disponíveis para a língua portuguesa. Sao Paulo Med J. 2013;131(2):112-22.

Lucchetti G (2013c), Oliveira LR, Koenig HG et al. Medical students, spirituality and religiosity-results from the multicenter study SBRAME. BMC Medical Education. 2013, 13:162.

Lucchetti G (2014a), Lucchetti AL. Spirituality, religion, and health: over the last 15 years of field research (1999-2013). Int J Psychiatry Med. 2014;48(3):199-215.

Lucchetti G (2014b) Oliveira LR De, Leite JR, Lamas A, Lucchetti G. Medical students and controversial ethical issues: results from the multicenter study SBRAME. BMC Med Ethics. 2014; 15: 85.

Lucchetti G, Lucchetti AL, Vallada HP. Validation of the Portuguese version of the functional assessment of chronic illness therapy-spiritual well-being scale (FACIT-Sp 12) among Brazillian psychiatric inpatients. J Relig Health. 2015; 54(1):112-21.

Lucchetti G, Ramakrishnan P, Karimah A et al. Spirituality, Religiosity, and Health: a Comparison of Physicians' Attitudes in Brazil, India, and Indonesia. Int.J. Behav. Med. 2016; 23:63-70.

Maciel ELN, Figueiredo PF, Prado TN et al. Avaliação dos egressos do curso de especialização em Saúde da Família no Espírito Santo, Brasil. Ciência\&SaúdeColetiva. 2010;15(4):2021-8.

Malta DC, Santos MAS, Stopa SR et al. A Cobertura da Estratégia de Saúde da Família (ESF) no Brasil, segundo a Pesquisa Nacional de Saúde, 2013 [Family Health Strategy Coverage in Brazil, according to the National Health Survey, 2013]. Ciência \& Saúde Coletiva. 2016; 21(2):327-338. 
Maugans TA. The SPIRITual history. Arch Fam Medicine. 1996;5:11-11.

McCord G, Gilchrist VJ, Grossman, SD et al. Discussing Spirituality With Patients: A Rational and Ethical Approach. Ann Family Medicine.2004; 2(1):356-61.

McWhinney IR. Manual de Medicina de Família e Comunidade. Porto Alegre: Artmed, 2010 .

Menegatti-Chequini MC, Gonçalves JP, Leão FC, Peres MF, Vallada H. A preliminary survey on the religious profile of Brazilian psychiatrists and their approach to patients' religiosity in clinical practice. BJPsych Open. 2016; 2(6):346-52.

Monod S, Brennan M, Rochat E et al. Instruments Measuring Spirituality in Clinical Research: A Systematic Review. J Gen Intern Med. 2011; 26(11):1345-57.

Moreira-Almeida A, Peres MF, Aloe $\mathrm{F}$ et al. Versão em português da Escala de Religiosidade da Duke - DUREL (Portuguese version of Duke Religious Index DUREL). Rev. Psiq. Clín. 2008; 35(1):31-2.

Moreira-Almeida A, Pinsky I, Zaleski M. Envolvimento religioso e fatores sociodemograficos: resultados de um levantamento nacional no Brasil [Religious involvement and sociodemographic factors: a Brazilian national survey]. Rev Psiq Clín. 2010; 37(1):12-5.

Moreira-Almeida A., Sharma A., van Rensburg BJ. et al. WPA Position Statement on Spirituality and Religion in Psychiatry. World Psychiatry. 2016; 15: 87-8.

Neely D, Minford EJ. Current status of teaching on spirituality in UK medical schools. Medical education. 2008, 42: 176-182.

NHG - Nederlands Huisarts en Genootschap (Dutch College of General Practitioners). A series on communication and atitude. 2002. ISBN 90-5793-116-8.

Oliveira JAC, Anderson MIP, Lucchetti G et al. Approaching Spirituality Using the Patient-Centered Clinical Method. J Relig Health. 2018. Doi: 10.1007/s10943-0170534-6. [Epub ahead of print]

Organização Mundial de Saúde (OMS). Constituição da Organização Mundial de Saúde. OMS/WHO. Nova Iorque. 1946.

Panzini RG, Bandeira DR. Coping (enfrentamento) religioso/espiritual. Rev. Psiq. Clín. 2007;34(1); 126-35.

Panzini RG, Maganha C, Rocha NS et al. Validação brasileira do instrumento de qualidade de vida/espiritualidade, religião e crenças pessoais. Rev Saude Publica. 2011;45(1):153-65. 
Pargament KI, Koenig HG, Tarakeshwar $\mathrm{N}$ et al. Religious struggle as a predictor of mortality among medically ill elderly patients: a 2-year longitudinal study. Arch Intern Med. 2001 Aug 13-27;161(15):1881-5.

Peacock JL and Peacock PJ. Oxford handbook of medical statistics. Oxford Press. New York, 2011.

Pendleton $\mathrm{D}$ et al. A nova consulta: desenvolvendo a comunicação entre médico e paciente. Porto Alegre: Artmed, 2011.

Peres MFP, Kamei HH, Tobo PR et al. Mechanisms Behind Religiosity and Spirituality's Effect on Mental Health, Quality of Life and Well-Being. J Relig Health. 2017. Doi: 10.1007/s10943-017-0400-6. [Epub ahead of print]

Plsek PE and Greenhalgh T. Complexity science: the challenge of complexity in health care. BMJ. 2001; 323(7313):625-8.

Pratt R, Hibberd C, Cameron IM. The Patient Centered Assessment Method (PCAM): integrating the social dimensions of health into primary care. J Comorb. 2015; 5:110-9.

Puchalski C, Romer AL. Taking a spiritual history allows clinicians to understand patients more fully. J Paliative Med. 2000; 3: 129-37.

Puchalski CM. Spirituality and medicine: Curricula in medical education. Journal of Cancer Education. 2006; 21(1), 14-18.

Puchalski CM (2014 a). The FICA Spiritual History Tool. J Palliative Medicine. 2014;17(1):105-6.

Puchalski CM (2014 b), Blatt B, Kogan M and Butler A. Spirituality and Health: The Development of a Field. Acad Med. 2014; 89:10-6.

Reed P. Spirituality and mental health in older adults: extant knowledge for nursing. Fam Community Health. 1991;14(2):14-25.

Saguil A, Phelps K. The spiritual assessment. Am Fam Physician. 2012; 86(6):546-50.

Sawatzky R, Ratner PA, Chiu L. A meta-analysis of the relationship between spirituality and quality of life.Soc Indic Res. 2005;72(2):153-88. 
Scheffer M, Biancarelli A, Cassenote A. Demografia Média no Brasil. São Paulo: FMUSP/CFM/CREMESP, 2015. V.3. Dados atualizados até 29/11/2016 disponíveis pelo site: http://demografiamedica.org.br/atlas-de-especialidades/medicina-da-familia/, acessado em 10/11/2017.

Seccareccia D, Brown JB. Impact of spirituality on palliative care physicians: personally and professionally. J Palliat Med. 2009;12(9):805-9.

Segre M e Ferraz FC. O conceito de saúde. Rev. Saúde Pública. 1997; 31(5): 538-42.

Shafranske EP. The religious dimension of patient care within rehabilitation medicine: the role of religious attitudes, beliefs, and personal and professionals practices. In Plante TG and Sherman AC. Faith and health: psychological perspectives. Nova Iorque. Guilford Press. 2001.

Sherman AC, Merluzzi TV, Pustejovsky JE et al.A meta-analytic review of religious or spiritual involvement and social health among cancer patients. Cancer. 2015;121(21):3779-88.

Sinclair S, Raffin S, Pereira $\mathrm{J}$ et al. Collective soul: the spirituality of an interdisciplinary palliative care team. Palliat Support Care. 2006;4(1):13-24.

Smith RC, Dorsey AM, Lyles JS et al. Teaching self-awareness enhances learning about patient-centered interviewing. Acad Med. 1999; 74:1242-48.

Sociedade Brasileira de Medicina de Família e Comunidade (SBMFC), por Gérvas J e Fernández MP. Uma atenção primária forte no Brasil: relatório sobre como fortalecer os acertos e corrigir as fragilidades da estratégia de saúde da família. 2011. Disponível em http://www.sbmfc.org.br/media/file/documentos/relatoriofinal_portugues.pdf, acesso realizado em 23/05/2018.

Sociedade Brasileira de Medicina de Família e Comunidade (SBMFC). Currículo baseado em competências para medicina de família e comunidade. 2015. Disponível em http://www.sbmfc.org.br/media/Curriculo\%20Baseado\%20em\%20Competencias(1).pdf , acesso realizado em 13/08/2015.

Stange LJ. Introdução da espiritualidade em currículo de residência em medicina de família e comunidade. [trabalho de conclusão]. Florianópolis: Programa de Residência em Medicina de Família e Comunidade. Escola de Saúde Pública de Florianópolis. Universidade Federal de Santa Catarina; 2018.

Starfield B. Atenção Primária, equilíbrio entre necessidades de saúde, serviçostecnologia. Brasília: UNESCO, Ministério da Saúde, 2002.

Stewart M. Effective physician-patient communication and health outcomes: a review. CMAJ. 1995;152(9):1423-33.

Stewart, M. Towards a global definition of patient-centred care. BMJ. 2001, 322:444-5. 
Stewart M, Brown JB, McWhinney IR et al. (2014). Patient-centered medicine transforming the clinical method (3rd Edn.). London, UK: Radcliffe Publishing. ISBN13: 9781846195662.

Targa LV. Mobilizando coletivos e construindo competências culturais no cuidado à saude: estudo antropológico da política brasileira de atenção primária à saúde [dissertação]. Porto Alegre: Instituto de Ciências Humanas, Universidade Federal do Rio Grande do Sul; 2010.

Tomasso CS, Beltrame IL and Lucchetti G. Knowledge and attitudes of nursing professors and students concerning the interface between spirituality, religiosity and health. Rev. Latino-Am. Enfermagem. 2011; 19(5): 1205-13.

Tsuang MT e Simpson JC. Commentary on Koenig (2008): "Concerns About Measuring 'Spirituality' in Research”. The Journal of Nervous and Mental Disease. 2008; 196(8):647-9.

Unterrainer HF, Lewis AJ, Fink A. Religious/Spiritual well-being, personality and mental health: a review of results and conceptual issues. $J$ Relig Health. 2014;53(2):382-92.

Van Tongeren DR, Hill PC, Krause N et al. The Mediating Role of Meaning in the Association between Stress and Health. Ann Behav Med. 2017 Oct;51(5):775-81.

Vasconcelos EM. Espiritualidade na educação popular em saúde. Cad. Cedes, Campinas. 2009; 29(79): 323-34.

Vasconcelos, E.M. A espiritualidade no trabalho em saúde. São Paulo: Hucitec, 2011.

Vermandere M, Lepeleire J De. Spirituality in general practice: a qualitative evidence synthesis. Gen Pract [Internet]. 2011; (Nov):749-60.

Victora CG, Huttly SR, Fuchs SC et al. The role of conceptual frameworks in epidemiological analysis: a hierarchical approach. Int J Epidemiol. 1997; 26(1):224-7.

Wenceslau LD, Portocarrero-Gross E e Demarzo MMP. Compaixão e medicina centrada na pessoa: convergências entre o Dalai Lama Tenzin Gyatso e Ian McWhinney [Compassion and patient-centered medicine: convergences between the Dalai Lama Tenzin Gyatso and Ian McWhinney]. Rev Bras Med Fam Comunidade. 2016; 11(38):110 . 